\title{
Utility Requirements for Fusion
}

\author{
AP-2254 \\ Research Project 1413-1 \\ Topical Report, February 1982 \\ Prepared by \\ BURNS AND ROE, INC \\ 185 Crossways Park Drive \\ Woodbury, New York 11797 \\ Principal Investigator \\ $\mathrm{R} J$ Vondrasek
}

\section{$\cdots, \ldots, \ldots$ \\ PORTIONS OF THIS REPORT ARE ILLEGIBIE. T \\ has been reproduced from the best availais I \\ copy to permit the broadest possible avail \\ ab1lity.}

\author{
Prepared for \\ Electric Power Research Institute \\ 3412 Hillview Avenue \\ Palo Alto, Calıfornı 94304 \\ EPRI Project Manager \\ $N$ A Amherd \\ Fusion Power Systems Program \\ Advanced Power Systems Division
}




\section{ORDERING INFORMATION}

Requests for copies of this report should be directed to Research Reports Center (RRC), Box 50490, Palo Alto, CA 94303, (415) 965-4081. There is no charge for reports requested by EPRI member utilities and affiliates, contributing nonmembers, U.S. utılity associations, U.S. government agencies (federal, state, and local), media, and foreign organizations with which EPRI has an information exchange agreement. On request, RRC will send a catalog of EPRI reports.

\section{NOTICE}

This report was prepared by the organization(s) named below as an account of work sponsored by the Electric Power Research Institute, Inc (EPRI) Nelther EPRI, members of EPRI, the organization(s) named below, nor any person acting on behalf of any of them (a) makes any warranty, express or implied, with respect to the use of any information, apparatus, method, or process disclosed in this report or that such use may not infringe private ly owned rights, or (b) assumes any liabilities with respect to the use of, or for damages resulting from the use of, any information, apparatus, method, or process disclosed in this report

Prepared by

Burns and Roe, Inc

Woodbury, New York 


\section{DISCLAIMER}

This report was prepared as an account of work sponsored by an agency of the United States Government. Neither the United States Government nor any agency Thereof, nor any of their employees, makes any warranty, express or implied, or assumes any legal liability or responsibility for the accuracy, completeness, or usefulness of any information, apparatus, product, or process disclosed, or represents that its use would not infringe privately owned rights. Reference herein to any specific commercial product, process, or service by trade name, trademark, manufacturer, or otherwise does not necessarily constitute or imply its endorsement, recommendation, or favoring by the United States Government or any agency thereof. The views and opinions of authors expressed herein do not necessarily state or reflect those of the United States Government or any agency thereof. 


\section{DISCLAIMER}

Portions of this document may be illegible in electronic image products. Images are produced from the best available original document. 
ABSTRACT

This report describes work done and results obtained during performance of Task 1 of a study of utility Requirements and Criteria for Fusion Options. The work consisted of developing a list of utility requirements for fusion options containing definition of the requirements and showing their relative importance to the utility industry. The project team members developed a preliminary list which was refined by discussions and literature searches. The refined list was recast as a questionnaire which was sent to a substantial portion of the utility industry in this country. Forty three questionnaire recipients responded including thirty two utilities. A workshop was held to develop a revised requirements list using the survey responses as a major input. The list prepared by the workshop was further refined by a panel consisting of vice presidents of the three project team firms. The results of the study indicate that in addition to considering the cost of energy for a power plant, utilities consider twenty three other requirements. Four of the requirements were judged to be vital to plant acceptability: Plant Capital cost, Financial Liability, plant safety and Licensability. Ten requirements were considered very important, five were considered important, and the remaining four, moderately important. 
0 
EPRI PERSPECTIVE

\begin{abstract}
PROJECT DESCRIPTION
Utility industry requirements and criteria for fusion are being investigated in RP1413 as aids to R\&D planning and decision making. A questionnaire-workshop approach was used to define the requirements and criteria, and a method to apply them to the evaluation of different fusion concepts is under development. This topical report for RP1413-1 describes the final set of ranked utility requirements.
\end{abstract}

\title{
PROJECT OBJECTIVES
}

The objectives of this project are:

1. To develop a set of utility requirements relative to the application and projected performance of fusion power plants

2. To develop a methodology for selection of viable utility-oriented options for fusion applications, systems, and fuels

PROJECT RESULTS

This document describes the results of activities addressing the first objective. The final set of requirements contains 23 elements ranked from vital to slightly important. Three of the requirements originally listed on the questionnaire were determined to be unimportant and were dropped from further consideration in the project; however, they are reported here for information. Development of the requirements relied on input and review by representatives of the electric utility industry and its equipment suppliers.

Noel A. Amherd, Project Manager

Advanced Power Systems Division 
0

0 
CONTENTS

\section{Section}

$\underline{\text { Page }}$

1 INTRODUCTION

1-1

2 SUMMARY AND CONCLUSIONS

$2-1$

3 UTILITY REQUIREMENTS FORMULATION

$3-1$

4 QUESTIONNAIRE SURVEY

$4-1$

5 WORKSHOP

$5-1$

6 FINALIZED UTILITY REQUIREMENTS

$6-1$

APPENDIX A UTILITY REQUIREMENTS QUESTIONNAIRE SURVEY AND CHARACTERIZATION FORM MATERIALS

$A-i$

APPENDIX B

STATISTICAL RESULTS OF UTILITY REOUIREMENTS

$B-i$ SURVEY

APPENDIX C STATISTICAL RESULTS OF CHARACTERIZATION FORM

$c-i$ RESPONSES

APPENDIX D UTILITY REQUIREMENTS FOR FUSION OPTIONS

$\mathrm{D}-\mathbf{i}$ 
-

- 


\section{TABLES}

Table

$\underline{\text { Page }}$

2-1 Utility Requirements Summary - Overall Weightings

$2-3$

3-I List of Utility Requirements

$3-3$

3-2 Typical Utility Requirement

$3-5$

4-I Utility Requirements Questionnaire Respondents

$4-2$

4-2 Utility Requirements Survey Results

$4-4$

4-3 Characterization Results

$4-9$

5-1 List of Workshop Attendees

$5-2$

5-2 Utility Requirements Workshop Summary

$5-4$

6-1 Utility Requirements Summary

$6-2$

6-2 Summary of Utility Requirements Definitions

$6-8$ 
Section 1

INTRODUCTION

Although controlled fusion is still in the research and early development stage, the utility industry has shown interest in identifying those fusion options having the greatest potential for commercial application. Toward this end, EPRI has sponsored Research Project 1413. This project has two principal objectives: the first is the development of a set of utility requirements for fusion options; the second is the formulation of a method for evaluating how well a fusion option satisfies these requirements. This report discusses the approach used and the results obtained in achieving the first objective of describing, defining and assessing the relative importance of utility requirements associated with selection of fusion options. The utility requirements described in this report, which are based on projections of what the nature of the utility industry will be in the year 2000, are also suitable to a large degree for assessing nonfusion central station power plant options.

There is general agreement that fusion will not become available as a major source of energy until the first quarter of the twenty-first century. However, many utilities, manufacturers and engineering firms are deeply interested in participating in and contributing to the controlled fusion research and development program. It is this interest and enthusiasm on the part of so many members of the utility industry that facilitated development of, and added validity to, the Iist of requirements presented herein.

The steps involved in selecting, defining and weighting the relative importance of utility requirements for fusion options were: (1) compile list of requirements, (2) define the requirements, (3) conduct a questionnaire survey, by mail, to refine the requirements, (4) conduct a workshop to consider the results of the questionnaire survey and (5) review and finalize the utility requirements as produced by the workshop. Each of these steps are described in this report. 
This work was accomplished by Burns and Roe and its subcontractors: Public Service Electric and Gas Company (PSE\&G) and Northeast Utilities (NU). Principal investigators for Burns and Roe, PSE\&G and NU were: Robert Cherdack, Dr. Betty Jensen and Kenneth Burton, respectively. Dr. Robert Gross of Columbia University was a consultant to the project. The project organization also included two reviewing bodies: the select Committee and the senior Review Committee. The select Committee was composed of utility representatives and was chaired by Dr. Robert Goodrich of Northeast Utilities. Other Select Committee members included William Frederick of Pennsylvania Power and Light, David Hartman of Bonneville Power Administration, Ed Fiss of Duke Power and Dr. Betty Jensen of Public Service Electric and Gas. The project's Senior Review Committee was comprised of executives of the team companies: Dr. Seymour Baron, Senior Vice President of Burns and Roe; Raymond Huse, Vice President of Public Service Electric and Gas Research Corporation and Sidney Law, Director of Research of Northeast Utilities.

The project, of which the work discussed in this report forms a part, also includes several other distinct products. One of those products is an evaluation method to be used to evaluate fusion options and aid future funding decisions. The utility requirements are to be incorporated as a basic element of the method. The evaluation method is to be developed through an organized methodology that identifies, screens and selects the most suitable techniques for evaluating fusion options. Another product output is the characterization of fusion concepts in their projected commercial form and the generic characterization of fusion options as they are affected by fuel cycle (D-D, D-T, etc.) and applications (power generation, fissile fuel breeding, synfuel production, etc.). The aforementioned products will be documented in the forthcoming final project report and topical reports. 
Section 2

SUMMARY AND CONCLUSIONS

The utility requirements for fusion contained in this report were identified, defined and their relative importance evaluated by members of the utility industry representing a significant portion of the industry. The requirements reflect anticipated utility industry demands on power plants in the first quarter of the twenty-first century.

This report focuses on those requirements which have effects outside of the cost-of-energy. Requirements like Licensability and Weapons Proliferation clearly do not appear explicitly in the mill rate calculation. On the other hand, Plant capital cost which is a part of the cost-of-energy calculation, is also covered because it has a noncost-of-energy aspect. For example, if a central station power plant has a very low fuel cost but a high capital cost it may have an overall favorable cost-of-energy. However, that cost-of-energy may not reflect the difficulties associated with financing such a capital intensive project. The money market financial hurdles utilities face when they try to raise capital for new generating capacity must be considered to accurately assess the attractiveness of a plant to a utility.

Formulating the non-quantifiable utility requirements was a four step process. First, the project team identified and defined twenty-seven utility requirements applicable to commercial fusion options. Second, a questionnaire was formulated from the list of requirements and distributed to one hundred utilities, manufacturers and architect-engineering firms. The results of the forty-three responses to the questionnaire survey were then analyzed and summarized. The third step was the convening of a workshop composed of personnel from utilities, manufacturers, government agencies and architect-engineers to consider the utility requirements in light of the responses to the questionnaire survey. The workshop results were then documented. Lastly, the 
results of the questionnaire survey and workshop were submitted to the project Senior Review Committee for review, comment and revision.

A weighting scale was devised so that questionnaire respondents, workshop attendees and the Senior Review Committee could weight the requirements. The weighting scale consisted of the six descrete integers, $0,1,2,3,4$ and 5 . The meanings associated with the integers are as follows: "0" - unimportant, requirement can be dropped from consideration; "1" - slightly important; "2" - moderately important; "3" - important, mid-range significance; "4" - very important; and "5" - vital, absolutely necessary.

Examining the utility requirements and their importance, shown in Table 2-1, provides an overview of the significance placed by utilities on the various non-cost-of-energy requirements for new base load generating capacity similar to commercial fusion. Note that in final form, twenty-three requirements were identified owing to the dropping of three of the requirements as being "unimportant" and combining Forced and Planned Outage Rates as a single requirement called outace Rates. The requirements Plant Efficiency, Dependence on Other systems and Natural Resource Requirements were dropped because the significant factors associated with these requirements are contained in the requirements Plant Safety, Flexibility of Siting, Plant Operating Requirements and Hardware Materials Availability.

Four "vital" requirements were identified: Plant Capital Cost, Financial Liability, Plant Safety, and Licensability. Ten requirements were judged to be "very important": Outage Rates, Plant construction Time, Flexibility of Siting, Waste Handling and Disposal, Plant Operating Requirements, Plant Maintenance Requirements, Electrical Performance, Hardware Materials Availability, Industrial Base, and Fuel and Fertile Material Availability. Five requirements were rated "important": Plant Operating, Maintenance and Fuel Costs, Plant Life, Decommissioning, Weapons Proliferation, and Startup Power Requirements. Four requirements were deemed to be "moderately important": Unit Rating, Capability for Load Change, Part Load Efficiency, and Minimum Load. It is interesting to note that no requirement was judged to be "slightly important". This indicates a general conservatism and an understanding of the importance of non-cost-of-energy 
Table 2-1

UTILITY REQUIREMENTS SUMMARY

OVERALL WEIGHTINGS

A. UTILITY PLANNING AND FINANCE

1. Plant Capital Cost

2. Plant O\&M and Fuel costs

3. Outage Rates

4. Plant Life

5. Plant Construction Time

6. Financial Liability

7. Unit Rating

Vital

Important

Very Important

Important

Very Important

Vital

Moderately Important

B. SAFETY, SITING AND LICENSING

1. Plant Safety

2. Flexibility of Siting

3. Waste Handling and Disposal

4. Decommissioning

5. Licensability

6. Weapons Proliferation

Vital

Very Important

Very Important

Important

Vital

Important

C. UTILITY OPERATIONS

1. Plant Operating Requirements

2. Plant Maintenance Requirements

3. Electrical Performance

4. Capability for Load Change

5. Part Load Efficiency

6. Minimum Load

7. Startup Power Requirements

Very Important

Very Important

Very Important

Moderately Important

Moderately Important

Moderately Important

Important

D. MANUFACTURING AND RESOURCES

1. Hardware Materials Availability

2. Industrial Base

3. Fuel and Fertile Material Availability

Very Important

Very Important

Very Important

Notes

1. Forced and Planned Outage Rates were combined as Outage Rates

2. Plant Efficiency, Dependence on Other Systems and Natural

Resource Requirements were rated "unimportant" and dropped.

3. Weighting Code

Meaning

0

1

Unimportant (Dropped)

2

3

4

5

Slightly Important

Moderately Important

Important

Very Important

Vital 
issues by utilities. A similar trend appeared in a recent STARFIRF design study performed by McDonnell Douglas.

It is important to maintain the channels of information interchange between technology developers and technology users to ensure the timely appearance of a useable end product consistent with national needs. The utility requirements presented herein identify the characteristics of commercial base load power generating capacity that are significant to the utility industry. The consideration and application of these requirements by fusion concept developers will be an important step in the assimilation and feedback mechanisms associated with fusion information interchange.

The utility requirements are to become a basic element of an evaluation method that will be used to assess fusion options and aid in making future funding decisions. The evaluation method and the utility requirements are the two basic products of the project of which this report is a part. The body of this report documents the process by which the utility requirements were formulated and presents those activities and the utility requirements for fusion in some detail. 
Section 3

UTILITY REQUIREMENTS FORMULATION

To begin the formulation of the list of utility requirements, the project team produced a preliminary list of requirements and their associated factors based upon their experience. Then a literature search was undertaken which produced two significant reports wherein utility requirements for power generation options were addressed. These reports were: "Utility Requirements for Fusion Power" (EPRI ER-452-SR), prepared by McDonnell Douglas in March, 1977, and "Comparative Study and Evaluation of Advanced Cycle systems" (EPRI AF-664), prepared by General Electric in February, 1978. Both of these reports addressed criteria for future commercial power generation.

The project produced a preliminary list of forty-seven utility requirements in seven categories. There were thirty-seven requirements in eight categories identified in the EPRI Report, "Utility Requirements for Fusion Power". Twenty-seven utility requirements were identified in the EPRI Report "Comparative Study and Evaluation of Advanced cycle systems". After examining and considering these lists of requirements, it was determined that utility requirements could generally be categorized in two ways: those that are components of costof-energy and all other considerations which can not be described by direct economic formulation. The second category of requirements was labled "non-quantifiables" because of the difficulty in assigning dollar values to their impacts. The project team had an understanding of the significance of cost-of-energy considerations, the techniques to calculate the cost-of-energy and all the components that comprise it. However, it was determined that a procedure was required to identify the non-quantifiable utility requirements, their definitions, and their relative importance. Many of the non-quantifiables were factors in the cost-of-energy calculations, but also had impacts exclusive of the cost-of-energy. It is only these impacts which were considered 
in the non-quantifiable utility requirements. As this project dealt with the concept of commercial fusion power plants, projected cost, risk, and schedule considerations associated with fusion research and development were set aside as not being commercial stage concerns to utilities.

Twenty-seven non-quantifiable utility requirements, hereafter, referred to simply as "requirements", were identified. They were arranged in four categories: (1) Utility Planning and Finance; Safety, Siting and Licensing; (3) Utility Operations; and (4) Manufacturing and Resources. Table 3-1 lists these 27 requirements.

In defining the utility requirements, the project team was influenced by industry experience and practice, projected future utility industry needs, an awareness of "Three-Mile Island" implications, and projections of the future social and industrial environment. Fusion options are anticipated to be licensed by the NRC or its future equivalent, and hence, definitions were heavily influenced by current experience with light water reactors. This was particularly true in the areas of safety and licensing. Since fusion plants are generally expected to be base loaded, current utility practice concerning the operation of central station units also affected definitions of the requirements.

The utility requirements were to become an integral element of the method that the project formulated for evaluating fusion options. For this reason, a weighting, or measure of importance, had to be associated with each utility requirement to facilitate later incorporation of utility requirements into the method for evaluating fusion options. A numerical weighting system was devised using the integer codes 0,1 , $2,3,4$ and 5 . The numbers were codes for qualitative verbal weights. The integers were associated with estimated relative importance: "0" corresponded to an "unimportant" weighting, "l" was associated with "slightly important", "2" was "moderately important", "3" was "important", "4" was "very important", and "5" was used to weight a "vital" aspect. The components of the requirements were called "factors". Requirements having more than one factor, also had a factor weighting system utilizing the integers $0,1,2$ and 3 . The factor weights were: "0" corresponding to "unimportant", "l" to "moderately important", 
A. UTILITY PLANNING AND FINANCE

1. Plant Capital Cost

2. Plant Operating, Maintenance and Fuel Costs

3. Forced Outage Rate

4. Planned Outage Rate

5. Plant Life

6. Plant Construction Time

7. Financial Liability Associated with Major Accidents

8. Unit Rating

B. SAFETY, SITING AND LICENSING

1. Plant Efficiency

2. Plant Safety

3. Dependence on Other Systems

4. Flexibility of siting

5. Waste Handling and Disposal

6. Decommissioning

7. Licensability

8. Weapons Proliferation

C. UTILITY OPERATIONS

1. Plant Operating Requirements

2. Plant Maintenance Requirements

3. Electrical Performance

4. Capability for Load Change

5. Part Load Efficiency

6. Minimum Load

7. Startup Power Requirements

D. MANUFACTURING AND RESOURCES

1. Hardware Materials Availability

2. Industrial Base

3. Natural Resource Requirements

4. Fuel and Fertile Material Availability 
"2" to "important" and "3" to "very important".

In defining the utility requirements, the project team strove to handle requirements and factors in a manner which would properly, and most explicitly, reflect the way that they impacted the desirability of a utility project. This often involved taking what could have been considered a requirement in its own right and casting it as a factor associated with one or more requirements of more direct relevance to a utility's needs. For example, the amount of heat rejected by a plant affects both the ease of siting and licensing of the plant. This factor shows up in both the siting and licensing requirements rather than as an independent requirement. On the other hand, if. one requirement had an impact on another requirement, the definitions attempted to remove the impact on the second requirement in considering the weight of the first requirement. An example of this is the relationship among plant safety, financial liability and licensability. Generally, a safer plant is more easily licensable plant and poses a smaller liability. However, utilities have an interest in safety independent of licensability and financial risks. The definition of plant safety called for participants to weigh the importance of safety for its own sake in protecting employees, the public and property.

The project team formulated quantitative or qualitative ranqes corresponding to three ranges of merit for the requirements and their associated factors. For example, under the utility requirement "plant Construction Time", one of the factors of consideration was time to design, procure and erect the plant. This requirement is shown in Figure 3-1. It was judged that a design, procure and erect time of five years or less, was most favorable, preferred, and therefore, described as "good". A five to ten year design, procure and erect time was judged reasonable, but less attractive, and described as "fair". A design, procure and erect time exceeding ten years was deemed unattractive and was described as "poor". Hence, in considering the commercial potential of a fusion option, an evaluation could be made of its expected design, procure and erect time. Further, that information could be reduced through the factor weighting and overall utility requirement weightings to a component of the overall attractiveness of the non-quantifiable features of that option. 
Table 3-2

TYPICAL UTILITY REQUIREMENT

A. 6. PLANT CONSTRUCtion TIME OVERALL WTG. 0112345 This requirement consists of two factors. The first includes the time to design, procure components and erect the plant. The second includes the time required to develop, submit and receive approval of the documents necessary to obtain construction permits and operating licenses. The latter impacts the production planning and carrying charges for the plant, if a full license cannot be obtained by completion of construction.

Factors

1. Design, Procure and Erect: WTG. $\begin{array}{lllll}0 & 1 & 2 & 3\end{array}$

$$
\begin{array}{ll}
5 \text { years or less } & \text { - good } \\
5 \text { to } 10 \text { years } & \text { - fair } \\
\text { More than } 10 \text { years - poor }
\end{array}
$$

2. Permits and License Time in Excess of Construction Time:

WTG. $0 \begin{array}{llll}0 & 1 & 2 & 3\end{array}$

$$
\begin{array}{ll}
\text { Less than I year } & \text { - good } \\
\text { I to } 1.5 \text { years } & \text { - fair } \\
\text { Greater than } 1.5 \text { years } & \text { - poor }
\end{array}
$$


Section 4

QUESTIONNAIRE SURVEY

The method used to obtain the opinion of the utility industry on the requirements and their weightings was to conduct a questionnaire survey. To accomplish this result, a voluminous questionnaire form was prepared. The questionnaire consisted of the requirements and a characterization form.

The questionnaire was mailed to one hundred organizations associated with utility power generation, including public utilities and private utilities, architect-engineers and manufacturers. Forty-three organizations responded to the questionnaire, including thirty-two utilities, four architect engineers, six manufacturers and one government agency. A list of organizations responding to the questionnaire is given in Table 4-1. The requirements section of the questionnaire consisted of the set of twenty-seven utility requirements produced by the project team organized into four packages corresponding to the four major categories: Utility Planning and Finance; Safety, Siting and Licensing; Utility Operations; and Manufacturing and Resources. Each package contained its own set of instructions to facilitate dividing the questionnaire among appropriate experts within an organization. Each requirement was defined and component factors relating to that requirement were described. In addition, ranges of merit were identified for each factor.

The questionnaire respondents were asked to review the requirements and provide weightings of their perception of the importance of each requirement and each requirement's associated factors. Further, the questionnaire respondents were asked to consider the definition of the requirements, the factors associated with the requirements and the ranges associated with the factors corresponding to "good", "fair" and "poor" characteristics. Respondents were encouraged to provide 
Table 4-1

\author{
UTILITY REQUIREMENTS \\ QUESTIONNAIRE RESPONDENTS
}

1. Alleghany Power Services Corp.

2. Arizona Public Service Co.

3. Baltimore Gas \& Electric Co.

4. Bonneville Power Administration

5. Central Power \& Light Co.

6. Columbus \& Southern Ohio Electric Co.

7. Commonwealth Edison Co.

8. Consolidated Edison Co. of New York

9. Consumers Power Co.

10. Delmarva Power \& Light Co.

11. Duke Power Co.

12. East Kentucky Power Cooperative

13. Florida Power \& Light Co.

14. Kentucky Utilities Co.

15. Nebraska Public Power District

16. New York State Electric \& Gas Corp.

17. Northern States Power Co.

18. Ohio Edison Co.

19. Pacific Gas \& Electric Co.

20. Pennsylvania Power \& Light Co.

21. Philadelphia Electric Co.

22. Public Service Co. of Colorado

23. Public Service Co. of New Mexico

24. Public Service Co. of Oklahoma

25. Public Service Electric \& Gas Co.

26. Rochester Gas \& Electric Corp.

27. San Diego Gas \& Electric Co.

28. South Carolina Electric \& Gas Co.

29. Southern California Edison Co.

30. Union Electric Co.

31. Washington Public Power Supply System

32. Wisconsin Public Service Corp. together with Wisconsin Power \& Light Co.

33. Babcock \& Wilcox, Inc.

34. Combustion Engineering, Inc.

35. Grumman Aerospace Corp.

36. McDonnel1-Douglas Corp.

37. Rockwell International

38. Westinghouse Electric Corp.

39. Bechtel National, Inc.

40. Gilbert/Commonwealth

41. Stone \& Webster Engineering Corp.

42. United Engineers \& Constructors, Inc.

43. U.S. Department of Energy 
comments, rewrite, add and delete material as they thought appropriate based upon their experience and their perception of non-cost-of-energy aspects of utility requirements for fusion power.

The questionnaire mailing also included a characterization form. The purpose of the characterization form was threefold. First, to assist the respondents to project their thinking to the end of the century. second, to determine what the utility industry view of the future was. Third, to help identify how the type and size of an organization affected its responses to the requirements questionnaire. The characterization form included questions on the utilities' projected load growth and load factor, likelihood of energy parks, likelihood of a National Grid, opinion of future regulatory climate and what role the federal government might be playing in power generation in the future. Questionnaire respondents were also asked when fusion might become commercial. The Utility Requirements Questionnaire (four packages) and the Characterization form are contained in Appendix A.

All questionnaire recepients were invited to attend a utility requirements workshop that reviewed the questionnaire results, addressed the respondents' written comments and recast the utility requirements as appropriate. Respondents' utility requirements and characterization form data were entered into a computerized data base and reduced using a sorting and statistical analysis routine. Written comments were sorted manually. The results of the Utility Requirements survey are summarized in Table 4-2. Detailed statistical results of the utility requirements survey are contained in Appendix B. For each requirement and factor, the statistical data includes the mean (average response), standard deviation from the mean, number of responses, distribution of responses by weight and distribution of comments received by weight. From the distribution of responses by weight, the "mode", or most frequent response, can be identified by inspection of the data.

Characterization results based on responses from thirty-two utilities are given in Table 4-3. Statistical results of responses to the characterization forms are contained in Appendix $C$ where characterization form response statistical data is broken out by respondent type. 
Table 4-2a

UTILITY REQUIREMENTS SURVEY RESULTS

\begin{tabular}{|c|c|c|c|c|}
\hline & & & & \\
\hline & & MEAN & MODE & MODE $\%$ \\
\hline & $\begin{array}{l}\text { UTILITY PLANNING AND FINANCE } \\
\text { 1. Plant Capital Cost } \\
\text { 2. Plant O\&M and Fuel Costs } \\
\text { 3. Forced Outage Rate } \\
\text { 4. Planned Outage Rate } \\
\text { 5. Plant Life } \\
\text { 6. Plant Construction Time } \\
\text { 7. Financial Liability } \\
\text { 8. Unit Rating }\end{array}$ & $\begin{array}{l}4 \cdot 1 \\
1 \cdot 3 \\
3.7 \\
3.3 \\
3.4 \\
3.7 \\
3.9 \\
2.8\end{array}$ & $\begin{array}{l}5 \\
0 \\
4 \\
4 \\
4 \\
3 / 4 \\
5 \\
3\end{array}$ & $\begin{array}{l}39 \\
63 \\
53 \\
44 \\
41 \\
32 / 32 \\
45 \\
41\end{array}$ \\
\hline B. & $\begin{array}{l}\text { SAFETY, SITING AND LICENSING } \\
\text { 1. Plant Efficiency } \\
\text { 2. Plant Safety } \\
\text { 3. Dependence on Other Systems } \\
\text { 4. Flexibility of Siting } \\
\text { 5. Waste Handling and Disposal } \\
\text { 6. Decommissioning } \\
\text { 7. Licensability } \\
\text { 8. Weapons Proliferation }\end{array}$ & $\begin{array}{l}0.5 \\
4.3 \\
0.1 \\
3.7 \\
3.8 \\
2.7 \\
4.4 \\
3.0\end{array}$ & $\begin{array}{l}0 \\
5 \\
0 \\
4 \\
4 \\
2 \\
5 \\
2 / 4\end{array}$ & $\begin{array}{l}85 \\
53 \\
94 \\
48 \\
38 \\
29 \\
53 \\
29 / 29\end{array}$ \\
\hline C. & UTILITY OPERATIONS & & & \\
\hline & $\begin{array}{l}\text { 1. Plant Operating Requirements } \\
\text { 2. Plant Maintenance Requirements } \\
\text { 3. Electrical Performance } \\
\text { 4. Capability for Load Change } \\
\text { 5. Part Load Efficiency } \\
\text { 6. Minimum Load } \\
\text { 7. Startup Power Requirements }\end{array}$ & $\begin{array}{l}3.7 \\
3.6 \\
3.9 \\
2.9 \\
2.4 \\
2.7 \\
2.8\end{array}$ & $\begin{array}{l}3 \\
4 \\
5 \\
3 \\
3 \\
3 \\
3\end{array}$ & $\begin{array}{l}33 \\
31 \\
41 \\
32 \\
35 \\
38 \\
41\end{array}$ \\
\hline D. & $\begin{array}{l}\text { MANUFACTURING AND RESOURCES } \\
\text { 1. Hardware Materials Availability } \\
\text { 2. Industrial Base } \\
\text { 3. Natural Resource Requirements } \\
\text { 4. Fuel and Fertile Material } \\
\text { Availability }\end{array}$ & $\begin{array}{l}3.3 \\
3.4 \\
0.4 \\
4.1\end{array}$ & $\begin{array}{c}3 / 4 \\
3 \\
0 \\
5\end{array}$ & $\begin{array}{c}31 / 31 \\
44 \\
86 \\
39\end{array}$ \\
\hline
\end{tabular}

Note:

\begin{tabular}{|c|c|}
\hline Number Code & Meaning \\
\hline 0 & Unimportant \\
\hline 1 & Slightly Important \\
\hline 2 & Moderately Important \\
\hline 3 & Important \\
\hline 4 & Very Important \\
\hline 5 & Vital \\
\hline
\end{tabular}


Table $4-2 b$

\section{UTILITY REQUIREMENTS SURVEY RESULTS BY RESPONDENT TYPE}

\begin{tabular}{|c|c|c|c|c|c|c|}
\hline \multirow{3}{*}{\multicolumn{2}{|c|}{$\begin{array}{r}\text { Classification } \\
\text { No. of Respondents }\end{array}$}} & \multicolumn{5}{|c|}{ Mean Requirement Weights } \\
\hline & & Pub.U. & Priv.U. & $A-E$ & Manf & DOE \\
\hline & & 9 & 23 & 4 & 6 & 1 \\
\hline A. & $\begin{array}{l}\text { UTILITY PLANNING AND FINANCE } \\
\text { 1. Plant Capital Cost } \\
\text { 2. Plant O\&M and Fuel Costs } \\
\text { 3. Forced Outage Rate } \\
\text { 4. Planned Outage Rate } \\
\text { 5. Plant Life } \\
\text { 6. Plant Construction Time } \\
\text { 7. Financial Liability } \\
\text { 8. Unit Rating }\end{array}$ & $\begin{array}{l}3.9 \\
1.8 \\
3.8 \\
3.4 \\
3.6 \\
3.6 \\
4.2 \\
2.8\end{array}$ & $\begin{array}{l}4.3 \\
1.4 \\
3.9 \\
3.3 \\
3.3 \\
3.8 \\
4.0 \\
2.9\end{array}$ & $\begin{array}{l}4.0 \\
1.0 \\
2.8 \\
2.8 \\
3.3 \\
3.0 \\
4.3 \\
2.8\end{array}$ & $\begin{array}{l}3.5 \\
0.3 \\
3.5 \\
3.3 \\
2.5 \\
3.8 \\
2.8 \\
2.3\end{array}$ & $\begin{array}{l}4.0 \\
1.0 \\
3.0 \\
3.0 \\
4.0 \\
3.0 \\
3.0 \\
3.0\end{array}$ \\
\hline B. & $\begin{array}{l}\text { SAFETY, SITING AND LICENSING } \\
\text { 1. Plant Efficiency } \\
\text { 2. Plant Safety } \\
\text { 3. Dependence on Other Systems } \\
\text { 4. Flexibility of Siting } \\
\text { 5. Waste Handing and Disposal } \\
\text { 6. Decommissioning } \\
\text { 7. Licensability } \\
\text { 8. Weapons Proliferation }\end{array}$ & $\begin{array}{l}0.6 \\
4.5 \\
0.2 \\
3.6 \\
3.4 \\
2.7 \\
4.1 \\
2.7\end{array}$ & $\begin{array}{l}0.5 \\
4.2 \\
0.0 \\
3.8 \\
4.1 \\
3.0 \\
4.6 \\
3.2\end{array}$ & $\begin{array}{l}0.0 \\
5.0 \\
0.0 \\
3.3 \\
4.7 \\
2.0 \\
4.7 \\
3.0\end{array}$ & $\begin{array}{l}0.0 \\
4.0 \\
0.0 \\
3.0 \\
2.8 \\
1.8 \\
4.0 \\
2.3\end{array}$ & $\begin{array}{c}3.0 \\
4.0 \\
0.0 \\
- \\
- \\
1.0 \\
5.0 \\
0.0\end{array}$ \\
\hline C & $\begin{array}{l}\text { UTILITY OPERATIONS } \\
\text { 1. Plant Operating Requirements } \\
\text { 2. Plant Maintenance Requirements } \\
\text { 3. Electrical Performance } \\
\text { 4. Capability for Load Change } \\
\text { 5. Part Load Efficiency } \\
\text { 6. Minimum Load } \\
\text { 7. Startup Power Requirements }\end{array}$ & $\begin{array}{l}3.5 \\
3.3 \\
4.0 \\
3.3 \\
3.0 \\
3.1 \\
3.1\end{array}$ & $\begin{array}{l}4.0 \\
3.9 \\
4.2 \\
3.0 \\
2.6 \\
2.7 \\
2.9\end{array}$ & $\begin{array}{l}3.7 \\
3.7 \\
3.0 \\
2.0 \\
1.7 \\
2.0 \\
3.0\end{array}$ & $\begin{array}{l}2.8 \\
2.5 \\
3.0 \\
2.3 \\
1.8 \\
2.5 \\
2.0\end{array}$ & $\begin{array}{c}- \\
- \\
- \\
3.0 \\
1.0 \\
3.0 \\
4.0\end{array}$ \\
\hline$D$ & $\begin{array}{l}\text { MANUFACTURING AND RESOURCES } \\
\text { 1. Hardware Materials Availability } \\
\text { 2. Industrial Base } \\
\text { 3. Natural Resource Requirements } \\
\text { 4. Fuel and Fertile Material } \\
\text { Availability }\end{array}$ & $\begin{array}{l}3.1 \\
3.4 \\
0.3 \\
4.2\end{array}$ & $\begin{array}{l}3.4 \\
3.4 \\
0.3 \\
4.1\end{array}$ & $\begin{array}{l}3.7 \\
3.7 \\
0.0 \\
3.3\end{array}$ & $\begin{array}{l}3.2 \\
3.5 \\
0.6 \\
4.3\end{array}$ & $\int_{-}^{-}$ \\
\hline
\end{tabular}


Table $4-2 c$

UTILITY REQUIREMENTS SURVEY RESULTS

BY UTILITY SIZE

\begin{tabular}{|c|c|c|c|c|c|}
\hline & \multirow{3}{*}{$\begin{array}{r}\text { MW Size } \\
\text { No. of Utilities }\end{array}$} & \multicolumn{4}{|c|}{ Mean Requirement Weight } \\
\hline & & $<2000$ & $\begin{array}{l}2000- \\
4000 \\
\end{array}$ & $\begin{array}{l}4000- \\
8000\end{array}$ & $>8000$ \\
\hline & & 7 & 9 & 8 & 7 \\
\hline & UTILITY PLANNING AND FINANCE & & & & \\
\hline & $\begin{array}{l}\text { 1. Plant Capital Cost } \\
\text { 2. Plant O\&M and Fuel Costs } \\
\text { 3. Forced Outage Rate } \\
\text { 4. Planned Outage Rate } \\
\text { 5. Plant Life } \\
\text { 6. Plant Construction Time } \\
\text { 7. Financial Liability } \\
\text { 8. Unit Rating }\end{array}$ & $\begin{array}{l}3.7 \\
2.0 \\
3.9 \\
3.0 \\
3.6 \\
3.7 \\
4.4 \\
3.0\end{array}$ & $\begin{array}{l}4.3 \\
1.4 \\
3.7 \\
3.4 \\
3.4 \\
3.6 \\
3.7 \\
3.0\end{array}$ & $\begin{array}{l}4.3 \\
0.9 \\
3.9 \\
3.4 \\
3.4 \\
4.0 \\
3.9 \\
2.6\end{array}$ & $\begin{array}{l}4.3 \\
1.4 \\
4.0 \\
3.6 \\
3.1 \\
4.0 \\
4.1 \\
2.9\end{array}$ \\
\hline B. & SAFETY, SITING AND LICENSING & & & & \\
\hline & $\begin{array}{l}\text { 1. Plant Efficiency } \\
\text { 2. Plant Safety } \\
\text { 3. Dependence on other systems } \\
\text { 4. Flexibility of Siting } \\
\text { 5. Waste Handling and Disposal } \\
\text { 6. Decommissioning } \\
\text { 7. Licensability } \\
\text { 8. Weapons Proliferation }\end{array}$ & $\begin{array}{l}0.0 \\
3.7 \\
0.0 \\
3.0 \\
3.0 \\
2.3 \\
4.0 \\
2.8\end{array}$ & $\begin{array}{l}0.3 \\
4.1 \\
0.1 \\
4.0 \\
4.1 \\
2.8 \\
4.3 \\
3.0\end{array}$ & $\begin{array}{l}0.6 \\
4.8 \\
0.3 \\
4.3 \\
4.5 \\
3.5 \\
4.6 \\
3.1\end{array}$ & $\begin{array}{l}1.0 \\
4.5 \\
0.0 \\
3.9 \\
4.0 \\
2.9 \\
4.8 \\
3.5\end{array}$ \\
\hline c. & UTILITY OPERATIONS & & & & \\
\hline & $\begin{array}{l}\text { 1. Plant Operating Requirements } \\
\text { 2. Plant Maintenance Requirements } \\
\text { 3. Electrical Performance } \\
\text { 4. Capability for Load Change } \\
\text { 5. Part Load Efficiency } \\
\text { 6. Minimum Load } \\
\text { 7. Startup Power Requirements }\end{array}$ & $\begin{array}{l}3.5 \\
2.5 \\
2.9 \\
2.7 \\
2.1 \\
2.3 \\
2.1\end{array}$ & $\begin{array}{l}3.9 \\
3.9 \\
4.2 \\
2.9 \\
2.4 \\
2.8 \\
2.7\end{array}$ & $\begin{array}{l}4.4 \\
4.4 \\
5.0 \\
3.8 \\
3.4 \\
3.1 \\
3.3\end{array}$ & $\begin{array}{l}3.6 \\
4.2 \\
4.7 \\
3.0 \\
2.7 \\
3.1 \\
3.7\end{array}$ \\
\hline D. & MANUFACTURING AND RESOURCES & & & & \\
\hline & $\begin{array}{l}\text { 1. Hardware Materials Availability } \\
\text { 2. Industrial Base } \\
\text { 3. Natural Resource Requirements } \\
\text { 4. Fuel and Fertile Material } \\
\text { Availability }\end{array}$ & $\begin{array}{l}3.1 \\
3.0 \\
0.4 \\
4.1\end{array}$ & $\begin{array}{l}3.4 \\
3.4 \\
0.0 \\
4.0\end{array}$ & $\begin{array}{l}3.4 \\
3.6 \\
0.4 \\
4.3\end{array}$ & $\begin{array}{l}3.4 \\
3.6 \\
0.4 \\
4.0\end{array}$ \\
\hline
\end{tabular}


Table $4-2 d$

UTILITY REQUIREMENTS SURVEY RESULTS

BY UTILITY RELIABILITY REGION

\begin{tabular}{|c|c|c|c|c|c|c|}
\hline \multirow{3}{*}{\multicolumn{2}{|c|}{$\begin{array}{l}\text { NERC Reliability Region(s) } \\
\text { No. of Utilities in Region }\end{array}$}} & \multicolumn{5}{|c|}{ Mean Requirement weights } \\
\hline & & ECAR & $\begin{array}{l}\text { NPCC } \\
\text { MAAC } \\
\end{array}$ & SERC & $\begin{array}{l}\text { MARCA } \\
\text { MAIN } \\
\text { ERCCT- } \\
\text { SPP } \\
\end{array}$ & WSCC \\
\hline & & 6 & 8 & 3 & 7 & 8 \\
\hline & $\begin{array}{l}\text { UTILITY PLANNING AND FINANCE } \\
\text { 1. Plant Capital Cost } \\
\text { 2. Plant O\&M and Fuel costs } \\
\text { 3. Forced Outage Rate } \\
\text { 4. Planned Outage Rate } \\
\text { 5. Plant Life } \\
\text { 6. Plant Construction Time } \\
\text { 7. Financial Liability } \\
\text { 8. Unit Rating }\end{array}$ & $\begin{array}{l}4.4 \\
0.0 \\
4.0 \\
4.0 \\
4.0 \\
3.5 \\
4.3 \\
2.7\end{array}$ & $\begin{array}{l}4.3 \\
1.6 \\
4.0 \\
3.5 \\
3.3 \\
3.8 \\
3.9 \\
2.5\end{array}$ & $\begin{array}{l}4.3 \\
1.0 \\
3 \cdot 7 \\
3.0 \\
3.3 \\
4.3 \\
4.0 \\
2.3\end{array}$ & $\begin{array}{l}3.7 \\
1.9 \\
4.1 \\
3.3 \\
3.3 \\
3.3 \\
4.2 \\
3.0\end{array}$ & $\begin{array}{l}4.3 \\
2.1 \\
3.4 \\
3.0 \\
3.3 \\
4.1 \\
3.9 \\
3.5\end{array}$ \\
\hline B. & $\begin{array}{l}\text { SAFETY, SITING AND LICENSING } \\
\text { 1. Plant Efficiency } \\
\text { 2. Plant Safety } \\
\text { 3. Dependence on Other systems } \\
\text { 4. Flexibility of Siting } \\
\text { 5. Waste Handling and Disposal } \\
\text { 6. Decommissioning } \\
\text { 7. Licensability } \\
\text { 8. Weapons Proliferation }\end{array}$ & $\begin{array}{l}0.0 \\
4.5 \\
0.0 \\
4.2 \\
4.5 \\
3.5 \\
4.3 \\
2.8\end{array}$ & $\begin{array}{l}0.3 \\
4.4 \\
0.3 \\
3.8 \\
3.9 \\
3.0 \\
4.4 \\
3.9\end{array}$ & $\begin{array}{l}0.0 \\
4.0 \\
0.0 \\
3.3 \\
3.3 \\
2.7 \\
4.5 \\
2.0\end{array}$ & $\begin{array}{l}0.9 \\
4.1 \\
0.0 \\
3.3 \\
3.3 \\
2.4 \\
4.3 \\
2.2\end{array}$ & $\begin{array}{l}0.9 \\
4.3 \\
0.1 \\
4.1 \\
4.3 \\
2.8 \\
4.8 \\
3.5\end{array}$ \\
\hline $\mathrm{C}$. & $\begin{array}{l}\text { UTILITY OPERATIONS } \\
\text { 1. Plant Operating Requirements } \\
\text { 2. Plant Maintenance } \\
\text { 3equirements } \\
\text { 3. Electrical Performance } \\
\text { 4. Capability for Load Change } \\
\text { 5. Part Load Efficiency } \\
\text { 6. Minimum Load } \\
\text { 7. Startup Power Requirements }\end{array}$ & $\begin{array}{l}4.2 \\
4.2 \\
4.7 \\
3.0 \\
2.8 \\
3.3 \\
3.2\end{array}$ & $\begin{array}{l}3.9 \\
3.8 \\
4.1 \\
2.9 \\
2.4 \\
2.6 \\
3.0\end{array}$ & $\begin{array}{l}2.7 \\
3.5 \\
4.3 \\
4.0 \\
3.3 \\
3.7 \\
3.3\end{array}$ & $\begin{array}{l}4.2 \\
3.7 \\
3.9 \\
3.6 \\
3.1 \\
3.1 \\
2.7\end{array}$ & $\begin{array}{l}3.9 \\
3.6 \\
4.0 \\
2.6 \\
2.3 \\
2.1 \\
2.8\end{array}$ \\
\hline D. & $\begin{array}{l}\text { MANUFACTURING AND RESOURCES } \\
\text { 1. Hardware Materials } \\
\text { Availability } \\
\text { 2. Industrial Base } \\
\text { 3. Natural Resource } \\
\text { Requirements } \\
\text { 4. Fuel and Fertile Material } \\
\text { Availability }\end{array}$ & $\begin{array}{l}3.3 \\
0.0 \\
4.3\end{array}$ & $\begin{array}{l}3.3 \\
0.6 \\
4.5\end{array}$ & $\begin{array}{l}4.0 \\
3.3 \\
0.0 \\
4.3\end{array}$ & $\begin{array}{l}3.6 \\
3.6 \\
0.0 \\
4.0\end{array}$ & $\begin{array}{l}2.8 \\
3.5 \\
0.8\end{array}$ \\
\hline
\end{tabular}


Table $4-2 e$

UTILITY REQUIREMENTS SURVEY RESULTS

BY UTILITY LOAD FACTOR

\begin{tabular}{|c|c|c|c|}
\hline & \multirow{3}{*}{$\begin{array}{r}\text { Average Load Factor } \\
\text { No. of Utilities }\end{array}$} & \multicolumn{2}{|c|}{ Mean Requirement Weights } \\
\hline & & $<.6$ & $\geq .6$ \\
\hline & & 17 & 14 \\
\hline & $\begin{array}{l}\text { UTILITY PLANNING AND FINANCE } \\
\text { 1. Plant Capital Cost } \\
\text { 2. Plant O\&M and Fuel Costs } \\
\text { 3. Forced Outage Rate } \\
\text { 4. Planned Outage Rate } \\
\text { 5. Plant Life } \\
\text { 6. Plant Construction Time } \\
\text { 7. Financial Liability } \\
\text { 8. Unit Rating }\end{array}$ & $\begin{array}{l}4.0 \\
0.8 \\
3.9 \\
3.2 \\
3.2 \\
3.9 \\
3.9 \\
2.9\end{array}$ & $\begin{array}{l}4.4 \\
2.1 \\
3.8 \\
3.5 \\
3.6 \\
3.7 \\
4.1 \\
2.8\end{array}$ \\
\hline B. & $\begin{array}{l}\text { SAFETY, SITING AND LICENSING } \\
\text { 1. Plant Efficiency } \\
\text { 2. Plant Safety } \\
\text { 3. Dependence on Other Systems } \\
\text { 4. Flexibility of Siting } \\
\text { 5. Waste Handling and Disposal } \\
\text { 6. Decommissioning } \\
\text { 7. Licensability } \\
\text { 8. Weapons Proliferation }\end{array}$ & $\begin{array}{l}0.6 \\
4.4 \\
0.0 \\
3.9 \\
3.9 \\
2.9 \\
4.5 \\
3.3\end{array}$ & $\begin{array}{l}0.4 \\
4.2 \\
0.2 \\
3.7 \\
4.0 \\
2.8 \\
4.3 \\
2.9\end{array}$ \\
\hline C. & $\begin{array}{l}\text { UTILITY OPERATIONS } \\
\text { 1. Plant Operating Requirements } \\
\text { 2. Plant Maintenance Requirements } \\
\text { 3. Electrical Performance } \\
\text { 4. Capability for Load Change } \\
\text { 5. Part Load Efficiency } \\
\text { 6. Minimum Load } \\
\text { 7. Startup Power Requirements }\end{array}$ & $\begin{array}{l}3.8 \\
3.6 \\
4.4 \\
3.5 \\
2.9 \\
3.0 \\
2.9\end{array}$ & $\begin{array}{l}3.9 \\
4.0 \\
4.0 \\
2.6 \\
2.4 \\
2.6 \\
3.0\end{array}$ \\
\hline D. & $\begin{array}{l}\text { MANUFACTURING AND RESOURCES } \\
\text { 1. Hardware Materials Availability } \\
\text { 2. Industrial Base } \\
\text { 3. Natural Resource Requirements } \\
\text { 4. Fuel and Fertile Material } \\
\text { Availability }\end{array}$ & $\begin{array}{l}3.2 \\
3.5 \\
0.2 \\
4.2\end{array}$ & $\begin{array}{l}3.5 \\
3.4 \\
0.4 \\
4.0\end{array}$ \\
\hline
\end{tabular}


Table 4-3

CHARACTERIZATION RESULTS

(32 Utility Responses)

1. Type of Companies:
a) 9 Public Utilities
b) 23 Private Utilities

2. Present installed generating capacity: $5500 \mathrm{MW}$ (RANGE: $800-17,800 \mathrm{MW}$ )

3. Present average load factor: 57\% (RANGE: 36-68\%)

4. Increase in installed capacity in utility by 2000: $190 \%$ (RANGE : $5-1000 \%$ )

5. Average load factor in 2000: 62\% (RANGE: 50-75\%)

6. Total installed capacity in the US in 2000: $1220 \mathrm{GW}$ (RANGE : $400 \mathrm{GW}-1770 \mathrm{GW}$ )

7. National Grid in 2000: 30\% said "Yes"; $70 \%$ said "No"

8. Energy parks in 2000: 33\% said "Yes"; $67 \%$ said "No"

9. Kinds of plants in energy parks:
a) 10 said Nuclear (including LWR's, Breeders and Fusion)
b) 4 said Fossil
c) 4 said Solar
d) 2 said Geotherma1

10. Utility role in 2000 in addition to generating electricity:
a) 17 said process steam
b) 8 said district heating
c) 7 said synfuel production
d) 2 said fissile fuel production

11. Government will own:
a) $12 \%$ of nuclear power plants in 2000
b) $13 \%$ of all power plants in 2000

12. Government will operate:

a) $15 \%$ of nuclear power plants in 2000
b) $12 \%$ of all power plants in 2000 
13. Regulatory climate in 2000:
a) Nuclear Safety:
4 said "same"; 1 said "eased"; 26 said "stricter"
b) Air Pollution:
5 said "same"; 7 said "eased"; 18 said "stricter"
c) Water Pollution:
10 said "same"; 3 said "eased"; 17 said "stricter"
d) Thermal Pollution:

8 said "same"; 8 said "eased"; 14 said "stricter"

14. Federal government will become the primary licensing body for

all types of power generating plants in 2000 with state and local licensing bodies having little or no power plant licensing jurisdiction:

7 said "Yes"; 22 said "No"

15. Federal government will routinely provide financial assistance to utilities in 2000 for:
a) Base Load Capacity Additions:
3 said "Yes"; 28 said "No"
b) Other Capacity Additions:
0 said "Yes"; 31 said "No"
c) Transmission Interties:
7 said "Yes"; 23 said "No"
d) District Heating:
15 said "Yes"; 15 said "No"
e) Synthetic Fuel Production:
18 said "Yes"; 13 said "No"

16. Fusion power will become commercially available in the year: 2024 (RANGE: 2009-2100) 


\section{Section 5}

WORKSHOP

The results of the questionnaire survey were considered by the participants of a workshop, specifically to further develop the list of utility requirements. The invitees to the workshop included all recepients of the questionnaire, DOE Office of Fusion Energy staff members, project team members and colleagues from the participating organizations. The workshop was organized into four working groups, one for each category of requirement. Plenary sessions were held before and after the working group sessions to provide orientation and for the presentation of results respectively.

The one and a half day workshop was held in Boston, Massachusetts on August 23 and 24, 1979 at the EPRI Semi-Annual Fusion Review. The purpose of the workshop was to establish a list of utility requirements using the results of the utility requirements survey as a point of departure. The workshop considered the questions and comments from the questionnaire respondents and assessed the respondent organizations' weighting of the relative importance of each of the utility requirements.

The workshop was attended by thirty-seven people. There were four working groups corresponding to the four categories into which the utility requirements were divided. A list of the working group members and their affiliations is given in Table 5-1. The Utility Planning and Finance working group was composed of eleven people. They were charged with considering eight utility requirements and eightyfive pages of questionnaire respondents' comments on those requirements. The safety, Siting and Licensing working group was comprised of ten people who were charged with considering eight utility requirements and fifty-five pages of respondents' comments. The Utility operations working group was comprised of six members who were responsible for seven utility requirements and handled nineteen pages of 
Table 5-1

LIST OF ATTENDEES

UTILITY REQUIREMENTS AND CRITERIA FOR FUSION OPTIONS WORKSHOP

AUGUST $23 \& 24,1979$

BOSTON, MASSACHUSETTS

UTILITY PLANNING AND FINANCE

* T. M. Piascik

* R. W. Goodrich

S. Baron

L. A. Carosella

S. K. Ghose

B. K. Jensen

T. Lepley

C. H. Shih

D. Villacres

W. C. Wolkenhauer

SAFETY, SITING AND LICENSING

* W. A. Frederick

* R. N. Cherdack

W. B. Allred

R. Bagley

J. L. Ellis

J.A. Gray

C. R. Head

G. L. Kulcinski

G. Miley

C. E. Rossi

UTILITY OPERATIONS

* J. M. Black

* E. C. Fiss

M. J. Corson

R. D. Endicott

G. S. Janik

M. J. Mulcahy

MANUFACTURING AND RESOURCES

* D. Hartman

* K. L. Burton

S. C. Burnett

L. R. Fleischer

A. L. Gaines

M. W. Wertheim

OBSERVERS/COORDINATORS

N. A. Amherd

K. Billman

R. C. Ford

F. R. Scott

R. J. Vondrasek

* Denotes Co-Chairman
Public Service Electric and Gas Co. Northeast Utilities

Burns and Roe, Inc.

McDonnell-Douglas Corp.

Bechtel National, Inc.

Public Service Electric and Gas Co.

Arizona Public Service Co.

American Electric Power Service Corp. Houston Lighting and Power Co.

Washington Public Power Service Supply

Pennsylvania Power and Light Co.

Burns and Roe, Inc.

Stone and Webster Engineering Corp.

Northeast Utilities

Gilbert/Commonwealth

Burns and Roe, Inc.

D.O.E.-Office of Fusion Energy

University of Wisconsin-Madison

University of Illinois

D.O.E.-Office of Inertial Fusion

Northeast Nuclear Energy Co.

Duke Power Co.

Rochester Gas \& Electric Corp.

Public Service Electric and Gas Co. New York State Electric and Gas Co. Boston Edison Co.

Bonneville Power Administration

Northeast Nuclear Energy Co.

General Atomic Co.

Gilbert Associates Inc.

Combustion Engineering, Inc.

Grumman Aerospace Corp.

Electric Power Research Institute

Electric Power Research Institute

Electric Power Research Institute

Electric Power Research Institute

Burns and Roe, Inc. 
comments. The Manufacturing and Resources working group was comprised of seven members who were responsible for four utility requirements and addressed ten pages of comments. Each working group had two cochairmen who were responsible for leading and pacing the discussions. The workshop was structured for efficiency as time was limited and the material to be handled was voluminous. On the morning of the workshop, prior to beginning, the co-chairmen attended a briefing where they were given guidance as to what was to be accomplished, how it was to be accomplished and the importance of time. Two advantages the chairmen had in this workshop were that almost all of the attendees were familiar with the questionnaire section which they were addressing and the working groups were of a manageable size.

All materials had to be considered in a one day working session. On the following morning of the workshop, the chairmen gave brief presentations of the results of each of their working groups and handed in marked-up copies of the utility requirements which reflected changes in definitions, weightings, and ranges of merit based upon consideration of the questionnaire responses, as well as experience and opinion of the members of the working groups. A summary of the workshop results, along with a comparison with the questionnaire survey results is shown in Table 5-2.

The following are the paraphrased summaries given by the co-chairmen of the four working groups at the conclusion of the workshop:

UTILITY PLANNING AND FINANCE (R. Goodrich and T. Piascik)

General

This area is going to be very system sensitive. One is going to have to look at revenue requirements and the cost per kilowatt hour of energy. It was implied in formulating these requirements that one was talking about a 1,000 MWe unit in the year 2025. It is important to recognize that this workshop is a second or third step in the requirements definition process. As the proqram continues, it may be necessary to make modifications to the definitions and the weightings which have been applied to each of the requirements. No major chanaes were made to the requirements. No "5" (vital) ratings, were assiqned in this area, thus, no real "show stoppers" exist in Planning and 
Table 5-2

UTILITY REQUIREMENTS WORKSHOP SUMMARY OVERALL WEIGHTINGS

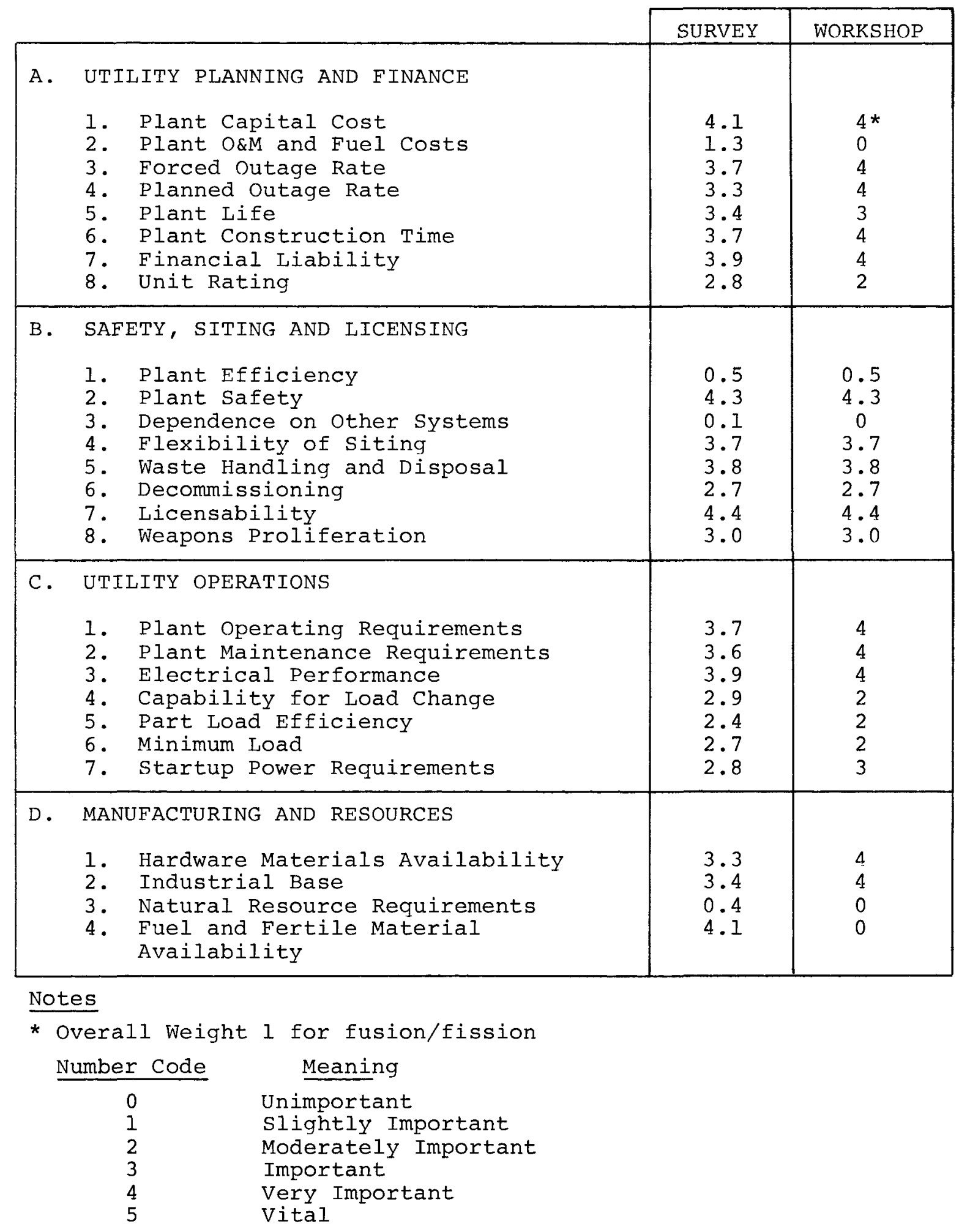


Finance. One way or another the problems in this area can be worked out.

It was noted that one is going to have to use care in applying the results. For instance, if there is an item which is judged "poor" and it has an overall weighting of "5", one should use care in saying its "score" is "one times five" (e.g., if poor is a one). On the other hand, if something has relatively small importance (e.q., overall weight 1 ) and is judged "good" (e.g., if good is three), the "one times three" in this case must be related to "five times one" in the previous example. One suggestion was that "good" be "plus one", if "fair" is "zero", and "poor" is "minus one".

\section{Capital cost}

In the area of capital cost, it was felt that there should be an overall weight of "one" or "four", depending whether it was a fusion/ fission unit or a fusion unit. The reason for putting a "one" for a fusion/fission unit was that presumably it will be servicing several burners and, therefore, have a somewhat smaller cost effect. In the handouts, the suggestion was that "fair" was half a billion dollars. This group felt that a range for "fair" was one to two billion dollars, or, on a dollars per kilowatt basis, on the order of one to two thousand dollars per kilowatt in 1979 dollars. In looking at the capital cost one can talk about dollars per kilowat,, which is implied in requirement number one, however, it was felt that there is another area that is a non-quantifiable that is going to be a problem. The problem can be illustrated by looking at the revenue requirements for a high capital cost plant with a low operating and fuel cost, compared to a medium capital cost plant with a medium operating and fuel cost assuming equal generating costs. An example might be a fusion plant and a fission plant respectively, assuming that the cost of fusion fuel will remain significantly lower than the cost of fission fuels. The more capital intensive fusion plant will have higher fixed charges and therefore have a greater impact on the utility rate base once it becomes operational. This impact is lessened in time by rate base changes due to escalating operating costs. One possibility to effect this impact in the early operating years is low interest government guaranteed financing. Another is third party lease arrangements. other possibilities are changes in accounting practices in order to 
help flatten this revenue requirement over the useable life of the plant. These aspects are all non-quantifiables, but they are very difficult to predict 50 years in advance because they are institutional and could be changed if the situation warrants it.

\section{Outages}

In the area of outages, it was felt that it is important to look at forced and planned outages together. An importance of four was placed on them. The group felt that the range for "fair" for forced outages should be $7 \%$ to $15 \%$ - the lower value being slightly higher than in the questionnaire. The group stayed with the planned outages in the order of 10 to $20 \%$ as being "fair". The availability that comes out of these outage rates is $65 \%$ to $83 \%$ as being the "fair" range. It was felt that no one would disagree with availability of better than $83 \%$ being "good". However, there might be some arguement as to whether something less than $65 \%$ is "poor". That value of availability may want to be raised.

\section{Plant Operating, Maintenance and Fuel Costs}

The group unanimously agreed that there are no non-cost related aspects of plant fuel and O\&M. Therefore, the overall weighting of this category was zero (unimportant).

\section{Plant Life}

Extensive discussion was generated concerning the meaning of plant life. With future restriction on available sites, it may be necessary to refurbish plants or components of a plant in order to extend the useful life. The group discussed possibilities such as replacement of the reactor chamber or the turbine generator set to extend the life of the plant to 80 to 100 years. The useful life of the original plant should be in the order of 30 to 40 years, similar to today's life expectancy of LWR and coal units. The group assigned an overall rating of 3 (important) to plant life.

\section{Plant Construction Time}

There are two components of total construction time: (1) design and construction of the plant and (2) time to obtain permits and licenses. 
The group assigned a weighting factor of two to the first component of total construction time and a weighting factor of three to the second component of total construction time. The logic of this choice is that the design and construction time is more controllable than the time to obtain licenses and permits. The time to obtain permits and licenses is predominantly controlled by regulatory bodies, intervenors and other considerations. The group selected a time period of six to eight years as a fair range for the design and construction phases and a time period of one to three years for the permit and licensing time. This gives a total construction time of seven to eleven years as being fair which is approximately the time frame for LWR construction now. The overall weighting for construction time was 4 , very important. With long lead times, utilities have to commit extensive capital well in advance of need which increases the risk involved.

Financial Liability Associated with Major Accidents

The group assigned a range of financial liability of $\$ 500$ million to a billion dollars as being "fair". The overall weighting of this aspect was four, very important. Throughout the project, the aspect of financial liability should receive close scrutiny. There was much discussion of this aspect and in general the group was hesitant to assign actual numbers. The group agreed that there are few utilities today that could withstand a financial loss of 500 million dollars and still stay solvent.

\section{Unit Rating}

Unit rating is very sensitive to the type of utility system being considered. With regard to large utilities within this country, the fair range of unit size is between 500 and 1500 MW based on what the group perceived as the types of utilities that would install fusion plants in the 21 st century. An overall rating of "2" was assigned to this aspect.

SAFETY, SITING AND LICENSING (R. Cherdack and W. Frederick)

General

The Safety, Siting and Licensing Requirements were perhaps the most complex set of utility requirements because of the many factors and subfactors associated with the Flexibility of siting, Plant safety, 
and Licensability requirements.

The amount of detail contained in the long lists of factors and subfactors associated with this portion of the utility requirements document was necessary to determine exactly what issues and features were deemed important in determining an option's desirability with regard to safety, licensability and siteability. This detailed information will be extremely useful in future work on this project.

\section{Plant Efficiency}

The first requirement considered was plant Efficiency. It was considered to have an overall weighting between "unimportant" and "slightly important". While the working group felt that all the significant impacts of Plant Efficiency were covered elsewhere, Plant Efficiency could be raised as a "straw man" issue by groups opposed to a plant for other reasons. For example, some groups opposed to nuclear power have used the argument that fissile material should not be consumed in plants with thermal efficiency as low as current LWRs because this represents a waste of an energy resource. It is generally accepted that this argument would not be raised in the case of a technology which is viewed favorably. Thus, the working group regarded it as a "straw man".

\section{Plant Safety}

The second requirement considered was plant safety. The overall weighting of Plant Safety does not include the impacts of safety on liability or licensability which are covered explicitly under other requirements. Rather, the weighting of this requirement is a measure of the importance of safety for social and moral reasons exclusive of direct financial and regulatory influences. Plant safety received a weighting of "more than very important" from the working qroup in concurrence with the results of the survey. The weighting for "out of plant property damage", a factor of Plant Safety, was altered from "unimportant" to "slightly less than important" and several subfactors were listed. These subfactors included presence of radioactive materials and presence of stored energy. 
Dependence on Other Systems

Dependence on Other Systems was considered to be a broad heading for requirements which are covered explicity elsewhere. For example, transportation requirements are covered under Flexibility of siting and Hardware Materials Availability and Manufacturing Base are requirements in their own right. One could consider fusion/fission breeders dependent on "other systems" in that a fission fuel cycle and fission power plants are required for such a plant to make sense. However, it makes more sense to evaluate the fusion/fission breeder, fission plants, and fuel cycle as a complete system with respect to well defined utility requirements rather than simply penalize a breeder plant because it is dependent of the existence of other kinds of plants.

Flexibility of siting

Flexibility of siting was given an overall weighting of "just less than very important" which is somewhat surprising in view of the difficulties utilities appear to be having in obtaining suitable plant sites. Plant Safety and Licensability were both rated "more than very important". The implication is that if a plant is licensable and safe, flexibility of siting follows and is less critical than the other two requirements.

Waste Handling and Disposal

Waste Handling and Disposal received a weighting of "very important". Utilities are obviously concerned about the spent fuel and radioactive waste disposal problems. The lack of a sound, accepted, waste disposal system is a key element in many anti-nuclear power arquments. Because of this and the fact that fusion wastes may be similar in a gross way to fissile fuel wastes the very important weighting is easy to understand. Factors relating to waste disposal included quantities and levels of radioactive waste. High level wastes are of major concern, but are not yet defined for other than the fissile fuel cycle. A reasonable definition for fusion high level wastes should be developed and should address heat and energy density, biological hazard, and half-life. 
Decommissioning

Decommissioning received a weighting between "moderately important" and "important". It is an issue beginning to receive some attention, and has been identified by intervenors in nuclear plant licensing as a potential weak point.

\section{Licensability}

Licensability received a weighting of "extremely important". It is universally recognized that it will be impossible to generate power until the appropriate regulatory bodies approve of and certify a plant, and the ease with which such approvals can be obtained strongly affects the desirability of a plant. For both Licensability and Flexibility of Siting, the appearance of safety and perception of hazards can be more important than real safety.

\section{Weapons Proliferation}

The last requirement was Weapons Proliferation, an area which has received a great deal of attention in the recent past. Proliferation resistance received a weighting of "important". Two subfactors were affecting Weapons Proliferation: adaptability of a technology to weapons material production; and availability of weapons grade material or material which could be "refined" to weapons grade. Contrary to the results of the survey which indicated these two factors were of similar importance, the working group determined that materials availability was more important than technology adaptability. The reasoning involved in this determination was based on the fact that to utilize a technology, such as a neutron source, to produce weapons grade materials would take a definite commitment on the part of a government or plant owner and would require large technical and financial resources, whereas a theft and use of weapons grade material could be done quickly, by less sophisticated and substantial groups such as terrorists.

\section{Summary}

One conclusion from our overall evaluation of these requirements was that radioactivity is a major concern. Also, the public perception of hazards, particularly radioactivity, impact licensability. For 
example, although electrical shock related injuries and deaths occur in power plants with some frequency, they are not perceived to be a serious hazard as long as industrial standards are being met. Also, electrocution is a well understood phenomenon. On the other hand, radioactivity is perceived to be a serious inplant hazard, although there has not been a single casualty to date from radiation hazards in a commercial power plant. The radiation hazard phenomenon and thresholds are not generally well understood by the public. What we felt is that the perception of public safety is a dominant feature in licensability. Public acceptance and public image are very important. The survey and workshop tell us that utilities also perceive the radiation hazard to be of primary concern when considering an energy option.

UTILITY OPERATIONS (M. Black)

\section{General}

We are concerned with seven requirements for utility operations. These seven requirements are the traditional entities you look at to evaluate the operation of a typical light water reactor. We only had a problem with the ratings of three of them, namely capability for Load Change, Part Load Efficiency and Minimum Load. The working group did not have a high degree of confidence in these requirements being imposed on the fusion plant because these requirements are dependent upon a utility's characteristics. We were talking about a plant in the 1,000 to 1,500 MW size range. While this size plant in the year 2000 or 2020 may be perfectly acceptable for a large utility like TVA or Duke Power, it may pose some problems for small utilities in terms of going down to low operating loads of $20 \%$ to $30 \%$. In the light water reactor program, where typical pressurized water reactors and boiling water reactors allow you to ramp and step load change at 5\% per minute between $50 \%$ and $100 \%$ power and $\pm 10 \%$ steps, a lot of flexibility to do load following is built in. But, in actuality, the operation of the LWR plants, due to the high capital cost, is base loaded. The LWR is generally not being operated at partial load except perhaps due to licensing restriction. We felt that the importance of these three characteristics should be diminished. If you look at the average rating of about "3" for these requirements by most 
of the respondents, which is "important", we tended to move them down to "moderately important" in overall rating.

MANUFACTURING AND RESOURCES (K. Burton)

General

The Manufacturing and Resources group dealt with four concepts. The Natural Resource requirement was deleted by assigning a "zero" overall weighting because the working group felt that all the aspects of this requirement (i.e., water, land, air materials, and fuel) were covered in other sections.

Fuel and Fertile Material Availability

Fuel and Fertile Material Availability was not considered to be a means for descriminating among fusion options. While fuel and fertile material are considered extremely important in the evaluation of an energy option, it was the working group's understanding that only fusion options were to be considered in this study. Based on the inclusion of only fusion options, the group's opinion was that adding items that did not measure differences among various options would detract from an evaluation technique. All fusion options would be rated good, as the fuel sources such as lithium, boron, seawater, etc. are well distributed. However, if the method being developed for evaluating fusion options was to be used for non-fusion concepts as well, this requirement should be reinserted.

Hardware Materials Availability

Hardware Materials Availability was modified to highlight helium as a material for which substitution may be impossible. The workshop group felt that most strategic materials would have potential substitutes or engineering solutions, therefore, a go-no-go test was left in based on a 500 gigawatt electrical economy. The postulation of substitute materials would require a new fusion option to be considered as it would have an entirely new set of cost, irradiation, plant availability, etc., characteristics. 


\section{Industrial Base}

The Industrial Base requirement was modified based on the assumption that if a prototype had been manufactured, competitors might be reluctant to enter the market and compete with the existing prototype manufacturer. The investment entry cost was referenced to a multiple of component selling price. Industrial Base was modified to include manufacturing of components for fuel preprocessing and reprocessing plants in addition to the power plant components. 
Section 6

FINALIZED UTILITY REOUIREMFNTS

The material from the workshop and the data from the questionnalre survey were reviewed and modified by the project senior Review Committee composed of engineering vice presidents from Burns and Roe, PSE\&G and NU. S. Baron, R. Huse and S. Law performed this function for their respective organizations. The changes to the utility requirements recommended by the Senzor Review committee and the evolution and rationale for the overall weightings of the requirements in their final form are described in this section. Table 6-1 summarizes the results of the questionnalre survey, workshop and Senior Review Committee deliberations.

The "Plant Capital Cost" requirement was written to reflect the financlal commitment associated with a fusion plant. The survey results Indicated that this was "very important". The workshop personnel concurred with the survey rating and qualified the requirement as being associated with a nominal $1000 \mathrm{~mW}$ plant. The workshop indicated that if this were a capital cost requirement for a fusion/fission plant, Its overall welghting should be downgraded to "slightly important" since in that application it would be fueling several "burners". The Senior Committee upgraded the overall welghting to "vital" and dropped the separate welghting for fusion/fission. The "vital" weighting was Justified based upon the "mode" (most frequent weighting) of the survey response data. The separate rating for fusion/fission breeders was dropped because it was thought that the utility requirements should be more general in nature. The Senior Review Committee added $\$ / k w$ considerations to the capital cost requirements to take into account financial considerations faced by potential part owners of fusion plants.

The "Plant Operatıng, Malntenance and Fuel Costs" requirement was rated "slightly important" by the survey respondents. The workshop 
Table 6-1

UTILITY REQUIREMENTS SUMMARY

OVERALL WEIGHTINGS

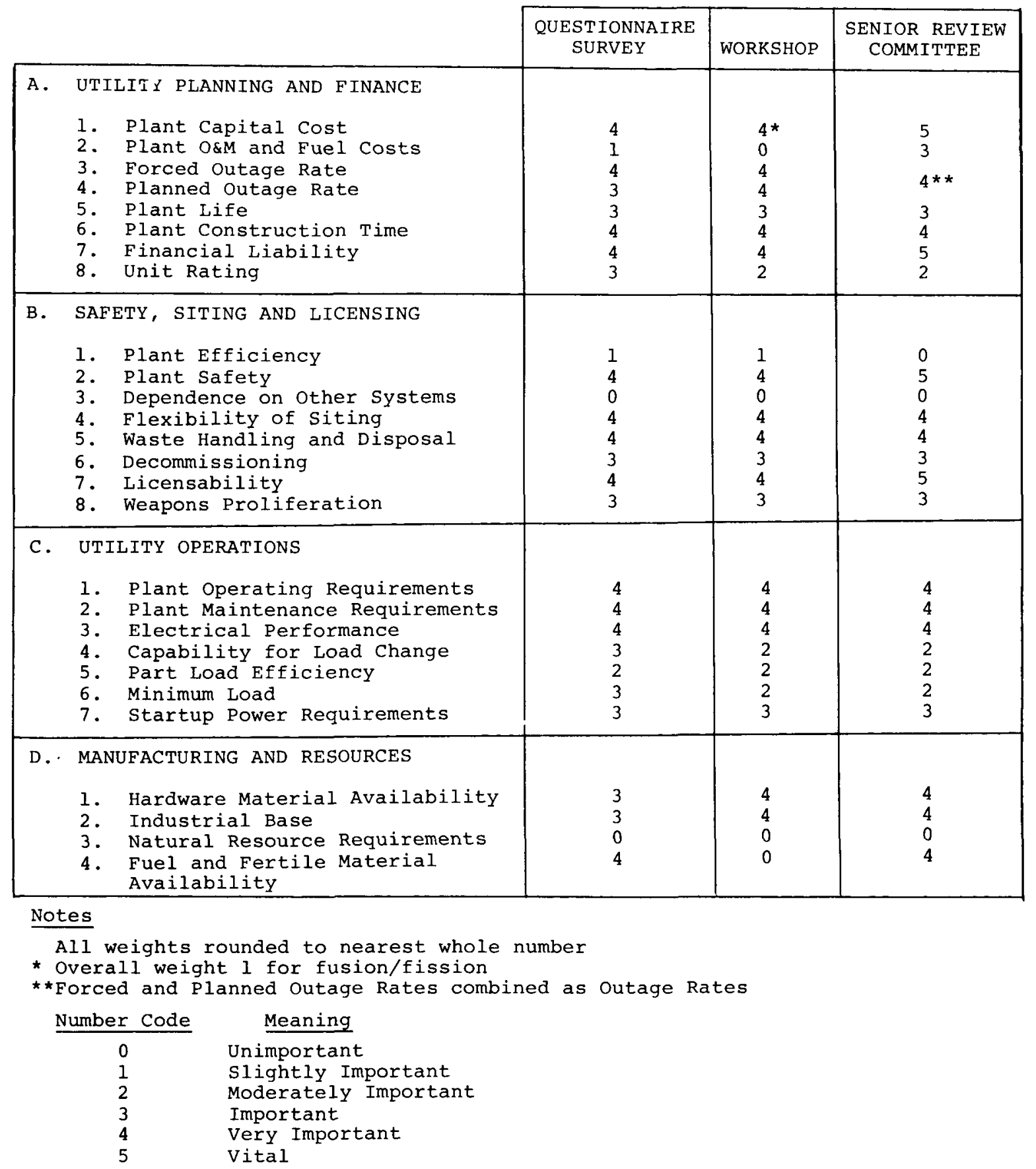


results indicated that this was an "unimportant" requirement and should be dropped, as the quantifiable aspects of operating, maintenance and fuel cost appear in cost-of-energy calculations, and there did not appear to be non-quantifiable aspects. The Senior Review Committee identified the fixed portion of operating, maintenance and fuel costs as posing a non-quantifiable financial risk. For example, if a plant is not able to meet its rate base anticipated capacity factor, the fixed portion of operating, maintenance and fuel costs presents a financial exposure. Revenues from operation of the plant will not be sufficient to cover fixed costs.

"Forced Outage Rate" was judged by the survey to be "very important" while "Planned Outage Rate" was judged to be "important". The difference stemmed from the fact that a utility could anticipate a planned outage and schedule it for a non-critical load period (e.g. off-peak season, weekend or night). Forced outages cannot be scheduled and thus impact a utility's spinning reserve requirement. Lossof-load probability increases with increasing forced outage rate. The workshop results indicated that both types of outage are "very important" and cannot be separated as they both impact system planning and plant availability. The senior committee combined the requirements under the new requirement "Outage Rates" having planned and forced outage rate components.

"Plant Life" was indicated to be "important" by the survey and workshop. The Senior Review Committee agreed. In considering the plant life requirement it was assumed that the fusion plant would be base loaded and capital intensive.

The "Plant Construction Time" requirement was rated as "very important" by the survey and workshop. The workshop results qualified this requirement as referring to a 1000 mWe plant. The Senior Review Committee refined the definition by noting the design, procure and erect time can overlap the permit and licensing time. Thus, overall construction time is not simply the sum of the component times. The Senior Review Committee agreed with the rating "very important". 
The "Financial Liability" requirement was a direct result of the Three-Mile Island experience. The survey indicated that this was "very Important" and the workshop results agreed. Further, the workIng group qualified the liablilty as being associated with the loss or damage associated with a $1000 \mathrm{MW}$ plant. The Senıor Review Committee upgraded this welghting to "vital" partly because the mode (most frequent weight) of the questionnalre survey responses was "vital".

"Unıt Ratıng" was judged to be "Important" by the survey respondents. The workshop and senıor Review Committee downgraded this to "moderately important". The workshop and senior Review Committee considered that fusion plants would probably be base loaded and have generating capacities of the same order of current LWR plants. This implies a reasonably large utility system or smaller utilities co-owning a large fusion unit. It is clear that there is an interaction among outage rates, unit rating, utility system size and load patterns which affects the significance of Unit Rating.

The "Plant Efflclency" requirement was welghted "sliqhtly important" by the survey and workshop. The Senıor Review commlttee downgraded this to "unimportant" recognizing that overall thermal efficiency effects were accounted for within the requirements "Plant safety" and "Flexibility of Sitng" and in the calculation of cost-of-energy on a net output basis. This requirement was dropped and therefore does not appear among the finalized requirements.

"Plant Safety" deals with actual hazards assoclated with the fusion plant and Its operation. It was deemed to be "very important" by the survey respondents and workshop participants. The Senior Committee upgraded this requirement to "vital" because the mode of the questionnalre response data for this requirement was "vital".

The requirement "Dependence on Other Systems" was thought to be "unimportant" by all reviewing bodies. The interaction of outside systems is covered under Plant operating Requirements to the extent it pertains to a fusion plant. This requirement was therefore dropped and does not appear among the finalized requirements.

"Flexıbılıty of Sitıng" refers to plant adaptabılıty to a varıety of 
sites with minimal impacts over the spectrum of environmental concern. It covers land use, water use, access, thermal pollution, airborne emissions, aesthetics, noise and construction impacts. All three groups agreed that this was "very important".

"Waste Handling and Disposal" addresses the need to handle and dispose of radioactive and toxic wastes. It considers quantity and frequency of disposal. All three groups concurred with a "very important" weighting for this requirement.

"Decommissioning" was concerned with the difficulty of safety, permanently removing a plant from service after its useful life. This requirement was weighted "important" by the survey, workshop and Senior Review Committee.

"Licensability" considers ease of licensing. It addresses the perception of hazards, hazard mechanisms, accident mitigation and public acceptance. The latter has been shown to be a significant factor in licensing current LWR's. The survey and workshop weighted this "very important". The senior Review Committee upgraded this to a "vital" requirement based on the statistical mode of the responses to the survey questionnaire and the committee's own experience.

"Weapons Proliferation" concerns were addressed as a separate requirement. Misuse of, and unauthorized fabrication of lethal nuclear devices has stirred government and public concern. This has opened the nuclear fuel reprocessing cycle and undermined the economics of LWR's. The survey, workshop, and senior Review Committee all agreed that this is an "important" issue.

"Plant Operating Requirements" addresses stability of the process and size of operating staff. This requirement was judged to be "very important" by all three reviewing bodies.

"Plant Maintenance Requirements" considers the frequency and difficulty of repairs, number of skilled maintenance personnel reguired and radiation exposure anticipated in performing maintenance tasks. All three reviewing groups weighted this a "very important" requirement. 
The "Electrical Performance" requirement deals with electrical generation stability and sensitivity to transients. This was consistently weighted "very important" through the survey, workshop and senior Review Committee processes.

"Capability for Load Change" is concerned with the rate at which a fusion plant can pick up or shed electric load. This was weighted "important" by the survey, but downgraded to "moderately important" by the workshop. The working group envisioned fusion to be base loaded, therefore, ability to load follow was not thought to be too important. The senior Review Committee concurred with the workshop weighting.

"Part Load Efficiency" considers the change in unit efficiency at loads other than nominal rating. The survey leaned toward a "moderately important" overall weight. The workshop and Senior Review Committee concurred that it was a "moderately important" factor. The reasoning was, that for base load plants, part load efficiency usually is not a serious concern.

"Minimum Load" is the lowest output at which a unit can be operated stably and continiously. The survey indicated that this requirement was "important". The workshop results indicated that this was "moderately important" for base loaded units since they are either up at full load or down. Concerns about partial power licenses (experienced by some LWR's) and the historical need for large plants to cycle during the end of their useful lives (as they are displaced by newer, more efficient units) were discussed. The Senior Review Committee agreed with the workshop weighting of "moderately important".

"Startup Power Requirements" concerns the amount of power needed from the utility grid to start a fusion plant. The survey indicated that this was "important" and the workshop results agreed. The Senior Review Committee agreed with the "important" weighting also. Further, they chose to recast the requirement in terms of percent of nominal output required for starting instead of megawatts required during start. 
"Hardware Materials Availability", that is, world resource and reserve impacts of commercial fusion, were judged to be "important" in the survey. The workshop and senior Review Committee both upgraded this requirement to "very important".

The "Industrial Base" requirement concerns itself with available technology, number of vendors, and $R \& D$ associated with manufacturing development. The survey showed this was "important". The workshop upgraded this weighting to "very important" and related the manufacturing development program cost to the selling price of components. The workshop also expanded the definition of Industrial Base to include fuel preprocessing plant components and fuel reprocessing plant components. The Senior Review Committee concurred with the workshop.

The "Natural Resource Requirements" issue was addressed in the "Flexibility of Siting" and "Hardware Materials Availability" requirements. As a result, all groups judged the "Natural Resource Requirements" to be "unimportant" as factors associated with it are elements of other requirements. Hence, this requirement was dropped and does not appear among the finalized requirements.

"Fuel and Fertile Material Availability" was judged to be "very important" in the survey. In fact, the mode of the survey response data was "vital" owing to recent utility experience with oil and nuclear fuels. The workshop position was that the availability of lithium and deuterium was not an issue when comparing fusion options with other fusion options and recommended that this requirement be weighted "unimportant" and dropped. The Senior Review Committee reinstated this requirement and weighted it "very important". Their reasoning was that the issue was not "whether or not fuel was readily available for all conceivable fusion options", but rather, "that utilities require that fuel and fertile material be available for any fusion option".

The twenty-three finalized Utility Requirements, their definitions and overall weights after consideration by the Senior Review Committee are given in Table 6-2. A complete description of the Utility Requirements giving their factor and subfactor definitions and weights is contained in Appendix D. 
Table 6-2

SUMMARY OF UTILITY REQUIREMENTS DEFINITIONS

1. Plant Capital Cost

Overall wtg. 5

The plant capital cost includes all materials, construction labor, equipment, and land costs necessary to bring the plant to commercial operation. Also included in capital cost are engineering and design cost, construction management cost, interest during construction, escalation, owner's cost, and sales tax.

Other than its effect on the cost of energy, capital cost impacts the desirability of a fusion option because of the financial limitations faced by utilities in obtaining capital to construct and start-up a new plant. High total plant cost makes it difficult to undertake a project. The cost per net kilowatt of new installed capacity is a measure of the difficulty faced by utilities that are buying only a percentage of a plant to meet growth needs.

2. Plant Operating, Maintenance and Fuel Costs

Overall Wtg. 3

Included in the operating, maintenance and fuel costs are the cost of operating and maintenance labor, cost of components requiring replacement over the life of the plant, cost of materials required for servicing or replacing components, cost of training personnel, and cost of materials consumed in producing energy.

The cost-of-energy includes both costs that are fixed and those that vary with power generation. Operating, maintenance and fuel costs that are fixed pose a financial risk similar to fixed charges on capital investment. When a plant is operated below the originally anticipated capacity factor (used in figuring its mill rate), revenues do not cover the fixed portion of operating, maintenance and fuel costs.

3. Outage Rates

Overall Wtg. 4

This requirement considers the percentage of a year that a unit is unavailable due to a component failure or other unforseen condition that requires the unit to be removed from service. It impacts the 
Table 6-2 (Continued)

need for system reserve capacity and overall difficulty of operating the plant.

This requirement also considers the percentage of a year a unit is unavailable due to scheduled maintenance of reactor and balance of plant systems. Plants for which the yearly maintenance of the reactor and balance of plant systems could be carried out in parallel and scheduled for periods of low demand would be advantageous, since they would require less system reserve capacity.

4. Plant Life

Overall Wtg. 3

This requirement considers the total time a plant can be operated before decommissioning. It includes all additional time which may be gained by replacing/refurbishing any of the major components to the extent that the payback period for the replacements is less than the remaining life of the plant.

5. Plant Construction Time

Overall Wtg. 4

This requirement consists of two factors. The first includes the time to design, procure components and erect the plant. This is controllable and can be planned. The second factor includes the time required to develop, submit and receive approval of the documents necessary to obtain construction permits and operating licenses. There is uncertainity associated with this due to the intervention activities of regulatory bodies. If a full license cannot be obtained by completion of construction, production planning and carrying charges for the plants are impacted.

Note that these two factors can overlap so that overall construction time (for a 1000 MWe plant) is not necessarily the sum of the two.

6. Financial Liability Associated With

Overall Wtg. 5 Major Accidents

This requirement measures the attractiveness of a fusion option from the point of view of financial liability associated with death, in- 
jury, property damage, loss of revenue, and other financial losses resulting from the single worst credible accident attributable to a fusion option.

The direct loss to the utility includes damage to equipment and injury to employees. The direct loss to the public includes property damage, personal injury, lost work, displacement, decline in property values, and other hardships. Additional losses which may have financial impact on the utility include: loss of sales, increased cost of replacement power, and loss of depreciable assests.

The financial liability of a fusion option is evaluated based upon all the items discussed in connection with the worst credible accident.

\section{Unit Rating}

Overall Wtg. 2

This requirement considers the economic base load unit size that can be effectively integrated into a power system. Flexibility of unit rating is necessary for a plant to be attractive for both large and small additions to existing capacity. The availability of only larger size units increases the need to commit single sites to large incremental increases in capacity well in advance of needs. The availability of smaller size units provides flexibility for making incremental capacity additions at separate sites within closer planning constraints.

\section{Plant Safety}

Overall Wtg. 5

The safety of a plant is its capability to be built and operated with minimal injury to plant personnel or the public and minimal damage to property internal or external to the plant. Plant safety, both actual and perceived, impacts siting, licensing, operating and maintenance costs, liability risks, and forced outage rates. In addition, it has an intrinsic value independent of the above considerations: a utility would prefer to operate a plant which does not injure its personnel, the public, or cause property damage exclusive of economic, siting, licensability, or similar considerations. In considering these inde- 
Table 6-2 (Continued)

pendent aspects of plant safety only actual, rather than perceived hazards are included.

Four factors affecting overall plant safety were identified. In determining the weightings for each factor, impacts of safety on licensability, financial risk, siting, operating cost, capital cost and outage rates, which are covered elsewhere, are excluded.

For each major factor affecting plant safety, several related features of characteristics have been identified. The relative importance of each of these characteristics in terms of impact on plant safety may be estimated. Note that when a particular plant is evaluated, not only the presence or absence of a potentially hazardous feature, but also the quantity and degree of the hazard associated with such a feature, the accident mechanisms which could result in realization of the hazard potential, and effects of systems designed to prevent or mitigate the various hazards will all be considered.

\section{Flexibility of Siting}

Overall Wtg. 4

Siting is a major concern for most utilities at present and is expected to continue to be so in the future. It is important to recognize that siting flexibility is not only an option's ability to be located at already identified sites, but also its ability to make a whole new class of sites available and its ability to be sited close to a load center.

Utilities presently identify potential sites based on the needs of coal or fission power plants. In order to obtain a true measure of siting flexibility, it is necessary to look beyond the site choices resulting from such assumptions. To do this, flexibility of siting is divided into eleven factors.

10. Waste Handling and Disposal Overall Wtg. 4 Waste handling and disposal considers the in-plant handling, on-site disposal (or transportation) and off-site disposal of waste materials 
Table 6-2 (Continued)

formed as a byproduct of the energy production process. Such wastes may include solid residues, fission products, activated structures and components, contaminated liquids, solids and gases. Waste handing and disposal requirements affect both the capital and operating costs of a plant.

Waste handling within the plant also may lead to increased complexity of operations, additional hazards, decreased plant reliability and the need for special personnel training. Waste disposal may lead to increased land area requirements and transportation needs. These considerations are covered elsewhere.

In addition, waste handling and disposal have other independent aspects. For example, toxic and radioactive waste disposal is becoming increasingly difficult, and increasing restrictions threaten the continued operation of nuclear plants.

The range of waste to be handled and disposed of by utilities is varied in quantity and type. The independent aspects of waste handling and disposal are concerned with impairment and restriction of plant operation. The quantity and toxicity of the waste, and the monitoring agency which has jurisdiction over the disposal are important factors.

11. Decommissioning

Overall Wtg. 3

Decommissioning refers to the steps taken to render a plant safe to the environment after its operating lifetime. The cost of decommissioning affects the cost of energy, but not the capital cost, since the funds to cover these costs can be accumulated over the operating life of the plant. Other aspects of decommissioning include the diversity of utility personnel required to carry out the operation, and the increased opportunity for public opposition.

The degree of difficulty associated with decommissioning is a function of the presence of fission products, extent of component and structure activation, and the configuration and overall size of the contaminated areas. 
12. Licensability

Overall Wtg. 5

This requirement considers how readily a fusion option can be expected to receive regulatory approvals. While a plant must be ultimately licensable to be of any interest to a utility, there can be different degrees of difficulty with which regulatory approval can be obtained.

Factors which affect licensability are: perceived potential accident hazards, perceived normal operating hazards and nuisances, presence of accident mechanisms, demonstrated effectiveness of accident prevention or suppression systems, similarity to previously licensed plants, and public acceptance. For many of these factors it is possible to list associated plant features or characteristics and to determine the relative importance of the various features in terms of their impact on licensing. This has been done below, where appropriate. Note that in evaluating a plant not only would the presence of a potentially hazardous feature or characteristic be considered, but also the quantitative and qualitative nature of hazards, the accident mechanisms which release the hazards and the systems and features contained in the design for the prevention and mitigation of accidents.

\section{Weapons Proliferation}

Overal1 Wtg. 3

Recently, the U.S. Government has declared that the prevention of fissile material from being diverted to weapons production by terrorist groups, criminals, or nations not presently in possession of nuclear weapons to be a major national priority. This action has led to the suspension of nuclear fuel reprocessing in this country and the search for plants utilizing proliferation resistant technologies and fuel cycles. The resistance of a plant to weapons proliferation impacts its attractiveness through its licensability, public acceptance, security related costs and operating requirements.

The weapons proliferation requirement is broken into two parts. The first is the proliferation resistance of the technology. The second is the proliferation resistance of the fuel cycle. 
This requirement considers process stability and control interactions between process variables during startup and shutdown as well as plant operating work force.

\section{Plant Maintenance Requirements}

Overall Wtg. 4

Plant maintenance requirements are broken down into three parts. The first considers all the work tasks for day-to-day and periodic and/or preventitive maintenance throughout the life of the plant. The second considers the numbers and skills of the personnel required to carry out the maintenance. The third considers the radiation exposure from maintenance and surveillance activities.

\section{Electrical Performance}

Overall Wtg. 4

This requirement considers all of the electrical operating characteristics of a plant. In particular, a plant must operate stably from startup through steady state to shutdown, and it must react predictably without erratic transients under faulted conditions. Since all fusion concepts require electrical energy to operate, even applications which ostensibly use a fusion reactor to generate heat only, must either be able to stably satisfy their electrical needs internally or be able to satisfy them from an external network. In the latter case, the input impedance presented to an existing network must be properly matched for stable operation, and the input must be protected from transients on the network. For an application in which electrical power is the primary product, the output impedance of the fusion system must be easily matched to the existing network for stable operation.

\section{Capability for Load Change}

Overall Wtg. 2

This requirement considers the mechanical and thermal characteristics that limit the rate of response of a unit to changes in load or that restrict the time required for startup or shutdown. This factor affects the decision by the utility to dispatch the plant under system 
load changes, and, therefore, affects the unit's average capacity factor. It is expected that the same characteristics that affect the rate of load following will also affect the rate of startup from a warm condition.

18. Part Load Efficiency

Overall Wtq. 2

Part load efficiency is evaluated at $50 \%$ load, or the minimum load obtainable if the unit cannot operate continuously at $50 \%$ load. The ratio of the change in efficiency to the change in load going from full load down to half load is referred to as "R".

The measure of part load efficiency is the value of $R$. A low $R$ value indicates a small change of efficiency with reduced load. A high $R$ value indicates a significant efficiency reduction with load reduction.

19. Minimum Load

Overall Wtg. 2

The minimum load is the energy output level below which the plant cannot operate continuously. A low minimum load capability facilitates load following, shakedown operation (license to operate at reduced load) and minimizes the potential for damaging generating equipment when picking up load.

20. Startup Power Requirements

Overall Wtg. 3

The startup power required by a fusion option impacts utility system planning, power reserves, and dispatching. Large startup power requirements could produce electrical grid upsets in bringing units on line or require the use of large, on-site "bootstrap" auxiliary qenerating equipment.

21. Hardware Materials Availability

Overall Wtg. 4

This requirement considers the use of strategically important materials apart from their effects reflected in plant capital and operating costs. All materials associated with plant construction and operation are considered except fuel and breeding material (e.g., lithium). 
Table 6-2 (Continued)

The aspects of materials availability which are of concern are the number of critical materials needed to build the plant and their relative abundance. If substitute materials are used in the design of the plant, this constitutes a new design.

22. Industrial Base

Overall Wtg. 4

This requirement considers the industrial capability to manufacture the components of a fusion plant and the preprocessing and reprocessing of fuels when the technology has reached the point of commercialization. In order to achieve general acceptance of fusion technology, the existence of a supporting industrial base will be necessary.

23. Fuel and Fertile Material Available

Overall Wtg. 4

For a fusion option to be attractive, it must utilize a fuel which is either readily available in adequate quantities or which can be bred in a reasonable manner from a readily available material. Recent history has indicated that basing energy production on a fuel which is in short supply or subject to control by a small number of firms or nations can have disastrous results.

If a fuel must be bred, the availability of the equipment or plant required to perform this breeding must be considered. 


\section{Appendix A \\ UTILITY REQUIREMENTS QUESTIONNAIRE SURVEY \\ AND CHARACTERIZATION FORM MATERIALS}

INTRODUCTION

Appendix A contains copies of the materials mailed to the utilities, architect-engineers and manufacturers in conducting the utility requirements survey. One hundred packages were mailed. Forty-three responses were received including 32 from utilities.

This appendix includes the letter of inquiry, enclosures inviting surveyed firms to attend the Utility Requirements Workshop, a characterization form and the four packages of utility requirements with instructions for responding.

The purpose of the characterization forms was to stimulate respondents to project their thinking to their needs and the utility environment in the year 2000. The utility requirements were issued in four separate packages to facilitate distribution to appropriate departments within the respondents' firms. Weightings for requirements and their factors were solicited. Written comments and suggested changes to requirements' definitions, their factors and the "good", "fair" and "poor" ranges of the factors were encouraged. Suggestions for additions and deletions of requirements and factors were also sought.

The questionnaire survey process and results are described in detail in section 4 of this report. 
Index to Appendix A

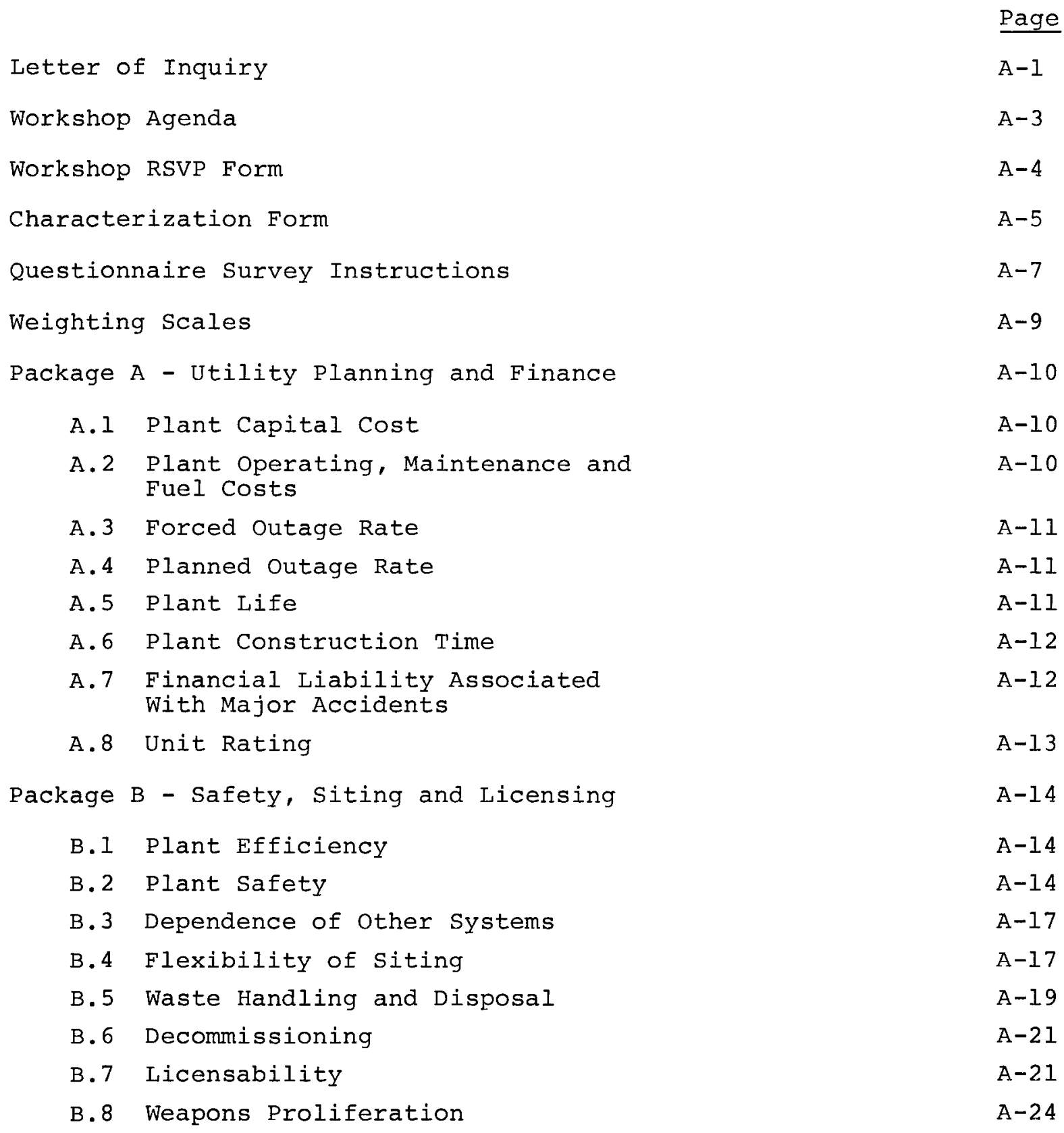




\begin{tabular}{|c|c|c|}
\hline Package & C - Utility operations & $A-26$ \\
\hline C.1 & Plant Operating Requirements & $A-26$ \\
\hline C. 2 & Plant Maintenance Requirements & $A-26$ \\
\hline C. 3 & Electrical Performance & $A-27$ \\
\hline C. 4 & Capability for Load Change & $A-28$ \\
\hline C. 5 & Part Load Efficiency & $A-28$ \\
\hline C. 6 & Minimum Load & $A-29$ \\
\hline C. 7 & Startup Power Requirements & $A-29$ \\
\hline Package & D - Manufacturing and Resources & $A-31$ \\
\hline D. 1 & Hardware Materials Availability & $A-31$ \\
\hline D. 2 & Industrial Base & $A-32$ \\
\hline D. 3 & Natural Resource Requirements & $A-32$ \\
\hline D. 4 & Fuel and Fertile Material Availability & $A-32$ \\
\hline
\end{tabular}


July 20,1979

\section{Attention:}

Gentlemen:

We are currently providing engineering services to the Electric Power Research Institute to identify Utility Requirements and Criteria for Fusion options. The purpose of this program is to develop a methodology for selection of viable, utility oriented options for fusion systems, applications, and fuels. Part of this effort is to identify a set of detailed utility requirements for fusion systems related to the application and projected performance of presently conceived fusion plants.

As part of this effort, Burns and Roe, Inc., is conducting a questionnaire survey. The purpose of this survey is to maximize utility and related industry input to the basic fusion evaluation framework being created for EPRI. With this objective in mind, we would sincerely appreciate your cooperation in providing responses to the questions on the enclosed questionnaire.

The questionnaire is based upon the utility requirements identified to date by us and our subcontractors, Public Service Electric and Gas Company and Northeast Utilities. The utility requirements identified fall into four major categories which constitute four separate questionnaire packages: 1) Utility Planning and Finance; 2) Safety, Siting and Licensing; 3) Utility Operations; and 4) Manufacturing and Resources. We believe that using separable packages will facilitate distribution of the questionnaire to appropriate functional entities within your company. Each individual package is complete with directions and has been formatted to facilitate response. We also ask that your company complete the enclosed Characterization Form and return it with the questionnaire packages.

The information received will be treated confidentially. All information will be compiled by Burns and Roe, Inc., exclusively. Compiled data will be divorced from source references. Compiled data will be statistically analyzed and the results made available to participants.

It is recognized that the response to this questionnaire requires considerable time and effort. However, the potential benefits this will bring in providing a consensus of guidance for the selection of fusion options for the utility industry will be extremely valuable. For your convenience, a pre-addressed, stamped return envelope is provided. We would appreciate receiving responses to the enclosed questionnaire by August 13.

A Workshop, sponsored by EPRI, will be held August 23 and 24 at the Colonnade Hotel in Boston, Massachusetts immediately following the EPRI Semi-Annual Fusion Project Review. The purpose of this workshop will be to review the compiled, statistical questionnaire data and reach consensus on the Utility Requirements definitions. The Workshop will be subdivided into four working groups as per the questionnaire: 1) Utility Planning and Finance; 2) Safety, Siting and Licensing; 
July 20, 1979

Page 2

3) Utility Operations; and 4) Manufacturing and Resources. A preliminary Workshop agenda is attached. Workshop participation in finalizing these requirements is being sought from utilities, manufacturers, architect-engineers and the Department of Energy.

As a questionnaire respondent you, or your designated representative, are invited to attend the Workshop. Workshop participants will be provided with additional background and updated information, prior to the Workshop, on the specific issues to be addressed. Please fill out the enclosed RSVP form and return it by August 6 .

The contributions made by the questionnaire respondents and the Workshop participants will help assure the timely development of fusion as an adaptable, useable source of renewable energy generation. We look forward to your response and hope you will be able to attend the Workshop.

Should you desire more information concerning the questionnaire or the Workshop, please call Mr. Robert Vondrasek of our Power Technology Division at (516) 677-2242. Thank you in advance for your cooperation.

very truly yours,

Dr. S. Baron

Senior Corporate Vice President

Director, Power Technology Division

$\mathrm{SB} / \mathrm{mc}$

Enclosure 
PRELIMINARY AGENDA

\section{UTILITY REQUIREMENTS AND CRITERIA \\ FOR FUSION OPTIONS WORKSHOP \\ BOSTON, MASSACHUSETTS \\ AUGUST 23-24, 1979}

Thursday, August 23, 1979
8:30 A.M. Opening Remarks, Background and Project Objectives, Presentation of Workshop Group Structure, and Intro- duction of Workshop Chairmen
9:30 A.M. Working Groups (In Parallel):
1. Utility Planning and Finance
2. Safety, Siting and Licensing
3. Utility Operations
4. Manufacturing and Resources
12:00 NOON Lunch Break
1:00 P.M. Working Groups (Continued)
5:00 P.M. Adjourn

Friday, August 24, 1979

8:30 A.M. Working Groups Reconvene

Summaries by Working Group chairmen

10:00 A.M. Utility Planning and Finance

10:30 A.M. Safety, siting and Licensing

11:00 A.M. Utility Operations

11:30 A.M. Manufacturing and Resources

12:00 NOON Closing Remarks 
Name (s)

Company

Will Attend

Unable to Attend

Workshop Session Preference:

Utility Planning and Finance

Safety, Siting and Licensing

Utility Operations

Manufacturing and Resources

(If you have a preference for a particular workshop, check off one above, otherwise a workshop assignment will be made.)

Comments :

Please mail to address below before AUGUST 6, 1979

Mr. Robert J. Vondrasek

Burns and Roe, Inc.

185 Crossways Park Drive

Woodbury, New York 11797 
UTILITY REQUIREMENTS AND CRITERIA FOR FUSION OPTIONS QUESTIONNAIRE

CHARACTERIZATION FORM

In responding to this questionnaire, we ask that you base your evaluations of Utility Requirements and their associated factors upon your projections of utility needs in the year 2000. In order for us to understand your conception of the utility industry in the year 2000 , please answer the following questions:

1. Type of Company (Check one)
a) Public Utility
b) Private Utility
c) Architect-Engineer
d) Regulatory Body
e) Research Organization
f) Manufacturer
g) Other (write in)

2. Present installed generating capacity MW

3. Present average load factor $\%$

4. What will the total installed MW capacity in the US be in $2000 ?$

5. What $\frac{\circ}{8}$ increase in installed capacity will your utility (or the average utility) realize by 2000 ? $\%$

6. Will a National Grid exist in 2000? (Check one) Yes No

7. Will energy parks be prevalent in 2000? (Check one) Yes No

8. If yes, what kinds of plants will be in energy parks? Check all that apply Nuclear*

Fossil

Solar

other (write in)

9. Your average (or the average utility's) load factor will be in 2000 .

10. Most utilities will be doing the following in 2000 (check all that apply) Generating electricity

Generating electricity
Generating process steam (heat)
District heating
Producing synthetic fuels
Producing fissile fuel

\footnotetext{
*For purposes of this questionnaire, "Nuclear" refers to lwr's, breeders, fusion and other types of nuclear plants that will be available in 2000 .
} 
11. The government will own:

$\%$ of nuclear power plants in 2000

of all power plants in 2000

12. The government will operate:

$\therefore$ of nuclear power plants in 2000

of all power plants in 2000

13. What changes in the regulatory climate in 2000 do you expect compared to the present? (Check one for each)

-Nuclear Safety:

-Air Pollution:

-Water Pollution:

-Thermal Pollution:

same $;$ eased
same
same
same

istricter

; stricter

stricter

; stricter

14. Will the federal government become the primary licensing body for all types of power generating plants in 2000--with state and local licensing bodies having little or no power plant licensing jurisdiction? (Check one)

Yes No

15. Will the federal government routinely provide financial assistance to utilities in 2000 for: (Check one for each)

-Base Load Capacity Additions: Yes

- Other Capacity Additions:

-Transmission Interties:

-District Heating:

-Synthetic Fuel Production:

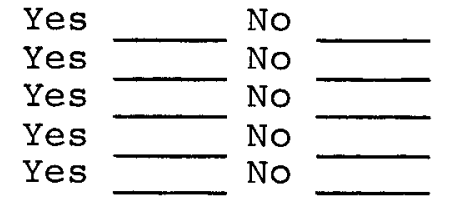

16. In what year do you think fusion power will become commercially available?

NAME

TITLE

COMPANY

Return to Burns \& Roe, Inc.

in enclosed mailer by August 13 . 


\section{QUESTIONNAIRE SURVEY INSTRUCTIONS}

The purpose of this Project is to define and establish the relative importance of Utility Requirements for fusion options that will become available in the next 20 to 30 years.

The quantifiable aspects of these Utility Requirements will be addressed in calculating the cost of energy (mills per kWh). The quantifiable features include capital cost, availability, net output, fuel cost, maintenance cost, operating cost, etc. The quantifiable aspects will be addressed later and are not dealt with here.

The aspects of Utility Requirement that are not strictly quantifiable are the subject of this questionnaire. Response to this questionnaire should include: review of, and comments on, the Utility Requirements definitions; overall weighting of each Requirement; weighting of the factors associated with each Requirement; and review of the definition of "good", "fair", and "poor" characteristics for each factor. It is recommended that the entire package be read first before proceeding with any of the weighting considerations.

The format of the questionnaire is based upon a numerical weighting system and is not intended to be a ranking. Consequently, several Utility Requirements and their associated factors may be given the same numerical weights, if appropriate. All weights need not be used. Note that any Requirement or factor that is believed to be of no importance may be zero weighted and in effect discarded.

In responding to the questionnaire, the following procedure is suggested:

1. Review each Requirement definition and the factors associated with it. Write in any changes and additions you feel are necessary to make the definitions and factors complete and accurate. Use non-black ink for comments.

2. Circle the overall Weighting value you feel is appropriate for each Requirement, considering its impact on the attractiveness of a fusion plant (or any new base load plant). The Overall Weighting scale is defined on the index page of this package for reference. 
3. Consider the factors associated with each Requirement, and listed under the heading "Factors". For each factor, circle the Weighting you think is appropriate for it, assessing its importance in relation to the Requirement being considered. The Factor Weighting scale is defined on the index page of this package for reference. Some factors have subweightings associated with them. These are to be handled in a similar manner. (Note that for some Requirements no factors or only one factor is listed, and this step may be omitted.)

4. For each factor consider the given parametric definitions and underlined characteristics used to determine "good", "fair", and "poor" ratings. If you think the underlined characteristics identified are inappropriate, write your suggesstions in non-black ink above the underlined characteristics.

5. Last, review the Requirements weighting system in this package and comment on the appropriateness of this system for evaluating the unquantifiable aspects of a fusion option (or any new base load plant). Please use the space below for you comments.

Comments :

NAME

TITLE

COMPANY

DATE 


\section{WEIGHTING SCALES}

Overall Weighting Scale - Associated with each Requirement

0 - Unimportant - Not Weighted

1 - Slightly Important

2 - Moderately Important

3 - Important

4 - Very Important

5 - Vital

Factor Weighting Scale - Associated with each factor of a Requirement

0 - Unimportant - Not Weighted

1 - Moderately Important

2 - Important

3 - Very Important 
PACKAGE A - UTILITY PLANNING AND FINANCE

A.1 Plant Capital Cost Overall Wtg. 0122345

The plant capital cost includes all materials, construction labor, equipment, and land costs necessary to bring the plant to commercial operation. Also included in capital cost are engineering and design cost, construction management cost, interest during construction, escalation owners cost, and sales tax.

Other than its effect on the cost of energy, capital cost impacts the desirability of a fusion option because of the financial limitations faced by utilities in obtaining capital to construct and start-up a new plant.

\section{Factors}

$$
\begin{aligned}
& \text { Capital cost (in } 1979 \text { dollars): } \\
& \frac{\text { Less than } \$ 500 \text { Million }- \text { good }}{\$ 500 \text { Million to } \$ 1500 \text { Million }- \text { fair }} \\
& \text { Greater than } \$ 1500 \text { Million - poor }
\end{aligned}
$$

A.2 Plant Operating, Maintenance and Overall Wtg. 0112344 Fuel Costs

Included in the operating, maintenance and fuel costs are the cost of operating and maintenance labor, cost of components requiring replacement over the life of the plant, cost of materials required for servicing or replacing components, cost of training personnel, and cost of materials consumed in producing energy.

No impact other than the direct effect on cost of energy has been identified. Therefore, this requirement was not weighted. (If you concur, please circle 0 ; if not please describe unquantifiable aspects and significant factors below.) 


\title{
A. 3 Forced Outage Rate
}

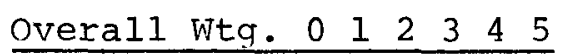

This requirement considers the percentage of a year that a unit is unavailable due to a component failure or other unforeseen condition that requires the unit to be removed from service. It impacts the need for system reserve capacity and overall difficulty of operating the plant.

\author{
Factors \\ Forced outage rate: \\ Less than $5 \%$ - good \\ $5-10 \%$ - fair \\ More than 10\% - poor
}

\begin{abstract}
A. 4 Planned Outage Rate Overall Wtg. $0 \quad 1 \quad 2 \quad 3 \quad 4 \quad 5$
This requirement considers the percentage of a year that a unit is unavailable due to scheduled maintenance of reactor and balance of plant systems. Plants for which the yearly maintenance of the reactor and balance of plant systems could be carried out in parallel and scheduled for periods of low demand would be advantageous, since they would require less system reserve capacity.
\end{abstract}

\section{Factors \\ Planned Outage Rate: \\ Less than $10 \%$ - good \\ $10 \%$ to $20 \%$ - fair \\ More than $20 \%$ - poor}

A.5 Plant Life Overall Wtg. 0122345

This requirement considers the total time a plant can be operated before decommissioning. It includes all additional time which may be gained by replacing/refurbishing any of the major components to the extent that the payback period for the replacements is less than the remaining life of the plant. 


\section{Factors}

Plant Life:

$$
\begin{aligned}
& \text { More than } 30 \text { years - good } \\
& \frac{20-30 \text { years - fair }}{\text { Less than } 20 \text { years - poor }}
\end{aligned}
$$
A. 6 Plant Construction Time
Overall Wtg. 0 \begin{tabular}{llllll}
0 & 1 & 2 & 3 & 4 & 5 \\
\hline
\end{tabular}
This requirement consists of two factors. The first includes the time to design, procure components and erect the plant. The second includes the time required to develop, submit and receive approval of the documents necessary to obtain construction permits and operating licenses. The latter impacts the production planning and carrying charges for the plant, if a full license cannot be obtained by com- pletion of construction.

\section{Factors}

1. Design, procure and erect:

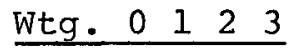

5 years or less - good

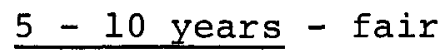

More than 10 years - poor

2. Permits and license time in excess

Wtg. \begin{tabular}{llll}
0 & 1 & 2 & 3 \\
\hline
\end{tabular} of construction time:

Less than 1 year - good

1 to 1.5 years - fair

Greater than 1.5 years - poor

A.7 Financial Liability Associated Overall Wtg. 0122345 With Major Accidents

This requirement measures the attractiveness of a fusion option from the point of view of financial liability associated with death, injury, property damage, loss of revenue, and other financial losses resulting from the single worst credible accident attributable to a fusion option. 
The direct loss to the utility includes damage to equipment and injury to employees. The direct loss to the public includes property damage, personal injury, lost work, displacement, decline in property values, and other hardships. Additional losses which may have financial impact on the utility include loss of sales, increased cost of replacement power, and loss of depreciable assets.

The financial liability of a fusion option is evaluated based upon all the items discussed above in connection with the worst credible accident.

\section{Factors}

A plant with a total liability (in 1979 dollars) of:

Less than $\$ 500$ million - good

$\$ 500$ million to $\$ 1500$ million - fair

Greater than $\$ 1500$ million - poor

A.8 Unit Rating Overall Wtg. 0122345

This requirement considers the minimum size plant that can be economically designed and constructed while maintaining near optimum efficiency. Flexibility of unit rating is necessary for a plant to be attractive for both large and small additions to existing capacity. The availability of only larger size units increases the need to commit single sites to large incremental increases in capacity well in advance of needs. The availability of smaller size units provides flexibility for making incremental capacity additions at separate sites within closer planning constraints.

\section{Factors}

Minimum Unit Rating:

Less than $500 \mathrm{MW}$ - good

$500 \mathrm{MW}$ to $1200 \mathrm{MW}$ - fair

Greater than $1200 \mathrm{MW}$ - poor 


\section{PACKAGE B - SAFETY, SITING AND LICENSING}

\section{B.1 Plant Efficiency $\quad$ Overall Wtg. $\begin{array}{llllll}0 & 1 & 2 & 3 & 4 & 5\end{array}$}

The overall plant efficiency is the ratio of energy consumed to the product energy produced at full load. The product energy may take different forms. For example, a plant which produces both electricity and process heat should have both of these energy outputs considered in calculating its efficiency. For some applications, electricity may be a more valuable product than process heat. In others, the reverse may be true.

Major impacts of plant efficiency are on siting and licensing. Quantity of heat rejection, makeup water use, and land area requirements are considered in Safety, siting and Licensing.

No other effects have been identified for plant efficiency which are not measurable in cost of energy. Therefore, this requirement is not weighted. (If you concur, please circle 0; if not, please describe the unquantifiable aspects and significant factors below.)

\section{B.2 Plant Safety $\quad$ Overall Wtg. 01123445}

The safety of a plant is its capability to be built and operated without injury to personnel or the public or damage to property internal or external to the plant. Plant safety, both actual and perceived, impacts siting, licensing, operating and maintenance costs, liability risks, and forced outage rates. In addition, it has an intrinsic value independent of the above considerations: a utility would prefer to operate a plant which does not injure its personnel, the public, or cause property damage exclusive of economic, siting, licensability, or similar consideration. In considering these independent aspects of plant safety, only actual, rather than perceived, hazards are included. 
Four factors affecting overall plant safety are listed below. In determining the weightings for each factor below, impacts of safety on licensability, financial risk, siting, operating cost, capital cost and outage rates, which are covered elsewhere, are excluded.

For each major factor affecting plant safety, several related features of characteristics have been identified. The relative importance of each of these characteristics in terms of impact on plant safety may be estimated. Note that when a particular plant is evaluated, not only the presence or absence of a potentially hazardous feature, but also the quantity and degree of the hazard associated with such a feature, the accident mechanisms which could result in realization of the hazard potential and effects of systems designed to prevent or mitigate the various hazards will all be considered.

\section{Factors}

1. Plant Personnel Safety:
a. Presence of gaseous and liquid radioactive material
b. Presence of activated structure and components
c. Maintenance in a radiation field
d. Indoor high voltage equipment and distribution
e. Frequent movement and mani- pulation of large pieces of equipment during maintenance
f. Presence of large quantities of stored energy
g. Presence of flammable or explo- sive materials
h. Presence of large cryogenic systems
i. Others?
$\left(\begin{array}{llll}0 & 1 & 2 & 3\end{array}\right)$
$\left(\begin{array}{llll}0 & 1 & 2 & 3\end{array}\right)$
$\left(\begin{array}{llll}0 & 1 & 2 & 3\end{array}\right)$
$\left(\begin{array}{llll}0 & 1 & 2 & 3\end{array}\right)$
$\left(\begin{array}{llll}0 & 1 & 2 & 3\end{array}\right)$
$\left(\begin{array}{llll}0 & 1 & 2 & 3\end{array}\right)$
$\left(\begin{array}{llll}0 & 1 & 2 & 3\end{array}\right)$
$\left(\begin{array}{llll}0 & 1 & 2 & 3\end{array}\right)$
$\left(\begin{array}{llll}0 & 1 & 2 & 3\end{array}\right)$

$\frac{\text { Wtg. } 0 \quad 1 \quad 2 \quad 3}{\text { (Subwtg.) }}$ 
2. In-plant Property Damage:

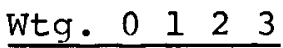

No impacts on plant attractiveness due to this category, which are not included under operating cost, forced and planned outages, and other listed requirements have been identified. If you concur, please circle 0 ; if not please describe unquantifiable aspects below.

3. Public Safety:

Wtg. \begin{tabular}{llll}
0 & 1 & 2 & 3 \\
\hline
\end{tabular}

Hazards with the potential to threaten public safety are:

(Subwtg •)
a. Normal emissions of toxic
$\left(\begin{array}{llll}0 & 1 & 2 & 3\end{array}\right)$ chemicals
b. Normal emissions of radio- active substances
c. Presence of large quantities of stored energy
d. Large toxic chemical inventories
$\left(\begin{array}{llll}0 & 1 & 2 & 3\end{array}\right)$
e. Presence of gaseous, liquid or volatile radioactive materials
$\left(\begin{array}{llll}0 & 1 & 2 & 3\end{array}\right)$
$\left(\begin{array}{llll}0 & 1 & 2 & 3\end{array}\right)$
f. Large quantities of chemically active systems
g. Electromagnetic emissions
h. Large quantities of flammable or explosive materials
i. Significant increase in rail, road or barge traffic
j. Shipments of liquid gaseous or volatile radioactive material
k. Shipments of toxic chemicals
1. Others?

4. External Property Damage:

Wtg. $0 \quad 12 \quad 3$

No impacts other than that discussed under Financial Liability Associated with Major Accidents have been identified. If you concur, please circle 0 ; if not please describe unquantifiable aspects below. 
A fusion option may be dependent on the existence, operation or close proximity of other systems or processes. For example, dependencies on fuel, transportation, waste disposal and electrical interties are possible. These are covered under other requirements.

No dependencies, which are not covered explicitly elsewhere, have been identified. Therefore, this requirement was not weighted. (If you concur, please circle 0 ; if not, please describe the unquantifiable aspects and significant factors below.)

\section{B. 4 Flexibility of siting}

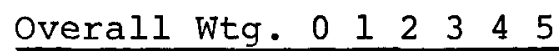

Siting is a major concern for most utilities at present, and is expected to continue to be so in the future. It is important to recognize that siting flexibility is not only an option's ability to be located at already identified sites, but also its ability to make a whole new class of sites available and its ability to be sited close to a load center.

Utilities presently identify potential sites based on the needs of coal or fission power plants. In order to obtain a true measure of siting flexibility, it is necessary to look beyond the site choices resulting from such assumptions. To do this, flexibility of siting is divided into eleven factors.

\section{Factors}

1. Land Area:

Wtg. $0 \quad 1 \quad 2 \quad 3$

Acreage required for the plant, its auxiliaries and exclusion area, if any.

Under 250 acres - good

250 to 500 acres - fair

Over 500 acres - poor

2. Transportation and Electrical Corridor Access:

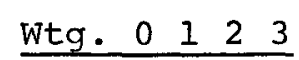

Access for construction; delivery of operating and maintenance supplies; and shipping products (fuels, heat, electricity or wastes). 
Standard highway and transmission lines - good

Heavy trucking or railway access - fair

Barge route or ultra high voltage transmission - poor

3. Makeup Water:

Wtg. 0 \begin{tabular}{llll} 
& 1 & 2 & 3 \\
\hline
\end{tabular}

Up to $5,000 \mathrm{gpm}-$ good

5000 to $25,000 \mathrm{gpm}$ - fair

Over $25,000 \mathrm{gpm}$ - poor

4. Hazards from Normal Emissions:

Wtg. \begin{tabular}{llll}
0 & 1 & 2 & 3 \\
\hline
\end{tabular}

Toxic and/or radioactive emissions.

No releases - good

Similar to current LWR - fair

Greater than current LWR - poor

5. Hazards from Potential Accidents: Wtg. 01123

Any substantial accident hazard, even if the possibility

is very remote, will impact chance for urban siting.

Similar to gas turbine - good

Similar to coal fired fossil plant - fair

Similar to LWR - poor

6. Heat Rejection:

Wtg. $010 \quad 1 \quad 2 \quad 3$

The quantity of heat rejected by the plant to the environment. Any recovery of this heat and its utilization for applications such as district heating or expansion cooling will reduce the quantity of heat rejected. Heat rejection is a consideration independent of makeup water and land area requirements because of its impact on climatic and microclimatic conditions; e.g., rejection of large quantities of heat in urban areas may be unacceptable.

Less than 3 billion BTU/h - good

3 billion to 6 billion BTU/h - fair

Over 6 billion BTU/h - poor 
7. Aesthetic Impacts:

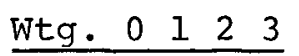

The anticipated public objection to physical appearance and detraction from existing landscape. The criteria to be judged are building volume and highest structural point. Less than 3,000,000 $\mathrm{ft}^{3}$ and $70 \mathrm{ft}$ - good

$3,000,000-15,000,000 \mathrm{ft}^{3}$ and $70-200 \mathrm{ft}$ - fair More than 15,000,000 $\mathrm{ft}^{3}$ and $200 \mathrm{ft}$ - poor

8. Seismic Design: Wtg. 0123

The requirement that a plant be siteable in an area of seismic activity. Siteable within Uniform Building Code Seismic Risk Zones.

zones $3 \& 4-$ good

Zone 2 - fair

Zones $0 \& 1$ - poor

9. Peak Construction Work Force:

Wtg. 0 \begin{tabular}{llll}
0 & 1 & 2 & 3 \\
\hline
\end{tabular}

Less than 1500 workers - good

1500 to 2000 workers - fair

More than 2000 workers - poor

10. Continuous Airborne sound (at nearest Wtg. 01223 residential property boundary):

Less than 45 dBA - good

45 to 65 dBA - fair

Greater than 65 dBA - poor

11. Impulsive Airborne Sound (at nearest Wtg. 0123 residential property boundary):

Less than 75 decibels - good

75 to 80 decibels - fair

Greater than 80 decibels - poor

B. 5 Waste Handling and Disposal

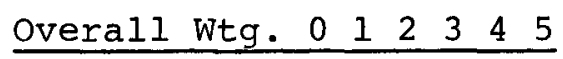

Waste handling and disposal considers the in-plant handling, on-site disposal (or transportation) and off-site disposal of waste materials 
formed as a by-product of the energy production process. Such wastes may include solid residues, fission products, activated structures and components, contaminated liquids, solids and gases. Waste handling and disposal requirements affect both the capital and operating costs of a plant.

Waste handling within the plant also may lead to increasing complexity of operations, additional hazards, decreased plant reliability and the need for special personnel training. Waste disposal may lead to increased land area requirements and transportation needs. These considerations are covered elsewhere.

In addition, waste handling and disposal have other independent aspects. For example, toxic and radioactive waste disposal is becoming increasingly difficult, and increasing restrictions threaten the continued operation of nuclear plants.

The range of waste to be handled and disposed of by utilities is varied in quantity and type. The independent aspects of waste handling and disposal are concerned with impairment and restriction of plant operation. The quantity and toxicity of the waste, and the monitoring agency which has jurisdiction over its disposal are important factors.

\section{Factors}

1. Quantity of high level radioactive waste produced by a 1000 MWe plant:

Wtg. $0 \quad 1 \quad 2 \quad 3$

None - good

0.2 metric tons per year - fair

2 metric tons per year - poor

2. Quantity of low level radioactive waste produced by a 1000 MWe plant:

Wtg. $0 \quad 1 \quad 2 \quad 3$

None - good

20 metric tons per year - fair

200 metric tons per year - poor 
3. Chemically toxic wastes:

Wtg. $0112 \quad 3$

None - good

Recycled or reclaimed - fair

Requires disposal or treatment - poor

4. Frequency with which wastes have to Wtg. 01223

be moved offsite:

Less than annually - good

Annually to monthly - fair

Less than monthly - poor

B. 6 Decommissioning

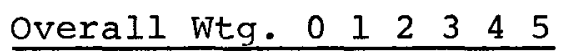

Decommissioning refers to the steps taken to render a plant safe to the environment after its operating lifetime. The cost of decommissioning affects the cost of energy, but not the capital cost, since the funds to cover these costs can be accumulated over the operating life of the plant. Other aspects of decommissioning include the diversity of utility personnel required to carry out the operation, and the increased opportunity for public opposition.

The degree of difficulty associated with decommissioning is a function of the presence of fission products, extent of component and structure activation, and the configuration and overall size of the contaminated areas.

\section{Factors \\ If plant decommissioning entails: \\ Abandonment - good \\ Dismantling and decontamination - fair \\ Entombment - poor}

B. 7 Licensability

Overall Wtg. 0 \begin{tabular}{llllll} 
& 1 & 2 & 3 & 4 & 5 \\
\hline
\end{tabular}

This requirement considers how readily a fusion option can be expected to receive regulatory approvals. While a plant must be ultimately licensable to be of any interest to a utility, there can be different degrees of difficulty with which regulatory approval can be obtained. 
Factors which affect licensability are: perceived potential accident hazards, perceived normal operating hazards and nuisances, presence of accident mechanisms, demonstrated effectiveness of accident prevention or suppression systems, similarity to previously licensed plants, and public acceptance. For many of these factors it is possible to list associated plant features or characteristics and to determine the relative importance of the various features in terms of their impact on licensing. This has been done below, where appropriate. Note that in evaluating a plant not only would the presence of a potentially hazardous feature or characteristic be considered, but also the quantitative and qualitative nature of hazards, the accident mechanisms which release the hazards and the systems and features contained in the design for the prevention and mitigation of accidents.

\section{Factors}

1. Perceived Potential Accident Hazards:

a. Quantities of gaseous radioactive materials onsite

b. Quantities of volatile radioactive materials onsite

c. Quantities of toxic liquids, gases, or potential gases onsite

d. Quantities of explosive materials onsite

e. Shipment of volatile, liquid, or gaseous radioactive material to or from the plant

f. Shipment of toxic chemicals to or from the plant

g. Shipment of explosive materials to or from the plant

h. Others?

2. Perceived Normal Operating Hazards and Nuisances:
a. Radioactive releases
b. Toxic releases - air
c. Electromagnetic radiation

\author{
$\frac{\text { Wtg. } 0123}{\text { (Subwtgs.) }}$ \\ $\left(\begin{array}{llll}0 & 1 & 2 & 3\end{array}\right)$ \\ $\left(\begin{array}{llll}0 & 1 & 2 & 3\end{array}\right)$ \\ $\left(\begin{array}{llll}0 & 1 & 2 & 3\end{array}\right)$ \\ $\left(\begin{array}{llll}0 & 1 & 2 & 3\end{array}\right)$ \\ $\left(\begin{array}{llll}0 & 1 & 2 & 3\end{array}\right)$ \\ $\left(\begin{array}{llll}0 & 1 & 2 & 3\end{array}\right)$ \\ $\left(\begin{array}{llll}0 & 1 & 2 & 3\end{array}\right)$ \\ $\left(\begin{array}{llll}0 & 1 & 2 & 3\end{array}\right)$

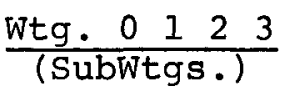 \\ $\left(\begin{array}{llll}0 & 1 & 2 & 3\end{array}\right)$ \\ $\left(\begin{array}{llll}0 & 1 & 2 & 3\end{array}\right)$ \\ $\left(\begin{array}{llll}0 & 1 & 2 & 3\end{array}\right)$
}



d. Transportation accidents
e. Noise
f. Water pollution
g. Heat rejection
h. Others?

3. Presence of Features Associated with Accident Mechanisms:
a. Cryogenic systems
b. Liquid metals
c. Plasma disruptions
d. Laser or particle beam disruptions
e. Quantities of volatile material under pressure
f. Quantities of stored energy
g. Superconducting materials
h. Quantities of explosive materials
i. Missile generating equipment
j. Afterheat requiring forced convection
k. Others?

4. Demonstrated Effectiveness of Accident Prevention or Suppression Systems:

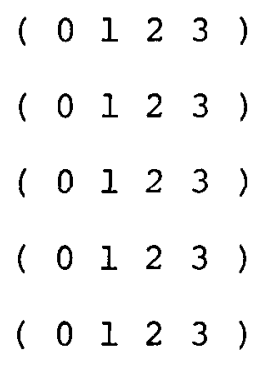

Wtg. \begin{tabular}{llll}
0 & 1 & 2 & 3 \\
\hline
\end{tabular}

For each of the accident mechanisms listed in (3), which would release a potential hazard listed in (1), is the normal prevention or suppression mechanism the same as or similar to well proven or demonstrated technology? Less than 2 nos - good

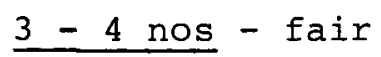

More than 4 nos - poor

5. Similarity to Previously Licensed Plants: Wtg. 0123 Whether or not a licensing agency is able to accelerate the licensing process after a reasonable exposure to a plant design will depend in part on how closely the de- 
sign resembles those which have been licensed previously and how many new issues must be addressed.

Many similar plants/no new issues - good

A few similar plants/few new issues - fair

No similar plants/many new issues - poor

6. Public Acceptance: $\quad$ Wtg. 0123

Acceptance of a design by the general public will help expedite licensing by preventing the use of licensing hearings as part of tactical campaigns to halt deployment of the technology and preventing the government from pressuring regulatory agencies into overly strict deliberations.

Plant is perceived as generally safe, clean, efficient and aesthetic

$-\operatorname{good}$

Plant is perceived as generally safe with some undesirable traits - fair

Plant is viewed as having questionable safety or a major hazard associated with its supporting supply and disposal cycles

- poor

B. 8 Weapons Proliferation

Overall Wtg. $0 \begin{array}{llllll} & 1 & 2 & 3 & 4 & 5\end{array}$

Recently, the U.S. Government has declared that the prevention of fissile material from being diverted to weapons production by terrorist groups, criminals, or nations not presently in possession of nuclear weapons to be a major national priority. This action has led to the suspension of nuclear fuel reprocessing in this country and the search for plants utilizing proliferation resistant technologies and fuel cycles. The resistance of a plant to weapons proliferation impacts its attractiveness through its licensability, public acceptance, security related costs and operating requirements.

The weapons proliferation requirement is broken into two parts. The first is the resistance of the technology. The second is the resistance of the fuel cycle. 
1. Technology:

Wtg. 01123

No connection between the technology and nuclear weapons proliferation

$-\operatorname{good}$

A technology which may be modified to produce weapons grade material

- fair

A technology, such as a flexible

neutron source, which can be

directly used to produce weapons grade material

- poor

2. Fuel Cycle:

Wtg. $0 \quad 1 \quad 2 \quad 3$

A fuel cycle which at no point has

a connection to nuclear weapons

proliferation

- good

A fuel cycle in which some material, which can be refined to weapons grade

by the application of moderately sophis-

ticated chemical or physical techniques,

is on site or frequently shipped

- fair

A fuel cycle in which weapons grade material is on site or frequently shipped

- poor 
PACKAGE C - UTILITY OPERATIONS

\section{C.1 Plant Operating Requirements Overall Wtg. $0 \quad 1 \quad 2 \quad 3 \quad 4 \quad 5$}

This requirement considers process stability and control interactions between process variables during startup and shutdown as well as plant operating work force.

\section{$\underline{\text { Factors }}$}

1. Process :

Wtg. \begin{tabular}{llll}
0 & 1 & 2 & 3 \\
\hline
\end{tabular}

Stable process, long reaction times for complex procedures, relatively insensitive to manipulative skills

Many possible plant trip initiators and system interactions requiring timely response extensive procedure knowledge similar to an LWR

Need for complex judgements in a short time span, inherently unstable process requiring extensive automated protection system - poor

2. Operating Work Force (including all Wtg. 0123 shifts):

Less than 100 personnel - good

100 to 150 personnel - fair

Greater than 150 personnel - poor

C.2 Plant Maintenance Requirements $\quad$ Overall Wtg. 01122345

Plant maintenance requirements are broken down into three parts. The first considers all the procedures for day-to-day and periodic maintenance throughout the life of the plant. The second considers the numbers and skills of the personnel required to carry out the maintenance. The third considers the radiation exposure from maintenance and surveillance activities. 
Factors

1. Procedures:

Wtg. 0 \begin{tabular}{llll}
0 & 1 & 2 & 3 \\
\hline
\end{tabular}

1-3 simple day-to-day repairs, 1-2 major yearly repairs/overhauls which can be done in parallel

$-\operatorname{good}$

4-6 simple day-to-day repairs, 1-2 major yearly repairs/overhauls which cannot be done in parallel - fair

More than 6 day-to-day repairs, more than 2 major yearly repairs/ overhauls which cannot be done in parallel

- poor

2. Personnel:

Wtg. 01223

Less than 15 skilled people - good

15 - 30 skilled people - fair

More than 30 skilled people - poor

3. Radiation Exposure:

Wtg. $012 \quad 2 \quad 3$

Less than 50 man-rem per year per $1000 \mathrm{MW}$

- good

$50-200$ man-rem per year per $1000 \mathrm{MW}$

- fair

Greater than 200 man-rem per year per $1000 \mathrm{MW}$ - poor

\section{3 Electrical Performance}

Overall Wtg. 0 \begin{tabular}{llllll} 
& 1 & 2 & 3 & 4 & 5 \\
\hline
\end{tabular}

This requirement considers all of the electrical operating characteristics of a plant. In particular, a plant must operate stably from startup through steady state to shutdown, and it must react predictably without erratic transients under faulted conditions. Since all fusion concepts require electrical energy to operate, even applications which ostensibly use a fusion reactor to generate heat only, must either be able to stably satisfy their electrical needs internally or be able to satisfy them from an external network. In the latter case, the input impedance presented to an existing network must be properly matched for stable operation, and the input must be pro- 
tected from transients on the network. For an application in which electrical power is the primary product, the output impedance of the fusion system must be easily matched to the existing network for stable operation.

\section{Factors}

A plant which is:

Inherently stable, easily matched to existing networks, and insensitive to network transients

- good

Stable but sensitive to network transients

- fair

Of questionable stability under faulted conditions

- poor

\section{C.4 Capability for Load Change}

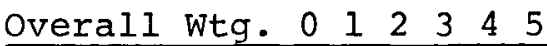

This requirement considers the mechanical and thermal characteristics that limit the rate of response of a unit to changes in load or that restrict the time required for startup or shutdown. This factor affects the decision by the utility to dispatch the plant under system load changes, and, therefore, affects the unit's average capacity factor. It is expected that the same characteristics that affect the rate of load following will also affect the rate of startup from a warm condition.

\section{Factors}

Time to change between full load to $50 \%$ load--going up or coming down in load, whichever is longer:

1 hour or less - good

1 to 4 hours - fair

Greater than 4 hours - poor

\section{C.5 Part Load Efficiency}

Overall Wtg. 0 \begin{tabular}{llllll}
0 & 1 & 2 & 3 & 4 & 5 \\
\hline
\end{tabular}

Part load efficiency is evaluated at $50 \%$ load, or the minimum load obtainable if the unit cannot operate continuously at 50\% load. The ratio of the change in efficiency to the change in load going from 
full load down to half load will be referred to as "R".

The factor of concern is the value of $R$. A low $R$ value indicates a small change of efficiency with reduced load. A high $R$ value indicates a significant efficiency reduction with load reduction.

\section{Factors}

A plant with a value of $R$ :

$$
\begin{aligned}
& \text { Less than } 0.2-\text { good } \\
& \text { Between } 0.2 \text { and } 0.5 \text { - fair } \\
& \text { Greater than } 0.5 \text { - poor }
\end{aligned}
$$

C.6 Minimum Load

Overall Wtg. $0 \begin{array}{llllll} & 1 & 2 & 3 & 4 & 5\end{array}$

The minimum load is the energy output level below which the plant cannot operate continuously. A low minimum load capability facilitates load following, shakedown operation (license to operate at reduced load) and minimizes the potential for damaging generating equipment when picking up load.

\section{Factors}

The minimum percent of full load operation at which a plant can operate continuously:

$$
\begin{aligned}
& \frac{20 \%}{20 \%} \text { good } \\
& \frac{20 \% \text { to } 40 \%}{\text { Above } 40 \%}-\text { fair }
\end{aligned}
$$

\section{C.7 Startup Power Requirements $\quad$ Overall Wtg. $0 \begin{array}{llllll}1 & 2 & 3 & 4 & 5\end{array}$}

The startup power required by a fusion option impacts utility system planning, power reserves, and dispatching. Large startup power requirements could produce electrical grid upsets in bringing units on line or require the use of large, on site "bootstrap" auxiliary generating equipment. 


\section{Factors}

A plant requiring startup power of:

$50 \mathrm{MW}$ or less - good

Between 50 and $150 \mathrm{MW}$ - fair

More than $150 \mathrm{MW}$ - poor

$A-30$ 


\section{PACKAGE D - MANUFACTURING AND RESOURCES}

D.1 Hardware Materials Availability $\quad$ Overall Wtg. 012345 This requirement considers the use of strategically important materials apart from their effects reflected in plant capital cost and operating costs. All materials associated with plant construction and operation are considered except fuel and breeding material (e.g., 1ithium).

The aspects of materials availability which are of concern are the number of critical materials (no substitutes available) needed to build the plant and their relative abundance.

\section{Factors}

A critical material is categorized by the fraction of world reserve $500 \mathrm{GW}$ of installed power requires: (a) less than $2 \%$ of world reserves; (b) between $2 \%$ and $10 \%$; or (c) more than $10 \%$.

Add the number of critical materials in category "(a)" plus $3 \mathrm{X}$ the number of critical materials in category "(b) "plus $5 \mathrm{X}$ the number of critical materials in category "(c)". If the sum total for a plant is:

Less than 5 - good Between 5 and 20 - fair Greater than 20 - poor

Note: Any plant for which a significant installed capacity requires more than $30 \%$ of the world's known reserves of a critical material should be dropped from consideration. 
D. 2 Industrial Base

Overall Wtg. 0 \begin{tabular}{llllll}
0 & 1 & 2 & 3 & 4 & 5 \\
\hline
\end{tabular}

This requirement considers the industrial capability to manufacture the components of a fusion plant when the technology has reached the point of commercialization. In order to achieve general acceptance of fusion technology, the existence of a supporting industrial base will be necessary.

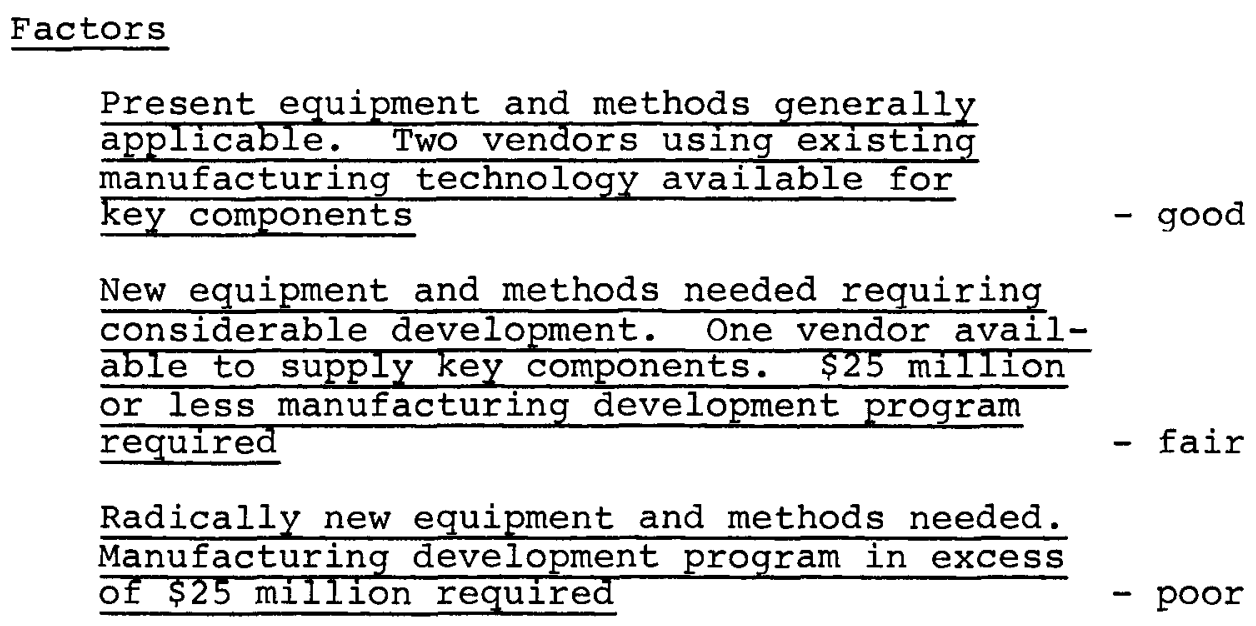

D.3 Natural Resource Requirements $\quad$ Overall Wtg. $01123 \quad 4 \quad 5$

All materials consumed or converted by the construction and operation of a fusion plant or resources, such as water, air, and land, which are degraded by operation of a fusion plant are covered elsewhere.

Therefore, this requirement was not weighted. (If you concur, please circle 0 ; if not, please describe the unquantifiable aspects and significant factors below.)

D.4 Fuel and Fertile Material Availability

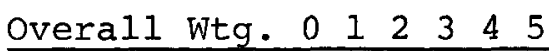

For a fusion option to be attractive, it must utilize a fuel which is either readily available in adequate quantities or which can be bred in a reasonable manner from a readily available material. Recent history has indicated that basing energy production on a fuel which is in short supply or subject to control by a small number of firms or nations can have disastrous results. 
If a fuel must be bred, the availability of the equipment or plants required to perform this breeding must be consicered.

\section{Factors}

An option which utilizes fuels or fertile materials that are:

Widely distributed and available (such as deuterium and lithium)

$-\operatorname{good}$

Moderately well distributed, including

deposits in this country or friendly

nations

- fair

Narrowly distributed and subject to cartel control or embargo

- poor 


\section{Appendix B \\ STATISTICAL RESULTS OF UTILITY REQUIREMENTS SURVEY}

\section{INTRODUCTION}

Appendix B contains computer sorted and analyzed statistical results of the utility requirements questionnaire survey. Responses have been tabulated for "ALL RESPONDENTS" including utilities, architectengineers and manufacturers. Responses have also been tabulated for "ONLY UTILITIES".

Each requirement is coded under the column titled "OUES. NO." (question number): first by a letter representing the questionnaire package group, followed by a decimal point and the requirement number and then by a space and the factor number, if any. For example, question number "A.6 2" is: package "A" - "Utility Planning and Financing", requirement "6" - "Plant Construction Time" and factor "2" - "permit and license in excess of construction time".

The statistical information shown with each question number includes: the arithmetic "mean" weighting of all responses (minimum 0, maximum 5), the standard deviation ("STD DEV") of the responses and the number of responses ("\#RES") to the question. This information is followed by the "NUMBER OF RESPONSES BY WEIGHTING" indicating how many respondents weighted the requirement "0", "1", "2", "3", "4" and "5"; "0", "1", "2" or "3" for factors. The number of responses by weighting sums to the number of responses (\#RES). An additional group of data is provided indicating "\# RESPONSES BY WEIGHTING W/COMMENT" which indicates how respondents who provided comments on a requirement or factor rated that requirement or factor. The sum of these is the total number of written comments received on a requirement or factor.

In using Appendix B, refer to Appendix A for package, requirement and factor designations. The questionnaire survey process and results are described in section 4 of this report. 
Index to Appendix B

$\underline{\text { Page }}$

Package A Responses - Utility Planning and Finance

B-1

Package B Responses - Safety, Siting and Licensing

B-2

Package C Responses - Utility Operations

B-8

Package D Responses - Manufacturing and Resources

B-9 
Package A

UTILITY PLANNING AND FINANCE

ALL RESPONIENTS

\begin{tabular}{|c|c|c|c|c|c|c|c|c|c|c|c|}
\hline JE: & MEAN & 516 & 7 & & $\mathrm{Num}$ & DF & $\bar{N} E S P O$ & 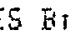 & WE & & \\
\hline NO & & II & RESS & & 0 & 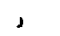 & 2 & ¿ & 4 & & 5 \\
\hline i & 14.11 & .91 & 40. & & 0.1 & $\bar{v}$. & 2 & 7. & \pm 7 & & $1+4$ \\
\hline .2 & 2.3 & 1.91 & 39. & & 24. & 2 & & 3. & 4. & & 4. \\
\hline & & .81 & $4 i$, & 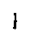 & 0 & 1. & $2+$ & $1+$ & 1 zá, & & 5. \\
\hline & & & 41. & 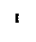 & 0. & 1 & 7 & & iT. & $i$ & \\
\hline † & & $i+01$ & 41 & 1 & 0.1 & 2 & ة. & 12. & $=17$. & & 3. \\
\hline+6 & & +9 & 41 & 1 & 0.1 & 0. & 4. & 14. & 15. & ! & 0 \\
\hline & & . 61 & & & 0.1 & & 5. & Itt & $1 \quad \bar{v}$. & 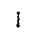 & U. \\
\hline & 12 & .71 & 37 & 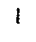 & 0. & 5. & 12. & 20. & 10. & 1 & 0. \\
\hline & & 1.11 & & 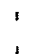 & 0. & & o. & 8 & 10. & 1 & so. \\
\hline & & & & & & & U. & & 8. & & \\
\hline
\end{tabular}

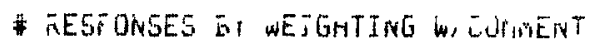

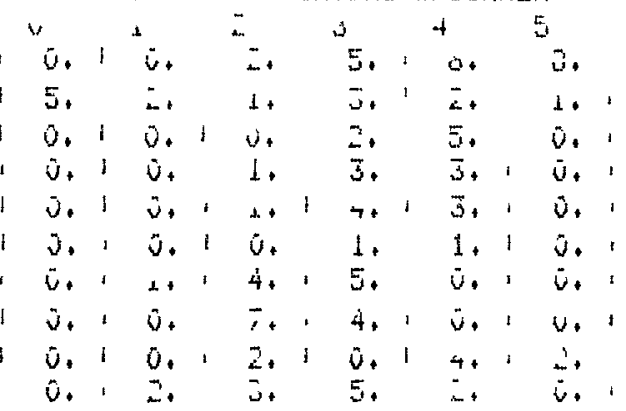

ONLY UTILITIES

QUES. MEAN SID $\$$ MUNEEN OF RESFONSES BI WLIGHTING

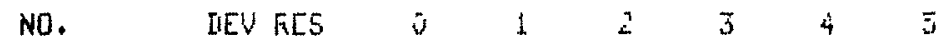

A.1 $4.211,0,31,10,13, \quad 3,4,14,13.1$

* RESTONSEJ G. WEJGHTING W/ LUNHENT

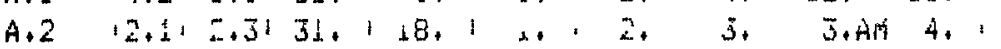

A.3 $13,8,1,0,32,1,0,1,0,1,15,18,15$,

A.4 $13.411 .0132,10.10,15,12,1+3, \quad 2.1$

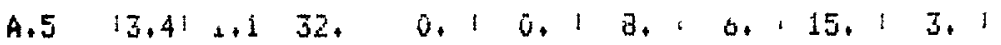

A.6 $3.911 .0132 .10 .10 .13 .150 .1,1.16 .1$

A.6 $112.4 \quad, 727,10,2,133,112,10,10.1$

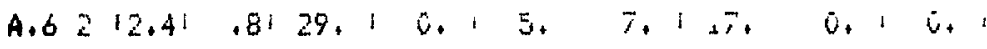

A.7 $14.011,3,31,10,15,14,15, \quad 6,114,1$

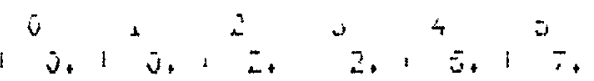

3. 1,1 , 1 3., 2., 1. 1

:

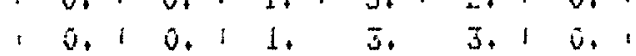

1 0. 0.10 .1 , 1.10 .10 .1

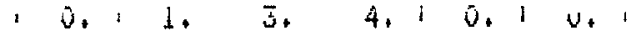

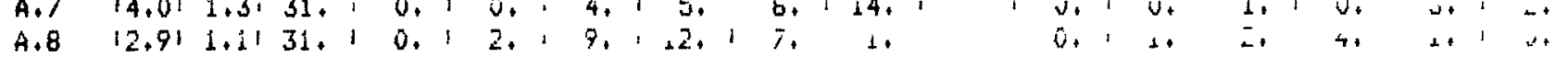


Package B

SAFETY, SITING AND LICENSING

\section{ALL RESPONDENTS}

\begin{tabular}{|c|c|c|c|c|c|c|c|c|c|c|c|c|c|c|c|c|c|c|c|c|c|c|c|c|c|c|c|}
\hline 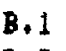 & 1.51 & .11 & 39. & & 3. & 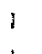 & U. & & 1. & & 4. & 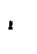 & $*$ & & 0. & 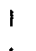 & & 0. & & 0. & & v. & & $\therefore$ & & 0. & 6. \\
\hline+2 & $(4, \overline{3})$ & +81 & 38. & 1 & 0. & 1 & 0. & 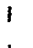 & 1. & ! & 6. & 4 & 11. & $1:$ & 20. & 1 & & 0. & i & 0 & & 6. & & 1. & & 0. & $1+$ \\
\hline 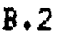 & 112.41 & +51 & 33. & 1 & 0. & . & 0. & & 20. & & 13 & ' & 3. & 1 & 0. & 1 & & 0. & & 0 & & 0. & & D. & & s. & 0. \\
\hline & A 12.51 & .81 & 40 & 1 & 0. & 1 & 0 & & 9. & 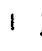 & 25 & 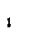 & 0. & $i$ & 0. & & & 0. & & $\tilde{v}$. & & 0. & & . & & i. & $\bar{v}$. \\
\hline & 1 & +81 & 40. & 1 & 1. & & 12. & & 16. & & 11. & 1 & $\dot{u}$. & 1 & 0. & & & 0. & & . & & . & & $1+$ & & 0. & 0. \\
\hline & & & $\pi$ & 1 & 0. & & 2. & & 15. & & 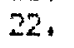 &, & $\therefore$ & 1 & 0. & & & . & & & & 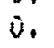 & & 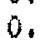 & & 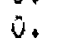 & 5 \\
\hline & 111.2 & .71 & 40. & 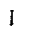 & 6. & 1 & 20 & 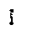 & 13. & & 1. & 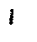 & 0. & 1 & 0. & & & 0. & & 0. & & . & & ). & & t. & . \\
\hline & $\left|E^{\prime}\right| 1+2 \mid$ & +81 & 40 & 1 & 7. & 1 & 19 & & $12+$ & & 2. & 1 & 0. & 1 & 0. & & & 0. & & 0 & &. & & 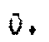 & & 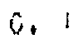 & $1+$ \\
\hline 12 & $1 F 12,01$ & .9 & 40. & 1 & 2. & 4 & s. & : & $s 7$ & $:$ & 15 & $t$ & 0. & $i$ & $\overrightarrow{0}$ & & & 0 & & 0. & & - & & & & i. & S. \\
\hline .2 & $6 \cdot 2+2$ & $+9 i$ & 40 & 1 & 1. & $\mathbf{i}$ & 8. & & 13. & 1 & is. & 。 & 0 & ; & s. & & & 0. & & 0. & & , & & 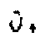 & & & . \\
\hline 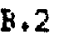 & $1 H ! 1.01$ & .8 & 40. & 1 & 2. & & 17. & i & 10. & 1 & 5. & i & 0 & 1 & 8 & & & 0. & 1 & 0. & & . & & $U_{t}$ & & & 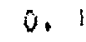 \\
\hline & III 2.51 & .81 & d. & 1 & 0. & 1 & $i$. & & 1. & & 4. & 1 & 0. & 1 & 0 & & & 0. & & 1. & & . & 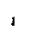 & 4. & & & 0. \\
\hline & $21+1$ & $.5 i$ & 38. & 1 & 35. & 1 & 2. & 1 & 0. & 1 & I. & 1 & 0. & i & 0. & & & $\vec{v}+$ & & i. & & 0. & 1 & 0. & & 0 & 0. \\
\hline & 22.81 & +5 & 36. & 1 & 0. & $i$ & + & i & 7. & 1 & 28. & 1 & 0. & $!$ & 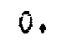 & & & 0. & 1 & v. & & L. & 1 & 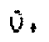 & & $\bar{v}$ & 0. \\
\hline & $3 \mathrm{H}^{2} \times 2.01$ & 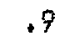 & 40. & 1 & 3. & 1 & 7. & & 17. & & 13. & 1 & c. & I & 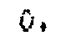 & & & 0. & 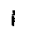 & L. & & ' & & $\theta+$ & & & 14 \\
\hline & $3 \mathrm{~B} \mid 2.21$ & .91 & 40. & 1 & 3. & $:$ & 5. & & i4. & 1 & 18. & & $\overrightarrow{0}$. & 1 & 6. & & & $v_{t}$ &  & + & & 6. & 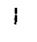 & a) & & $\ddot{v}$. & 0. \\
\hline & {$[11.7$} & .91 & 40. & $i$ & 3. & . & to. & & 13 & $:$ & a. & 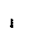 & $\bar{U}$. & & 0 & & & 0. & 1 & $\bar{u}_{.}$ & & $\bar{v}$. & 1 & 0. & & 0. & 0. \\
\hline 1.2 & $3 \pi 12.11$ & .7 & 40. & 1 & 1. & . & 0. & $i$ & 21. & 1 & $12+$ & 1 & 0. & 1 & $\hat{v}$ & & & 0 & 1 & 0. & & $\dot{v}$ & 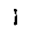 & C. & 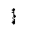 & . & 0 \\
\hline & 12.31 & .7 & 40. & 1 & 0. & 1 & 5 & & 17. & 1 & $\pm a$. & 1 & 0. & 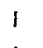 & 0. & & & 0. & 1 & 0. & & i. & & , & & & 0. \\
\hline & $35 \cdot 1.7=$ & .71 & 40. & 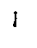 & 1. & 1 & 17. & 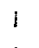 & 17 & $t$ & 5. & 1 & 0. & (5) & 0. & & & 0. & 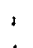 & U. & & $U_{4}$ & 1 & $6+$ & & & 0. \\
\hline & 361.11 & .71 & 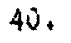 & & 9. & & 21. & 1 & 9. & 1 & 1. & 1 & 0. & t & i. & & & 0 & 1 & $j$ & & $1+$ & & & i & 0. & 0. \\
\hline . & $3 \mathrm{HI}_{1.81}$ & 1.01 & 40. & 1 & 3. & & .4 & & $1 \ldots$ & 1 & $12+$ & 1 & 0. & 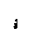 & 6. & & & 3. & 1 & $\bar{u}$ & & 0. & ' & 0 & & & 6 \\
\hline f. & $3 I 11+11$ & $\cdot \theta$ & 40. & 1 & 10. & 1 & 20 & & $\bar{B}$. & 1 & 2. & 1 & 3 & 1 & 3. & 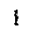 & & 0 & $i$ & $\hat{0}$ & 1 & 0. & 1 & $j$ & & 0. & $v+$ \\
\hline & 312.11 & .91 & 40. & 1 & 1. & & 10. & 1 & 4. & 1 & 15. & : & 0. & 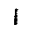 & 0 & 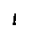 & & 0 & 1 & 0 & 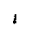 & 0. & 1 & 0. & & 0. & 0. \\
\hline & $3 k 12.0$ & .81 & 40. & 1 & 1. & 1 & 7. & & 20. & 1 & 10. & $i$ & 0. & 1 & 3. & 1 & 1 & 0 & 1 & 0 & & $j$ & & & & & \\
\hline & $3 L_{1}$ & ***1 & 0. & & 0. & 1 & $\hat{0}$. & & 0. & 1 & 0. & & 0. & & 0. & & & 0. & & 0. & & & & & & & 0. \\
\hline & $4, .11$ & $+0^{1}$ & $38+$ & & 30. & ${ }^{\circ}$ & 0. & & 1. & & 1. & 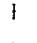 & $\hat{0}$ & & $\hat{O}_{+}$ & & & $\dot{0}$ & & $\hat{0}$ & & 1. & . & 0. & & $j$. & • \\
\hline+3 & 1.11 & .41 & 39. & 1 & 37. & & 1. & 1 & 1. & ' & 0 & 1 & $\theta$. & 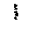 & $\bar{v}$. & 1 & 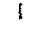 &.+ & & $\ddot{v}$. & & 1. & 1 & $v_{t}$ & 1 & 5.1 & $v_{*}$ \\
\hline
\end{tabular}


H.L RESFGNETH

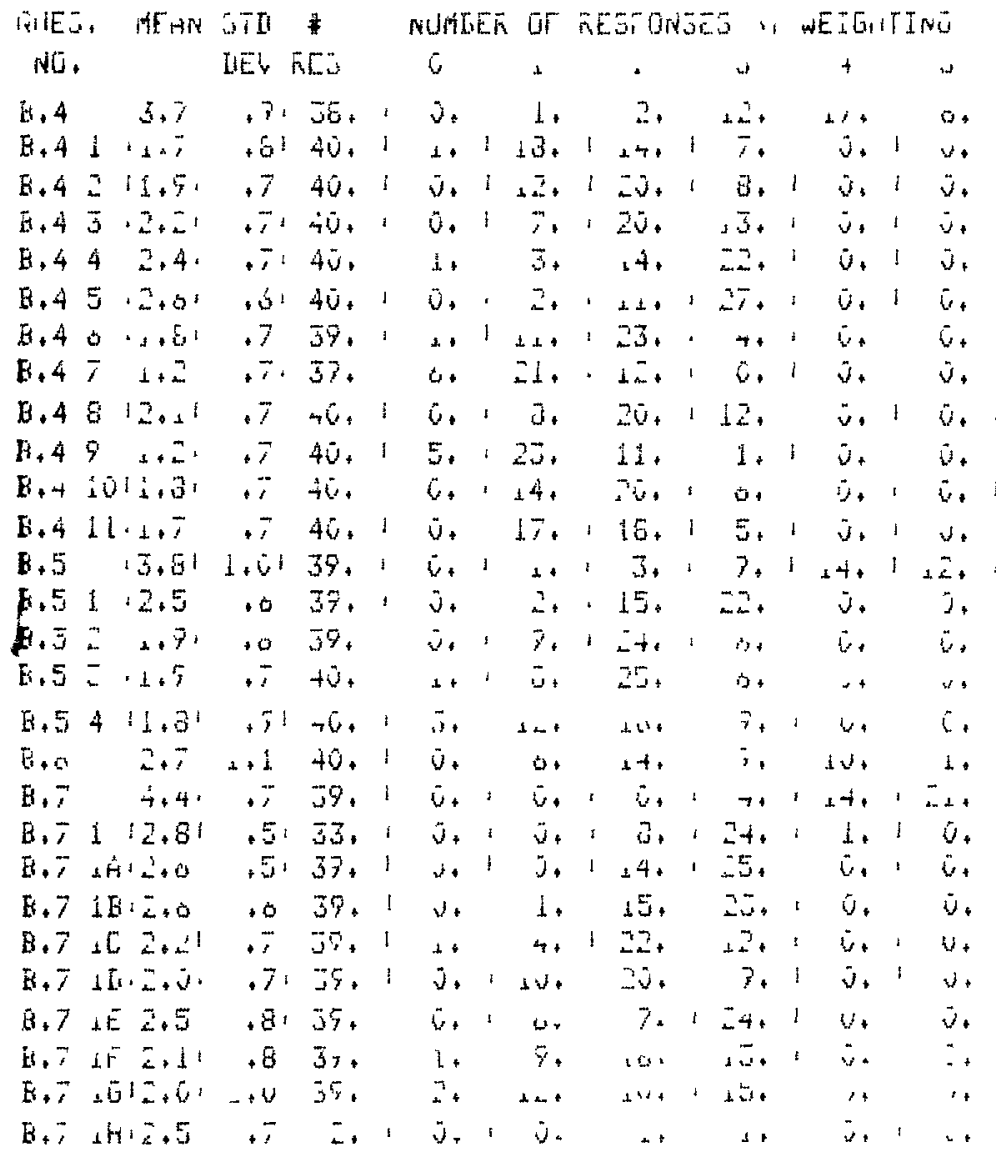

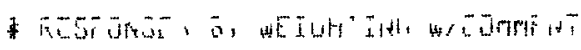

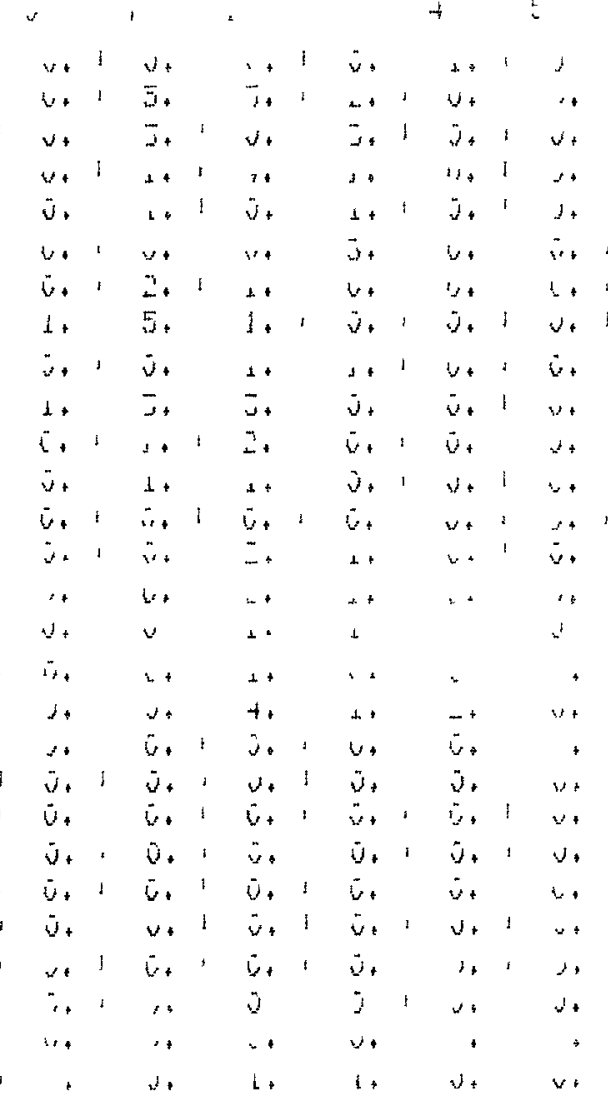




\section{ONLY UTILITIES}

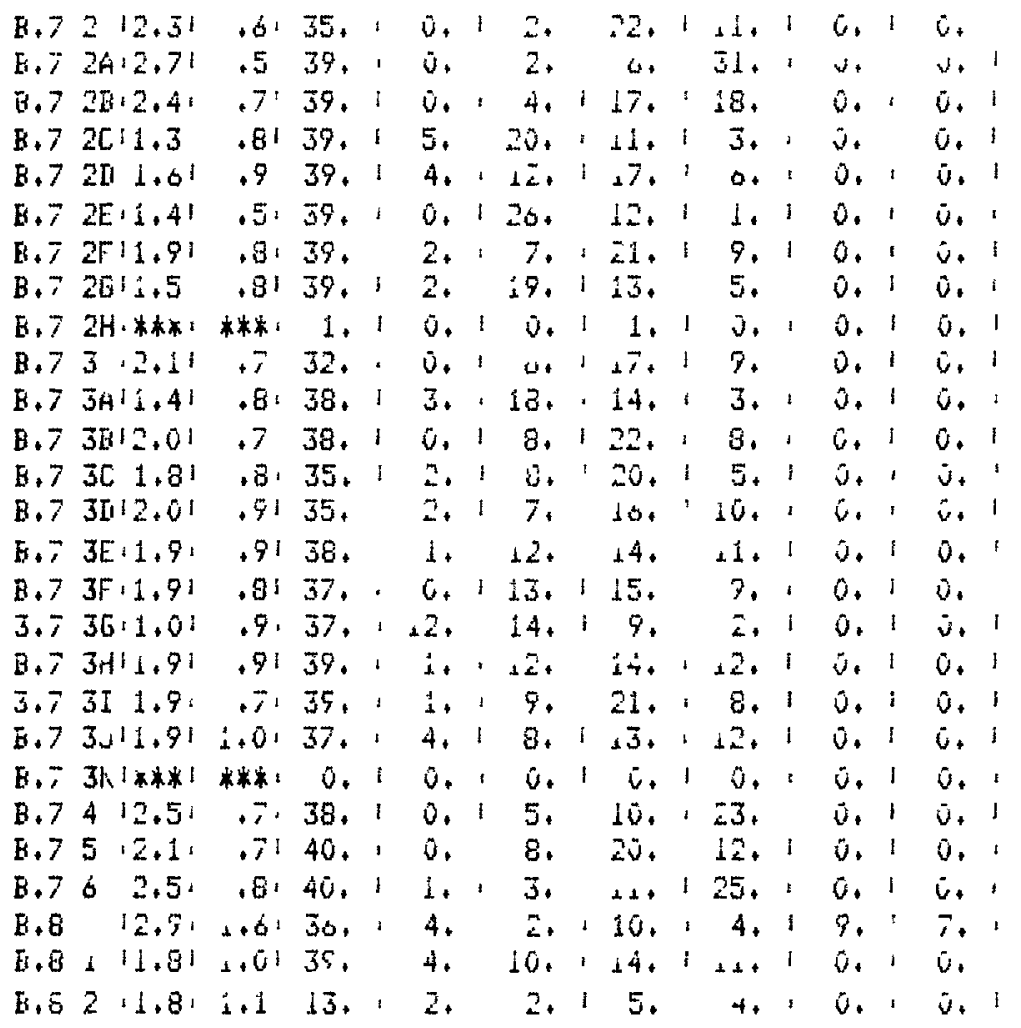

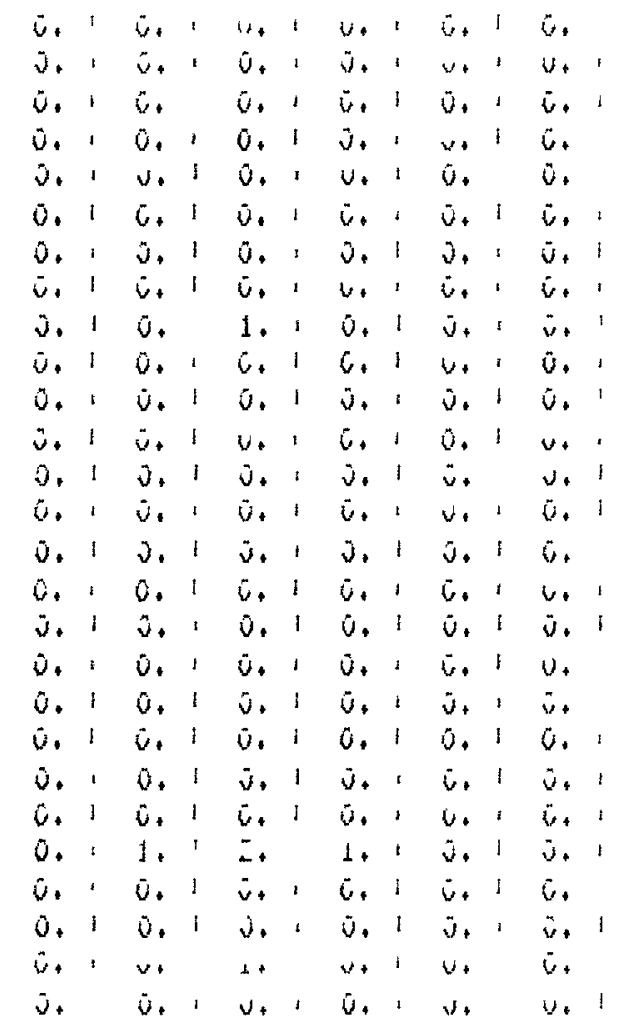


ONLY UTILITIES

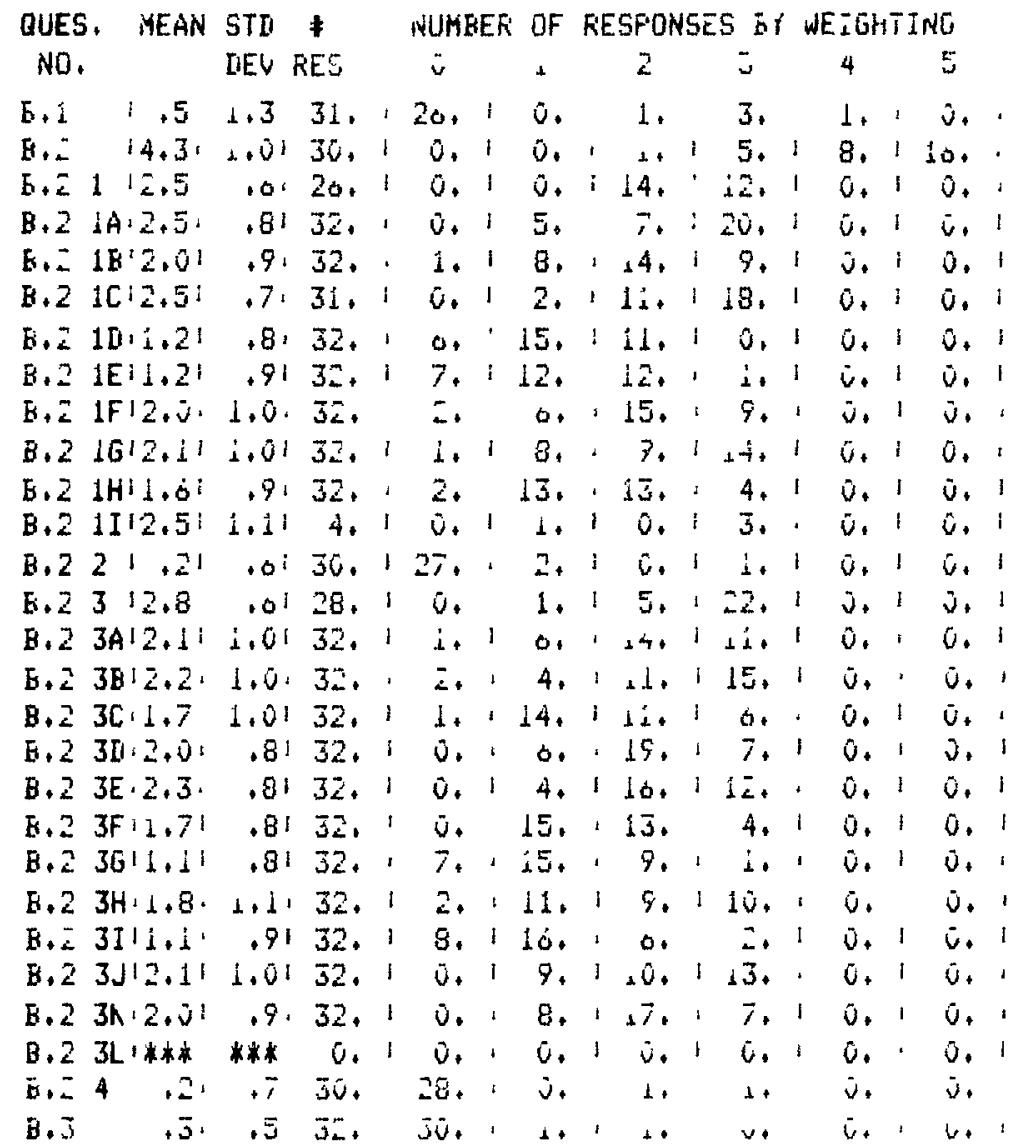

\# REST̈ONSES Dit wEIGHTINö w EDAMENT

$$
6+5+5
$$

v. $1 \quad \bar{v}, \quad \dot{v}, 1,1 \dot{v}, 1 j$,

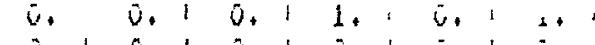

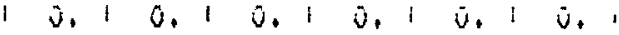

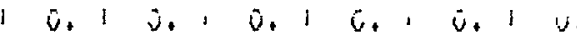

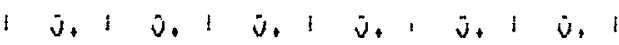

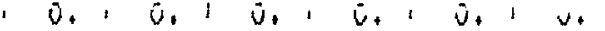

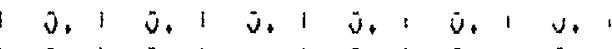

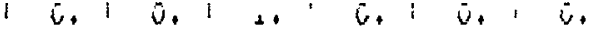

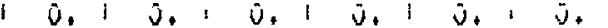
$\begin{array}{llllllllll}1 & u_{0} & i & u_{0} & u_{0} & \bar{u}_{0} & \bar{u}_{0} & i & u_{0}\end{array}$ $10.1 \hat{v}_{+} 1 \bar{v}_{+} 1 \bar{j}_{0} 1 \bar{v}_{1} 1 \bar{v}_{+}$

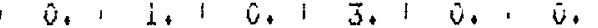

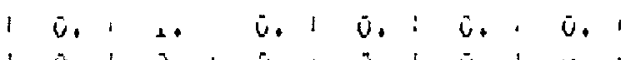
10.10 .10 .10 .10 .10 .1

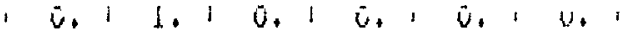

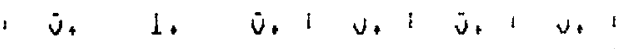
$1 \bar{v}_{1} 1 \bar{v}_{0} 1 \bar{v}_{1} 1 \bar{v}_{1} 1 \bar{v}_{1} 1 v_{1} 1$

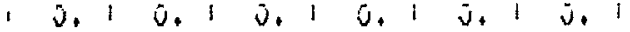
$1 \quad 0,1 \quad \bar{v}, 1 \quad \bar{v}, 1 \quad \bar{v}, 1 \quad \bar{l}, 1 \quad \bar{v}, 1$ $1 \quad j, 1 \quad j, 1 \quad j, 1 \quad u_{+} 1 \quad j, 1 \quad v, 1$

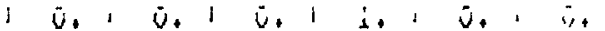

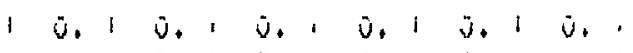

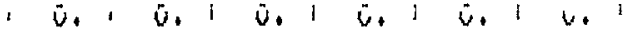

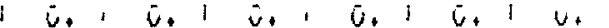

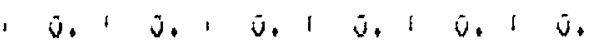

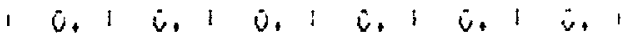
$u_{*}, j_{*}, 1, \cdots, v_{+}, v_{*}, \ldots$

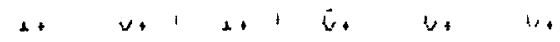




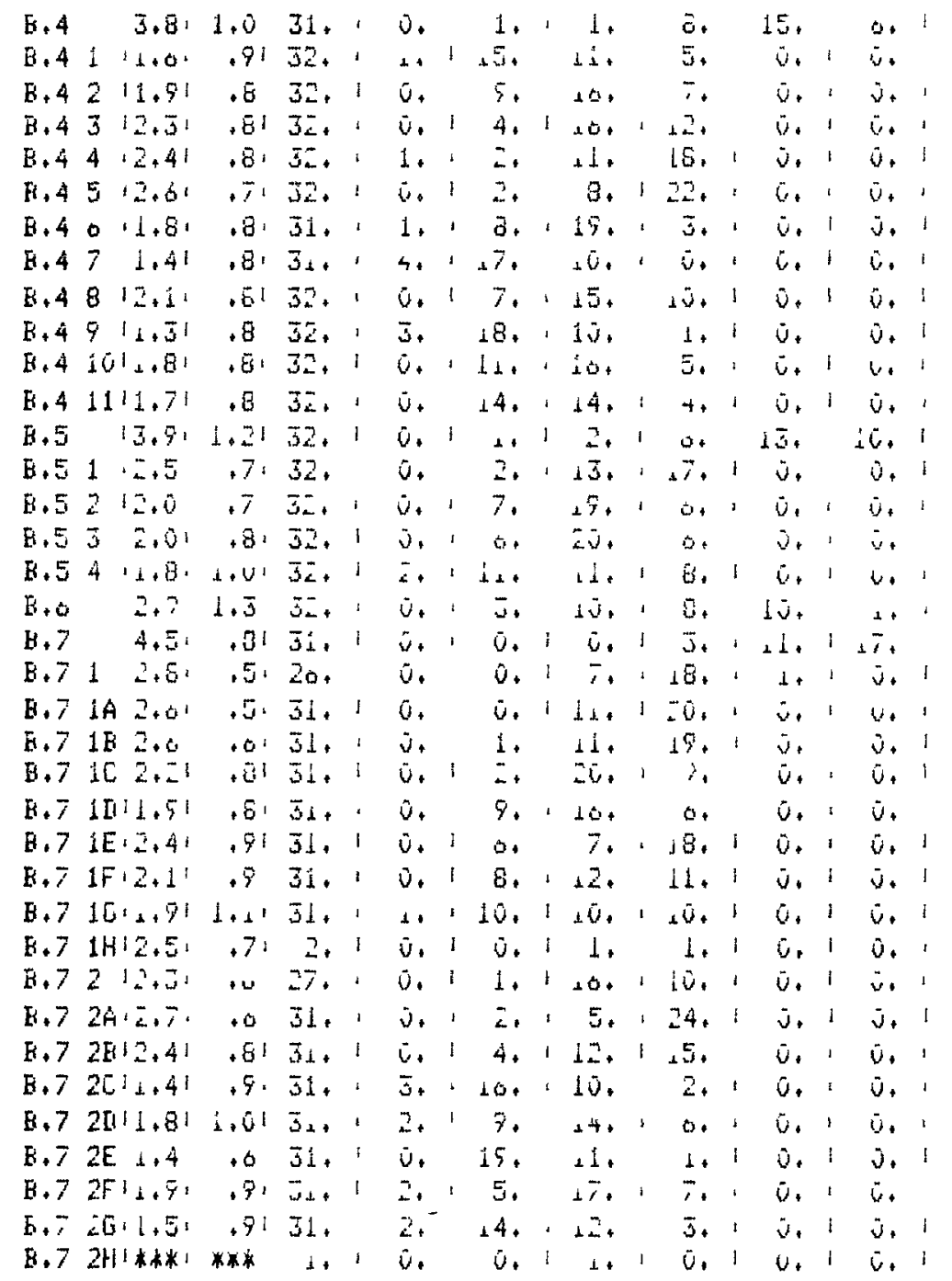

\begin{tabular}{|c|c|c|c|c|c|c|c|c|}
\hline $\begin{array}{l}u_{*} \prime \\
v_{+}\end{array}$ & $\begin{array}{l}j . \\
\bar{i} .\end{array}$ & $\begin{array}{l}\dot{v}_{t} \\
T_{t}\end{array}$ & & $\dot{u}_{+}$ & & $\begin{array}{l}1 . \\
\therefore\end{array}$ & & ${ }^{\circ}$ \\
\hline j. & $\therefore$. & $n$ & & ;. & & $v$. & & $\therefore$. \\
\hline$x+1$ & $w$ & $\rightarrow$. & & $x$ & & $\ldots$ & & l. \\
\hline$\dot{v}$. & 1. 1 & $\dot{v}, 1$ & & $\nu$ & & $\dot{v}$ & & $w$ \\
\hline$i+i$ & $\therefore 1$ & i. : & $:$ & 3 & & $\ddot{u}$. & & C. \\
\hline$\dot{v}$. & 1. & $1 .$, & . & $\dot{v}$ & $:$ & $\bar{u}_{.}$ & 1 & v. \\
\hline$x+1$ & $\overline{5}$. & $\bar{u}+1$ & & $\vec{u}$ & 1 & $\bar{t}$ & : & $\dot{u}$. \\
\hline$\dot{v}$. & $\therefore .1$ & i. 1 & & 1. & ' & 0. & : & u. \\
\hline 0.1 & 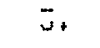 & 3.1 & & $v_{*}$ & & 1 & & $\bar{v}$. \\
\hline & U. 1 & $\therefore$ & & 6. & & 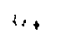 & & $v$ \\
\hline J. 1 & $v$. & $\ldots$ & & $\bar{v}$. & $i$ & $v$. & 1 & $v=1$ \\
\hline & $\therefore 1$ & c. 1 & 1 & $\theta$ & $،$ & $\therefore$ & ' & $\because$ \\
\hline 3. & $\dot{u}$ & 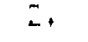 & & $1+$ & & $\mathrm{s}$ & & $j$. \\
\hline 1.1 & $v^{\prime \prime}$ & $\therefore$ & & $\ldots$ & & . & & $w$ \\
\hline$U_{t}$ & $\forall$ & $1+$ & & $1+$ & & $n$ & & '. \\
\hline$i$ & 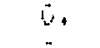 & $1+$ & & 4 & & $\approx$ & & $1 /$, \\
\hline$y .1$ & $\vec{b}$ & +4 & & $2+$ & & $\therefore$ & & $v_{t}$ \\
\hline$\vec{v}$. & 6. & $\ddot{v}_{+} \quad 1$ & & $\bar{v}$. & & $\bar{v}$. & & i. \\
\hline$j$. & $\ddot{v} \cdot 1$ & $\dot{j}+1$ & 1 & $\bar{v}$ & ' & 0. & ‘ & $\dot{v} .1$ \\
\hline 6.1 & i. & $\vec{u}_{+}$ & & $\ddot{v}$. & ' & $\dot{v}$ & 1 & $U$ \\
\hline $\bar{u} \cdot 1$ & $\tilde{u}$. & $v+$ & & $\dot{v}$. & 1 & $\ddot{U}$. & & 3 \\
\hline 0. & $6+$ & $v \cdot$ & & i. & ' & $w$ & & $v \cdot$ \\
\hline $\bar{v} .1$ & $\bar{v}$. & $\bar{v}+$ & 1 & $\bar{v}$. & & $\dot{v}$ & : & $v+1$ \\
\hline C. 1 & $\ddot{v} \cdot 1$ & i. 1 & 1 & $\bar{i}$. & 1 & u. & & 6. \\
\hline$\dot{v}_{+}$' & $\dot{v}+t$ & $\dot{v}, \quad$ & 1 & $\vec{v}$ & ' & $\overrightarrow{3}$ & & 0. \\
\hline $\bar{u} . \quad 1$ & u. ' & u. 1 & 1 & i. & 1 & v. & : & $1, .1$ \\
\hline $0+1$ & $\hat{v}_{t}$ & 1. & & L. & 1 & $\dot{v}_{n}$ & & 0,1 \\
\hline & $\bar{u}_{1}{ }^{\prime}$ & $\bar{b} .1$ & 1 & l. & 1 & $\vec{b}$ & : & $v$. \\
\hline $\bar{v}_{t}:$ & $\vec{v}_{*}$ & $v_{*}$ & , & $\ddot{v}$. & & $j$ & & $\therefore$. \\
\hline i. 1 & $\ddot{v}, 1$ & i. 1 & 1 & $\bar{v}$. & 1 & $\therefore$ & & $\hat{v}+1$ \\
\hline & j. 1 & 0 & & 0. & 1 & j. & & $\bar{v} .1$ \\
\hline$\dot{v}_{+} \quad:$ & $\bar{v}, 1$ & $i$. & & $\bar{t}$. & $i$ & $\therefore$ & & $\bar{u} .1$ \\
\hline$\dot{v}$ & $\dot{v}+1$ & $\therefore+1$ & 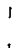 & $\dot{J}$ & , & $j$. & & $\dot{v}$ \\
\hline & $\bar{v}$. & $\therefore 1$ & 1 & 6. & & 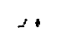 & & $\vec{b}+1$ \\
\hline$\dot{v}_{t}$ & $j_{t}$ & $\overrightarrow{3}+1$ & 1 & $v_{t}$ & 1 & $\because$ & & $v+1$ \\
\hline 0 & $\bar{v}$ & $\ldots, 1$ & & $v+$ & & u. & & 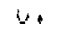 \\
\hline
\end{tabular}




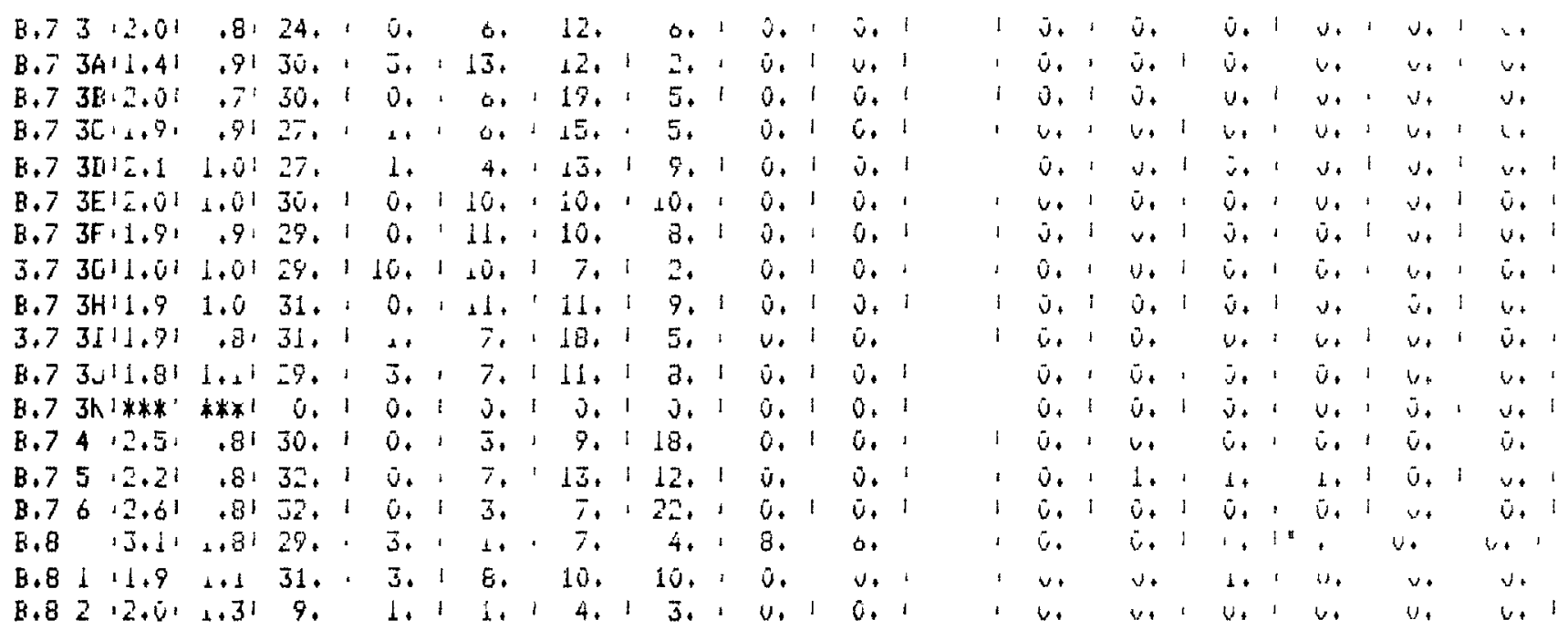

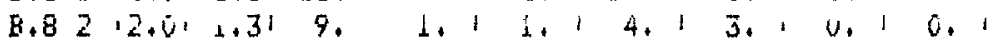


Package C

UTILITY OPERATIONS

\section{ALL RESPONDENTS}

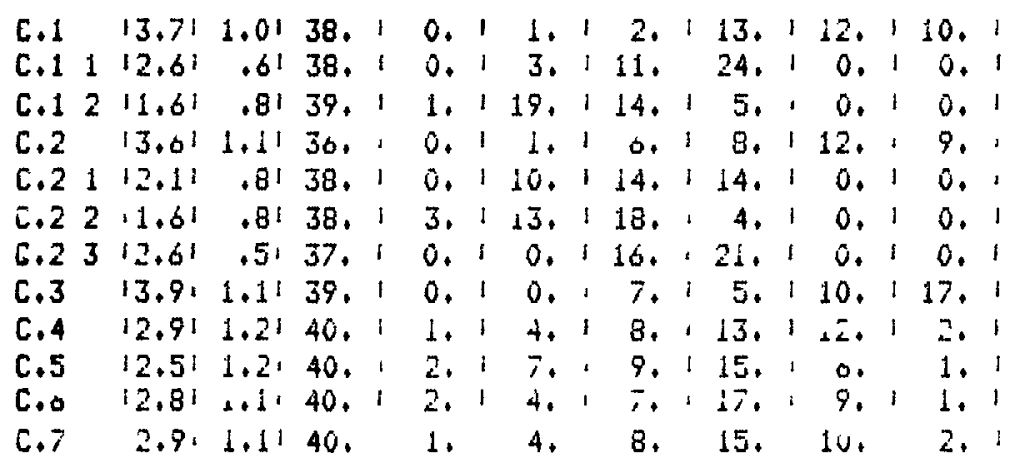

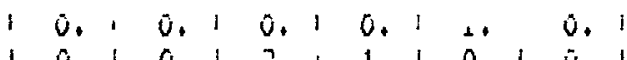
0.10 .12 .11 .10 .10 .1 $11.12 .00 .11, \quad 0.10 .1$ $10.10 .11,1 \quad \bar{v}+1 \ldots 1 \quad 0$. 10.1 u. 1 a. 1. 2., 4. 1 j. 10.10 .1 10.10 .11 .11 .10 .10 .1 10.10 .10 .10 .10 .10 .1 $10.11 .11 .11 .1,1,1$ 1. 1 i. 1.1 a. 1 l. 1 l. 0.1 0. 1.1 3. 1 . k.

DNLY UTILITIES

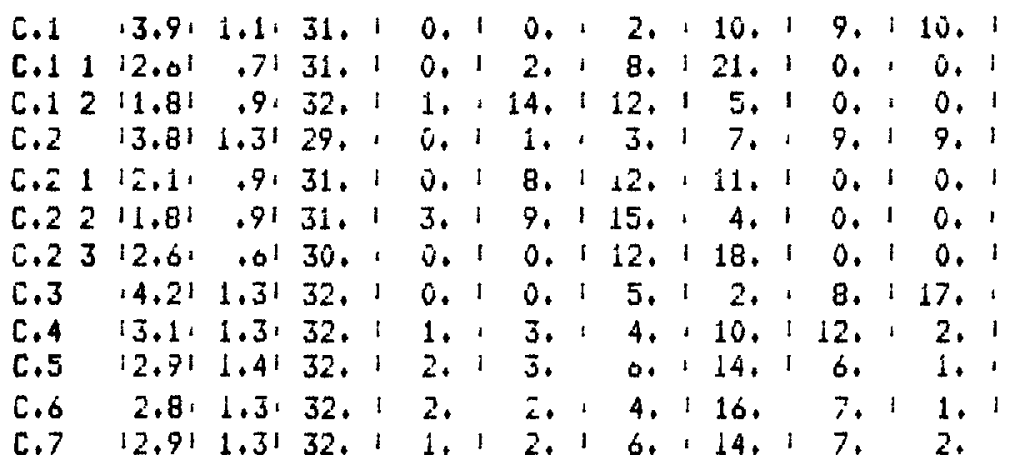

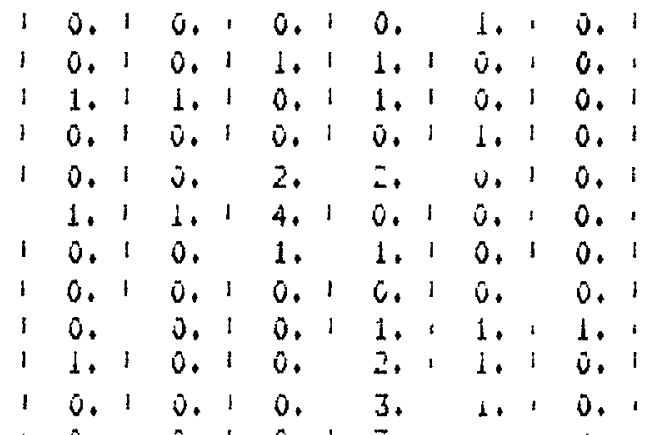


Package D

MANUFACTURING AND RESOURCES

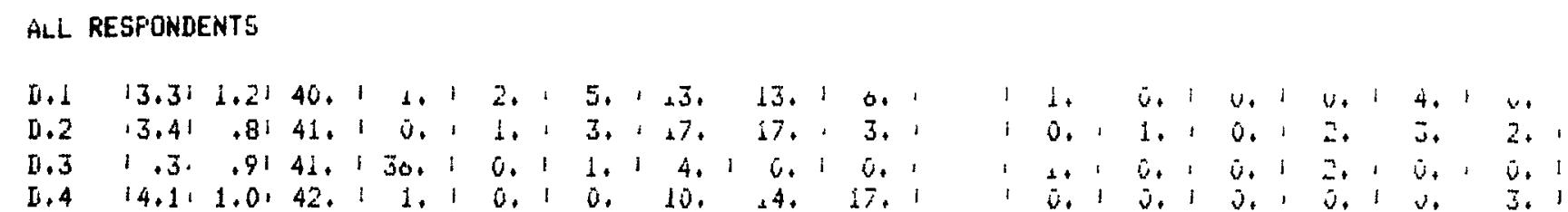

ONLY UTILITIES

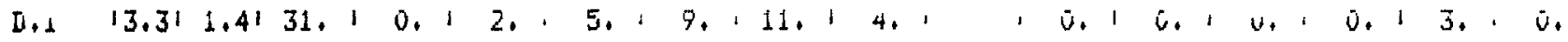

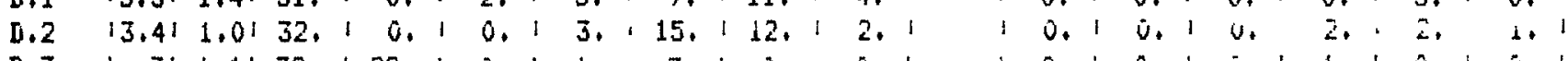

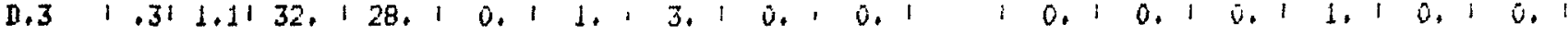

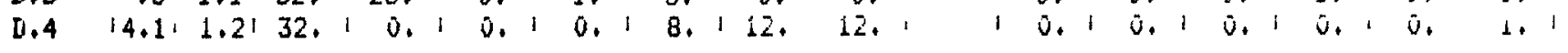




\author{
Appendix C \\ STATISTICAL RESULTS OF CHARACTERIZATION \\ FORM RESPONSES
}

\title{
INTRODUCTION
}

Appendix $C$ contains the results of the characterization form responses. The results shown are arithmetically averaged and grouped by respondent affiliation. The characterization results forms give averaged responses for "All Respondents" followed by averaged responses for "Private Utilities", "Public Utilities", "ArchitectEngineers", "Manufacturers" and "Research Orqanization" (D.O.E.).

For reference, the characterization form from which these responses were obtained is shown in Appendix A as part of the questionnaire survey mailing package. The questionnaire survey process and results are described in section 4 of this report. 
Index to Appendix C

$\begin{array}{ll}\text { Characterization Form Results for All Respondents } & \text { Page } \\ \text { Characterization Form Results for Private Utilities } & \mathrm{C}-1 \\ \text { Characterization Form Results for Public Utilities } & \mathrm{C}-3 \\ \text { Characterization Form Results for Architect-Engineers } & \mathrm{C}-5 \\ \text { Characterization Form Results for Manufacturers } & \mathrm{C}-7 \\ \text { Characterization Form Results for Research Organization } & \mathrm{C}-9\end{array}$




\section{CHARACTERIZATION FORM RESULTS \\ FOR \\ ALL RESPONDENTS}

1. Number of companies responding:
a) Public Utilities
b) Private Utilities
c) Architect-Engineers
d) Research Organizations
e) Manufacturers Total

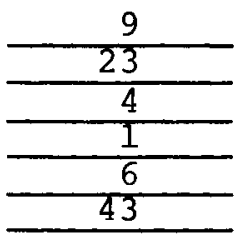

2. Average installed generating capacity: $5493 \mathrm{MW}$

3. Average load factor: $57.4 \%$

4. Total installed GW capacity in the U.S. in 2000: 1250 GW

5. Increase in installed capacity for the average utility by 2000: 193.58

6. National Grid in 2000: 13 "Yeses"; 26 "Noes"

7. Energy parks in 2000: 13 "Yeses"; 26 "Noes"

8. Kinds of plants in energy parks:

13 said nuclear (including LWR's, breeders, fusion)

$\frac{13}{5}$ said fossil

5 said solar

3 said geothermal

9. Average utility load factor in 2000:

10. Most utilities will be doing the following in 2000:

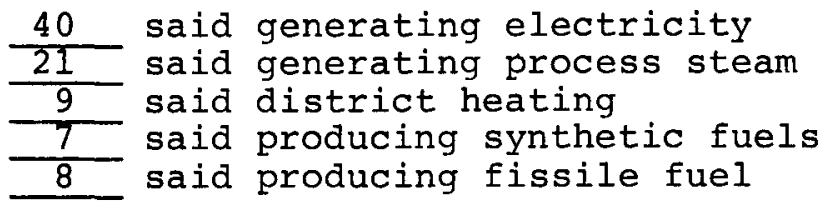

11. Government will own:

11.58 of nuclear power plants in 2000

12.38 of all power plants in 2000

12. Government will operate:

13.18 of nuclear power plants in 2000

$\overline{11.4} \%$ of all power plants in 2000 
13. Regulatory climate in 2000 compared to the present:

-Nuclear safety:

-Air pollution:

5 said "same"; 2 "eased"; 32 "stricter"

-Water pollution:

$\underline{9}$ said "same";

10 "eased"; $\overline{21}$ "stricter"

-Thermal pollution:

14 said "same";

14 said "same";

"eased";

20 "stricter"

14. Federal government will become the primary licensing body for all types of power generating plants in 2000 with state and local

licensing bodies having little or no power plant licensing jurisdiction:

9 "Yeses"; 28 "Noes"

15. Federal government will routinely provide financial assistance to utilities in 2000 for:

-Base load capacity additions:

- Other capacity additions:

-Transmission interties:

-District heating:

-Synthetic fuel production:

\begin{tabular}{rr}
7 "Yeses"; & 33 "Noes" \\
\hline 2 "Yeses"; & $\frac{38}{29}$ "Noes" \\
\hline 10 "Yeses"; & $\frac{29}{21}$ "Noes" \\
\hline 18 "Yeses"; & -17 "Noes" \\
\hline 23 "Yeses";
\end{tabular}

16. Fusion power will become commercially available in the year: 2025 


\section{CHARACTERIZATION FORM RESULTS \\ FOR \\ PRIVATE UTILITIES}

1. Number of companies responding:
a) Public Utilities
b) Private Utilities
c) Architect-Engineers
d) Research Organizations
e) Manufacturers
Total

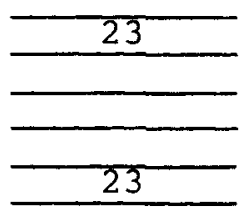

2. Average installed generating capacity: $5854 \quad M W$

3. Average load factor: $58.6 \div$

4. Total installed GW capacity in the U.S. in 2000: $1293 \mathrm{GW}$

5. Increase in installed capacity for the average utility by 2000: $133.6 \quad \%$

6. National Grid in 2000 :

5 "Yeses"; 16 "Noes"
8 "Yeses"; 13 "Noes"

7. Energy parks in 2000:

8. Kinds of plants in energy parks:

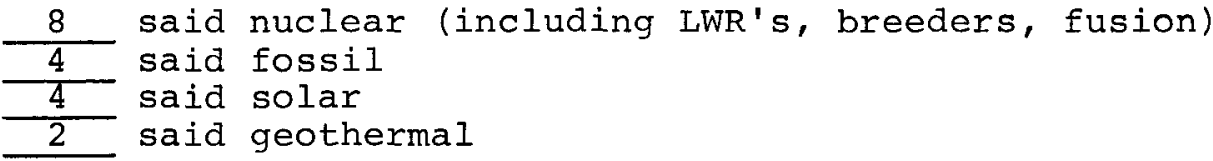

9. Average utility load factor in 2000: 61.9

10. Most utilities will be doing the following in 2000:

22 said generating electricity

13 said generating process steam

4 said district heating

6 said producing synthetic fuels

5 said producing fissile fuel

11. Government will own:

$15.3 \%$ of nuclear power plants in 2000

17.4\% of all power plants in 2000

12. Government will operate:

$12.8 \%$ of nuclear power plants in 2000

16.5: of all power plants in 2000 
13. Regulatory climate in 2000 compared to the present:

-Nuclear safety:

-Air pollution:

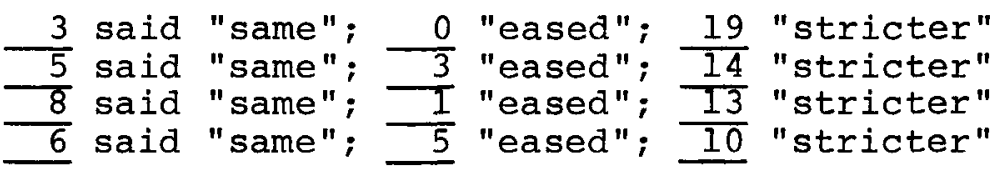

14. Federal government will become the primary licensing body for all types of power generating plants in 2000 with state and local

licensing bodies having little or no power plant licensing jurisdiction:

4 "Yeses"; 16 "Noes"

15. Federal government will routinely provide financial assistance to utilities in 2000 for:

-Base load capacity additions:

- Other capacity additions:

-Transmission interties:

-District heating:

-Synthetic fuel production:

\begin{tabular}{|c|c|c|c|}
\hline 0 & "Yeses" ; & 22 & es" \\
\hline 0 & "Yeses"; & 2 & " \\
\hline 3 & "Yeses"; & $\overline{1}$ & "Noes" \\
\hline 12 & "Yeses" ; & 12 & $\begin{array}{l}\text { "Noes" } \\
\text { "Noes" }\end{array}$ \\
\hline
\end{tabular}

16. Fusion power will become commercially available in the year: 2025 


\section{CHARACTERIZATION FORM RESULTS \\ FOR \\ PUBLIC UTILITIES}

1. Number of companies responding:
a) Public Utilities
b) Private Utilities
c) Architect-Engineers
d) Research Organizations
e) Manufacturers Total

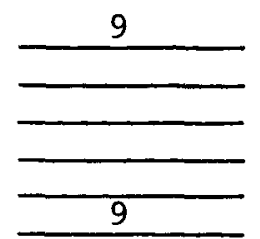

2. Average installed generating capacity: $4610 \quad M W$

3. Average load factor: $55.7^{8}$

4. Total installed GW capacity in the U.S. in 2000: 991 GW

5. Increase in installed capacity for the average utility by 2000: $\quad 319.2$ \&

6. National Grid in 2000: 4 "Yeses"; 5 "Noes"

7. Energy parks in 2000 : 2 "Yeses"; 7 "Noes"

8. Kinds of plants in energy parks:

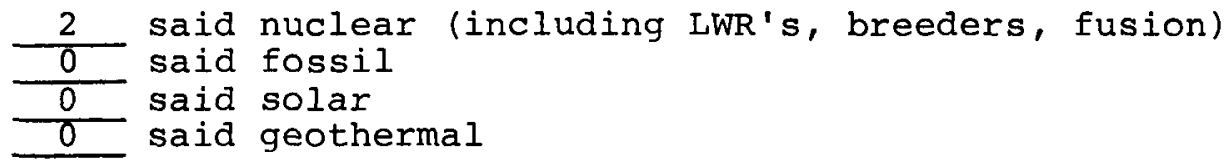

9. Average utility load factor in 2000: 62.1 \%

10. Most utilities will be doing the following in 2000:

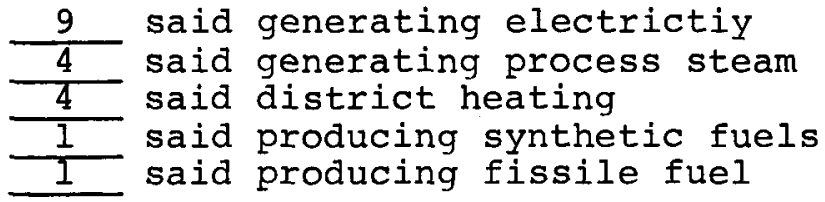

11. Government will own:

6.7 of nuclear power plants in 2000

4.78 of all power plants in 2000

12. Government will operate:

17.8 of nuclear power plants in 2000

4.7 of all power plants in 2000 
13. Regulatory climate in 2000 compared to the present:

-Nuclear safety:

-Air pollution:

$\frac{1}{1}$ said "same"; $\frac{1}{1}$ "eased"; $\frac{7}{\text { "stricter" }}$ "same"; $\frac{4}{3}$ "eased"; $\frac{4}{4}$ "stricter"
$\frac{2}{2}$ said "same"; said "same"; $\frac{3}{3}$ "eased"; $\frac{4}{4}$ "stricter"

-Water pollution:

-Thermal pollution:

14. Federal government will become the primary licensing body for all types of power generating plants in 2000 with state and local

licensing bodies having little or no power plant licensing jurisdiction:

3 "Yeses"; 6 "Noes"

15. Federal government will routinely provide financial assitance to utilities in 2000 for:

-Base load capacity additions:

- Other capacity additions:

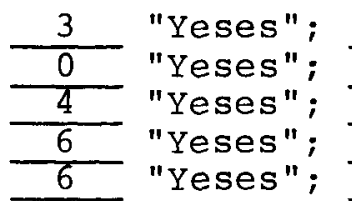

\begin{tabular}{l}
$\frac{6}{9}$ "Noes" \\
$\frac{5}{5}$ "Noes" \\
\hline 3 \\
\hline 3
\end{tabular} "Noes"

16. Fusion power will become commercially available in the year: 2022 


\section{CHARACTERIZATION FORM RESULTS \\ FOR \\ ARCHITECT-ENGINEERS}

1. Number of companies responding:
a) Public Utilities
b) Private Utilities
c) Architect-Engineers
d) Research Organizations
e) Manufacturers Total

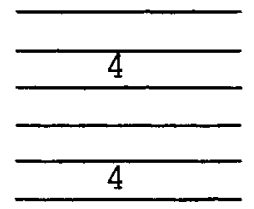

2. Average installed generating capacity: MW

3. Average load factor: $\stackrel{8}{\circ}$

4. Total installed GW capacity in the U.S. in 2000: GW

5. Increase in installed capacity for the average utility by 2000: $91.7 \div$

6. National Grid in 2000: __ 2 "Yeses"; 2 _Noes"

7. Energy parks in 2000: 0 "Yeses"; 4 "Noes"

8. Kinds of plants in energy parks:

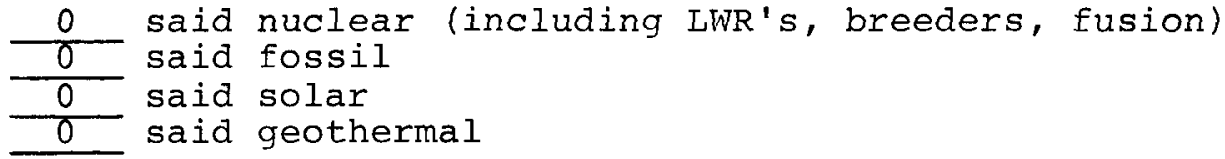

9. Average utility load factor in 2000: 66

10. Most utilities will be doing the following in 2000:

\begin{tabular}{l}
4 \\
\hline 2 \\
\hline 0 \\
\hline 0 \\
\hline 1 \\
\hline
\end{tabular}

$$
\begin{aligned}
& \text { said generating electricity } \\
& \text { said generating process steam } \\
& \text { said district heating } \\
& \text { said producing synthetic fuels } \\
& \text { said producing fissile fuel }
\end{aligned}
$$

11. Government will own:

$$
\begin{aligned}
& 6 \% \text { of nuclear power plants in } 2000 \\
& 6.8 \div \text { of all power plants in } 2000 \\
& \hline
\end{aligned}
$$

12. Government will operate:

$$
\begin{aligned}
& 6 \text { of nuclear power plants in } 2000 \\
& 4.3 \div \text { of all power plants in } 2000
\end{aligned}
$$


13. Regulatory climate in 2000 compared to the present:

-Nuclear safety:

-Air pollution:

-Water pollution:

$\frac{1}{1}$ said "same"; $\frac{1}{2}$ "eased"; $\frac{2}{\text { "stricter" }}$ "same"; $\frac{2}{1}$ "eased"; $\frac{1}{1}$ "stricter"
$\frac{2}{3}$ said "same"; said "same"; $\frac{1}{0}$ "eased"; $\frac{1}{1}$ "stricter"

-Thermal pollution:

14. Federal government will become the primary licensing body for all types of power generating plants in 2000 with state and local

licensing bodies having little or no power plant licensing jurisdiction:

$$
0 \text { "Yeses"; } 4 \text { _ Noes" }
$$

15. Federal government will routinely provide financial assistance to utilities in 2000 for:
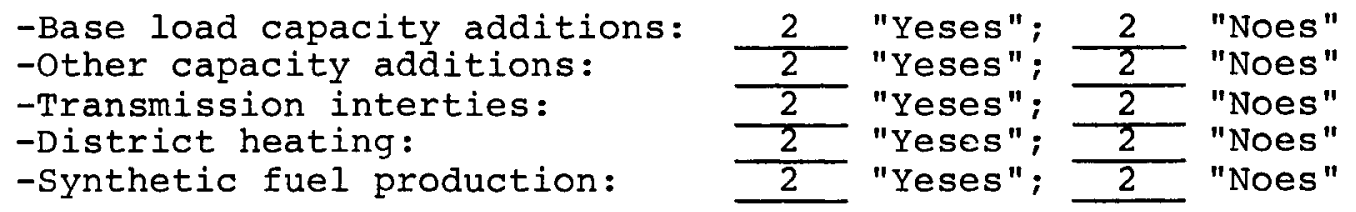

16. Fusion power will become commercially available in the year: 2030 


\section{CHARACTERIZATION FORM RESULTS \\ FOR \\ MANUFACTURERS}

1. Number of companies responding:
a) Public Utilities
b) Private Utilities
c) Architect-Engineers
d) Research Organizations
e) Manufacturers

Total

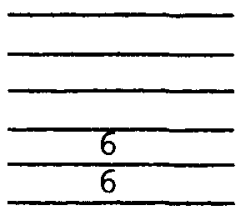

2. Average installed generating capacity: MW

3. Average load Factor: ___ _ _

4. Total installed GW capacity in the U.S. in 2000:

$1432 \mathrm{GW}$

5. Increase in installed capacity for the average utility by 2000 : 317.7 8

6. National Grid in 2000 :

1
2 "Yeses"; $\frac{3}{2}$ "Noes"

7. Energy parks in 2000: y parks:

8. Kinds of plants in energy parks:

2 said nuclear (including LWR's, breeders, fusion)

I said fossil

$\frac{1}{1}$ said solar

0 said geothermal

9. Average utility load factor in 2000: 66.1

10. Most utilities will be doing the following in 2000:

4 said generating electricity

2 said generating process steam

1 said district heating

0 said producing synthetic fuels

I said producing fissile fuel

11. Government will own:

$16.7 \%$ of nuclear power plants in 2000

20.0 8 of all power plants in 2000

12. Government will operate:

$15.0 \%$ of nuclear power plants in 2000

17.5 8 of all power plants in 2000 
13. Regulatory climate in 2000 compared to the present:

-Nuclear safety:

-Air pollution:

-Water pollution:

$\frac{1}{2}$ said "same"; $\frac{0}{1}$ "eased";
$\frac{2}{2}$ said "same"; said "same"; $\frac{1}{1}$ "eased";
$\underline{3}$ "eased";

3 "stricter"

-Thermal pollution:

"stricter"

I "stricter" I "stricter"

14. Federal government will become the primary licensing body for all types of power generating plants in 2000 with state and local

licensing bodies having little or no power plant licensing jurisdiction:

1 "Yeses"; 3 "Noes"

15. Federal government will routinely provide financial assistance to utilities in 2000 for:

-Base load capacity additions:

- Other capacity additions:

-Transmission interties:

-District heating:

-Synthetic fuel production:

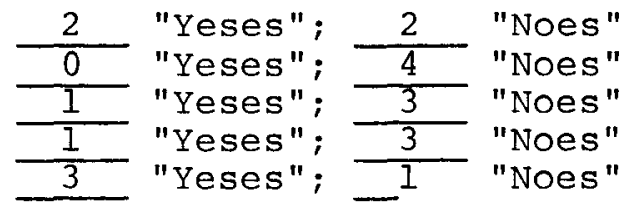

16. Fusion power will become commercially available in the year: 2031 


\section{CHARACTERIZATION FORM RESULTS \\ FOR \\ RESEARCH ORGANIZATIONS}

1. Number of companies responding:
a) Public Utilities
b) Private Utilities
c) Architect-Engineers
d) Research Organizations
e) Manufacturers Total

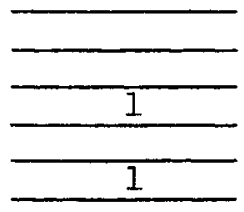

2. Average installed generating capacity: MW

3. Average load factor: $\div$

4. Total installed GW capacity in the U.S. in 2000: SW

5. Increase in installed capacity for the average utility by 2000: 응

6. National Grid in 2000: 1 -Yeses";

7. Energy parks in 2000: I 1 "Yeses"; 0 "Noes"

8. Kinds of plants in energy parks:

1 said nuclear (including LWR's, breeders, fusion)

1 said fossil

0 said solar

I said geothermal

9. Average utility factor in 2000: $\div$

10. Most utilities will be doing the following in 2000:

\begin{tabular}{l}
1 \\
\hline 0 \\
\hline 0 \\
\hline 0 \\
\hline 0 \\
\hline
\end{tabular}

said generating electricity said generating process steam said district heating said producing synthetic fuels said producing fissile fuel

11. Government will own:

$0 \quad \%$ of nuclear power plants in 2000

0 of all power plants in 2000

12. Government will operate:

$0 \quad$ of nuclear power plants in 2000

$0 \quad$ of all power plants in 2000 
13. Regulatory climate in 2000 compared to the present:

-Nuclear safety:

-Air pollution:

-Water pollution:

-Thermal pollution:

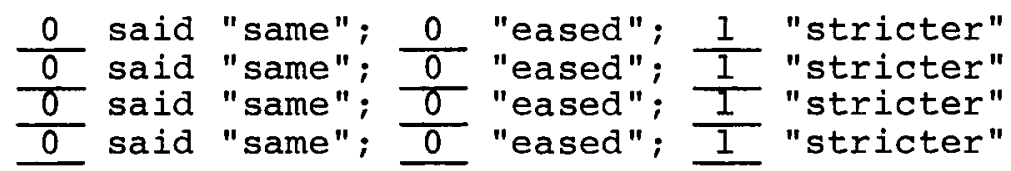

14. Federal government will become the primary licensing body for all types of power generating plants in 2000 with state and local licensing bodies having little or no power plant licensing jurisdiction:

1 "Yeses"; 0 "Noes"

15. Federal government will routinely provide financial assistance to utilities in 2000 for:

-Base load capacity additions: - other capacity additions:

-Transmission interties:

-District heating:

-Synthetic fuel production:

\begin{tabular}{c}
0 \\
\hline 0 \\
\hline 0
\end{tabular} "Yeses"; $\frac{1}{1}$ "Noes"

16. Fusion power will become commercially available in the year: 2015 
Appendix D

UTILITY REQUIREMENTS FOR FUSION OPTIONS

\section{INTRODUCTION}

Appendix D contains the utility requirements for fusion in their final form. The requirements and their associated factors are given with definitions and weightings. Note that there are twenty-three requirements in this appendix. Three of the original 27 requirements were dropped from consideration as being "unimportant". The dropped requirements were: "Plant Efficiency", "Dependence on Other systems" and "Natural Resource Requirements". In addition, the requirements "Forced Outage Rate" and "Planned Outage Rate" were combined and appear as factors of the single requirement "Outage Rates".

The margins of the Appendix pages are marked to indicate changes in the requirements from their original form in the questionnaire survey (see Appendix A). A "W" indicates a change in the requirement as a result of the Workshop. An "S" indicates a change in the requirement resulting from the deliberations, of the Senior Review Committee. All factor weights were finalized by the Senior Review Committee. The process by which the utility requirements were finalized into the form in which they appear in this appendix is described in section 6 of the report. Changes in the overall requirement weights as a result of the questionnaire survey, workshop and Senior Review Committee actions successively are documented in Table 6-1 in the report. 
Index to Appendix D

\section{$\underline{\text { Requirement }}$}

1. Plant Capital Cost

D-1

2. Plant Operating, Maintenance and Fuel Costs

D-1

3. Outage Rates

D-2

4. Plant Life

$\mathrm{D}-3$

5. Plant Construction Time

$\mathrm{D}-3$

6. Financial Liability Associated With Major Accidents

$\mathrm{D}-4$

7. Unit Rating

$\mathrm{D}-5$

8. Plant Safety

D-5

9. Flexibility of Siting

$\mathrm{D}-8$

10. Waste Handling and Disposal

D-11

11. Decommissioning

$\mathrm{D}-12$

12. Licensability

D-13

13. Weapons Proliferation

D-15

14. Plant Operating Requirements

D-16

15. Plant Maintenance Requirements

$\mathrm{D}-17$

16. Electrical Performance

$\mathrm{D}-18$

17. Capability for Load Change

D-19

18. Part Load Efficiency

D-19

19. Minimum Load

D-20

20. Startup Power Requirements

$\mathrm{D}-20$

21. Hardware Materials Availability

$\mathrm{D}-20$

22. Industrial Base

$\mathrm{D}-21$

23. Fuel and Fertile Material Availability

D-22

$$
D-i i
$$


The plant capital cost includes all materials, construction labor, equipment, and land costs necessary to bring the plant to commercial operation. Also included in capital cost are engineering and design cost, construction management cost, interest during construction, escalation, owner's cost, and sales tax.

Other than its effect on the cost of energy, capital cost impacts the desirability of a fusion option because of the financial limitations faced by utilities in obtaining capital to construct and startup a new plant. High total plant cost makes it difficult to undertake a project. The cost per net kilowatt of new installed capacity is a measure of the difficulty faced by utilities that are buying only a percentage of a plant to meet growth needs.

\section{Factors}

Capital cost in 1979 dollars:

Less than 1 billion dollars and less than

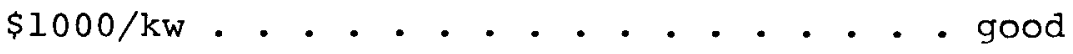

Between 1 billion and 2 billion dollars

and less than $\$ 2000 / \mathrm{kw}$. . . . . . f fair

Greater than 2 billion dollars or over

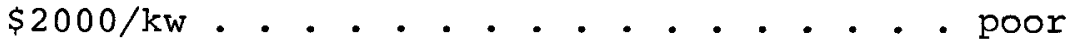

2. Plant Operating, Maintenance and Overall Wtg. 3 Fuel Costs

Included in the operating, maintenance and fuel costs are the cost of operating and maintenance labor, cost of components requiring replacement over the life of the plant, cost of materials required for servicing or replacing components, cost of training personnel, and cost of materials consumed in producing energy.

The cost-of-energy includes both costs that are fixed and 
those that vary with power generation. Operating, maintenance and fuel costs that are fixed pose a financial risk similar to fixed charges on capital investment. When a plant is operated below the originally anticipated capacity factor (used in figuring its mill rate), revenues do not cover the fixed portion of operating, maintenance and fuel costs.

\section{Factors}

Fixed portion of annual operating, maintenance and fuel costs in 1979 dollars:

Less than $1 \%$ of capital cost... . . . . good Between 1 and $3 \%$ of capital cost . . . . . fair More than 38 of capital cost .... . . . poor

\section{Outage Rates}

Overall Wtg. 4

This requirement considers the percentage of a year that a unit is unavailable due to a component failure or other unforeseen condition that requires the unit to be removed from service. It impacts the need for system reserve capacity and overall difficulty of operating the plant.

This requirement also considers the percentage of a year a unit is unavailable due to scheduled maintenance of reactor and balance of plant systems. Plants for which the yearly maintenance of the reactor and balance of plants systems could be carried out in parallel and scheduled for periods of low demand would be advantageous, since they would require less system reserve capacity.

\section{Factors}

Forced outage rate: $\underline{\text { Wtg. } 3}$

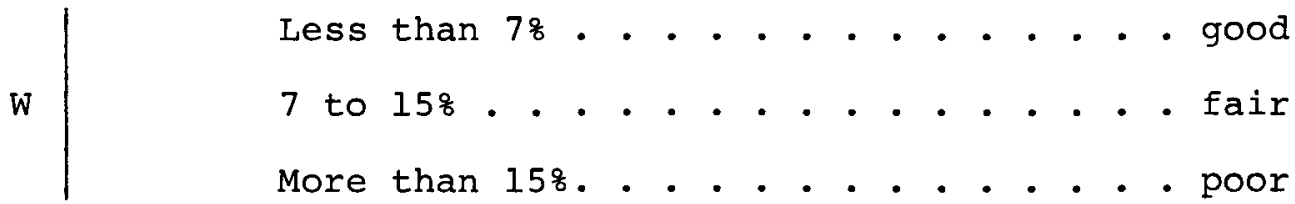




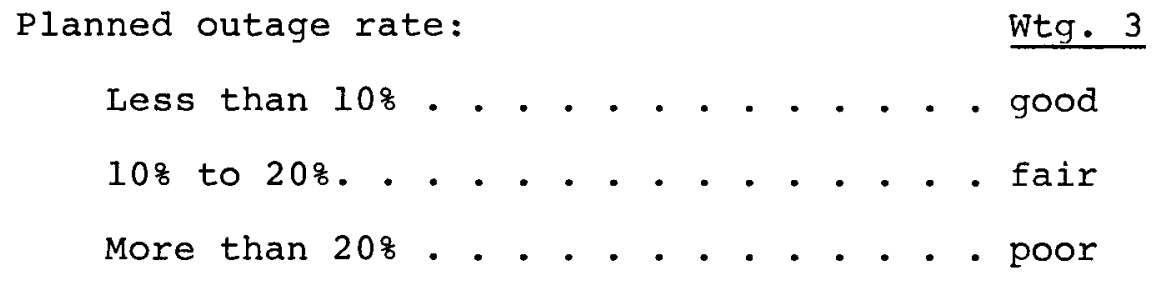

4. Plant Life

Overall Wtg. 3

This requirement considers the total time a plant can be operating before decommissioning. It includes all additional time which may be gained by replacing/refurbishing any of the major components to the extent that the payback period for the replacements is less than the remaining life of the plant.

\section{Factors}

Plant Life:

$$
\begin{aligned}
& \text { More than } 40 \text { years. . . . . . . . . good } \\
& 30 \text { to } 40 \text { years... . . . . . . . fair } \\
& \text { Less than } 30 \text { years... . . . . . . poor }
\end{aligned}
$$

\section{Plant Construction Time Overall Wtg. 4}

This requirement consists of two factors. The first includes the time to design, procure components and erect the plant. This is controllable and can be planned. The second factor includes the time required to develop, submit and receive approval of the documents necessary to obtain construction permits and operating licenses. There is uncertainty associated with this due to the intervention activities of regulatory bodies. If a full license cannot be obtained by completion of construction, production planning and carrying charges for the plant are impacted.

Note that these two factors can overlap so that overall construction time is not necessarily the sum of the two. A 1000 MWe plant has been assumed. 


\section{Factors}

1. Design, procure and erect: $\underline{\mathrm{Wtg} \cdot 2}$

6 years or less... . . . . . good

6 to 8 years. . . . . . . . . fair

More than 8 years . . . . . . . poor

2. Permits and license time in excess Wtg. 3 of construction time:

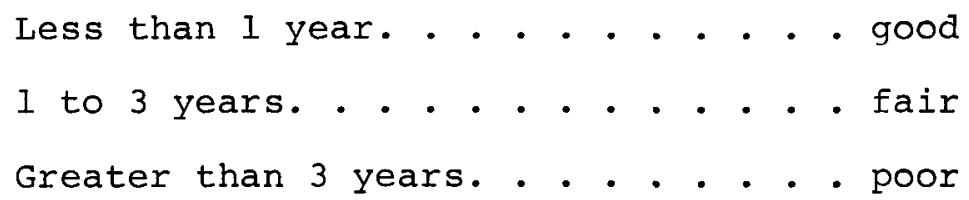

6. Financial Liability Associated With Overall Wtg. 5 Major Accidents

This requirement measures the attractiveness of a fusion option from the point of view of financial liability associated with death, injury, property damage, loss of revenue, and other financial losses resulting from the single worst credible accident attributable to a fusion option.

The direct loss to the utility includes damage to equipement and injury to employees. The direct loss to the public includes property damage, personal injury, lost work, displacement, decline in property values, and other hardships. Additional losses which may have financial impact on the utility include: loss of sales, increased cost of replacement power, and loss of depreciable assests.

The financial liability of a fusion option is evaluated based upon all the items discussed in connection with the worst credible accident.

\section{Factors}




$$
\begin{aligned}
& \text { Less than } \$ 500 \text { million . . . . . . good } \\
& \$ 500 \text { million to } \$ 1000 \text { million. . . . . fair } \\
& \text { Greater than } \$ 1000 \text { million...... poor }
\end{aligned} \mid \mathrm{W}
$$

7. Unit Rating Overall wtg. 2

This requirement considers the economic base load unit size that can be effectively integrated into a power system. W Flexibility of unit rating is necessary for a plant to be attractive for both large and small additions to existing capacity. The availability of only larger size units increases the need to commit single sites to large incremental increases in capacity well in advance of needs. The availability of smaller size units provides flexibility for making incremental capacity additions at separate sites within closer planning constraints.

\section{Factors}

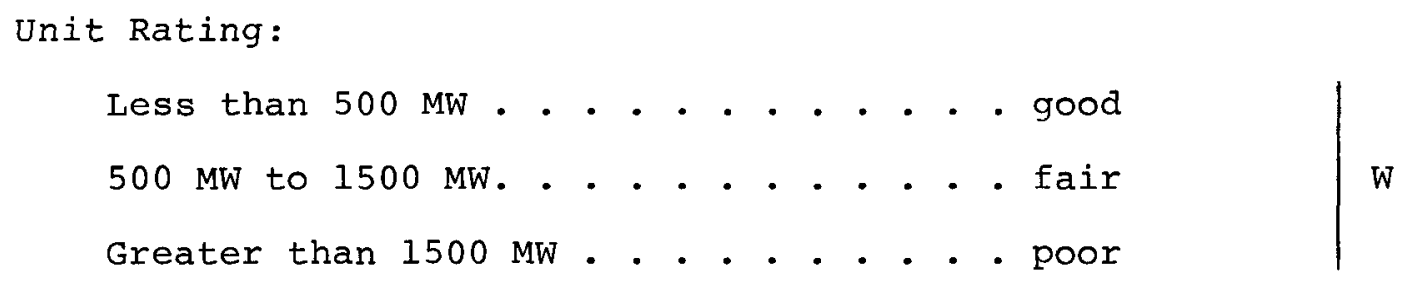

\section{Plant Safety Overall Wtg. 5}

The safety of a plant is its capability to be built and operated with minimal injury to plant personnel or the public and minimal damage to property internal or external to the plant. Plant safety, both actual and perceived, impacts siting, licensing, operating and maintenance costs, liability risks, and forced outage rates. In addition, it has an intrinsic value independent of the above considerations: a utility would prefer to operate a plant which does not injure its personnel, the public, or cause property damage exclusive of economic, siting, licensability, or similar considerations. In considering these independent aspects of plant safety only actual, rather than perceived hazards are included. 
Four factors affecting overall plant safety are listed below. In determining the weightings for each factor below, impacts of safety on licensability, financial risk, siting, operating cost, capital cost and outage rates, which are covered elsewhere, are excluded.

For each major factor affecting plant safety, several related features of characteristics have been identified. The relative importance of each of these characteristics in terms of impact on plant safety may be estimated. Note that when a particular plant is evaluated not only the presence or absence of a potentially hazardous feature, but also the quantity and degree of the hazard associated with such a feature, the accident mechanisms which could result in realization of the hazard potential and effects of systems designed to prevent or mitigate the various hazards will all be considered.

\section{Factors}

1. Plant Personnel/Safety/Inplant Property Damage:
a) Presence of gaseous and liquid radioactive material
b) Presence of activated structure and components
c) Maintenance in a radiation field
d) Indoor high voltage equipment and distribution
e) Frequent movement and mani- pulation of large pieces of equipment during maintenance
f) Presence of large quantities of stored energy
g) Presence of flammable or explo- sive materials
h) Presence of large cryogenic systems
(2)
(2)
(3)
( 1 )
( 1 )
(2)
(2)
(2)

Wtg. 2

(Subwtg.) 
i) Operations in a radiation field

j) Toxic Materials

k) Hazardous Materials

1) Noise

m) Presence of high magnetic fields and microwave fields

2. Public Safety:

Wtg. 3

Hazards with the potential to threaten public safety are:

(Subwtg.)
a) Normal emissions of toxic
(2) chemicals
b) Normal emissions of radio- active substances
c) Presence of large quantities of stored energy
d) Large toxic chemical inventories
e) Presence of gaseous, liquid or volatile radioactive materials
f) Large quantities of chemically active materials
g) Electromagnetic emissions
h) Large quantities of flammable or explosive materials
i) Significant increase in rail, road or barge traffic
j) Shipments of liquid gaseous or volatile radioactive material
k) Shipments of toxic chemicals

3. External Property Damage:

Wtg. 2

Hazards with the potential to damage property outside the plant are:

(subWtg.)
a) Presence of large quantities of stored energy
b) Large toxic materials 
$W \quad \begin{array}{ll}\text { c) } \begin{array}{l}\text { Presence of gaseous, liquid or } \\ \text { volatile radioactive materials }\end{array} & (2) \\ \text { d) } \begin{array}{l}\text { Large quantities of chemically } \\ \text { active materials }\end{array} & (1) \\ \text { e) } \begin{array}{l}\text { Large quantities of flammable } \\ \text { or explosive materials }\end{array} & (1) \\ \text { f) } \begin{array}{l}\text { Shipments of liquid gaseous or } \\ \text { volatile radioactive material }\end{array} & (2) \\ \text { g) Shipments of toxic chemicals } & (1)\end{array}$

9. Flexibility of siting

Overall Wtg. 4

Siting is a major concern for most utilities at present and is expected to continue to be so in the future. It is important to recognize that siting flexibility is not only an option's ability to be located at already identified sites, but also its ability to make a whole new class of sites available and its ability to be sited close to a load center.

Utilities presently identify potential sites based on the needs of coal or fission power plants. In order to obtain a true measure of siting flexibility it is necessary to look beyond the site choices resulting from such assumptions. To do this, flexibility of siting is divided into eleven factors.

\section{Factors}

1. Land Area:

Wtg. 2

Acreage required for the plant, its auxiliaries and exclusion area, if any.

Under 250 acres . . . . . . . good

250 to 500 acres. ....... . fair

Over 500 acres. . . . . . . . poor

2. Transportation and Electrical Wtg. 2

Corridor Access:

Access for construction; delivery of operating and maintenance supplies; and shipping products (fuels, heat, electricity or wastes). 
Heavy trucking and standard transmission

lines.................. good

Railway access . . . . . . . . . f fair

Barge route or ultra high voltage

transmission . . . . . . . . . . . poor

3. Makeup Water: Wtg. 2

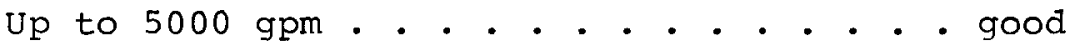

5000 to $25,000 \mathrm{gpm}$......... fair

Over 25,000................ poor

4. Hazards From Normal Emissions: Wtg. 3

Toxic and/or radioactive emissions:

No releases. . . . . . . . . . . good

Similar to current LWR actual releases . fair

Greater than current LWR actual releases - poor

5. Hazards From Potential Accidents: Wtg. 3

Any substantial accident hazard, even if the possibility is very remote, will impact chance for urban siting:

Siteable in urban area........ good

Siteable in suburban area. . . . . . fair

Siteable in rural area . . . . . . . poor

6. Heat Rejection: $\underline{\text { Wtg. } 2}$

This is the quantity of heat rejected by the plant to the environment. Any recovery of this heat and its utilization for applications such as district heating or expansion cooling will reduce the quantity of heat rejected. Heat rejection is a consideration independent of makeup water and land area requirements because of its impact on climatic and microclimatic conditions;, e.g. rejection of large quantities of heat in urban areas may be unacceptable. 
Less than 5 billion BTU/h. . . . . . good

5 billion to 10 billion BTU/h. . . . . fair

Over 10 billion BTU/h. . . . . . . poor

7. Aesthetic Impacts:

Wtg. 2

This is the anticipated public objection to physical appearance and detraction from existing landscape. The criteria to be judged are building volume and highest structural point.

Less than 3,000,000 $\mathrm{ft}^{3}$ and $100 \mathrm{ft}$. . good

$3,000,000-15,000,000 \mathrm{ft}^{3}$ and 100-300 ft. fair

More than 15,000,000 $\mathrm{ft}^{3}$ and $300 \mathrm{ft}$. . poor

8. Seismic Design:

Wtg. 2

This is the requirement that a plant be siteable in an area of seismic activity. Siteable within Uniform Building Code Seismic Risk zones:

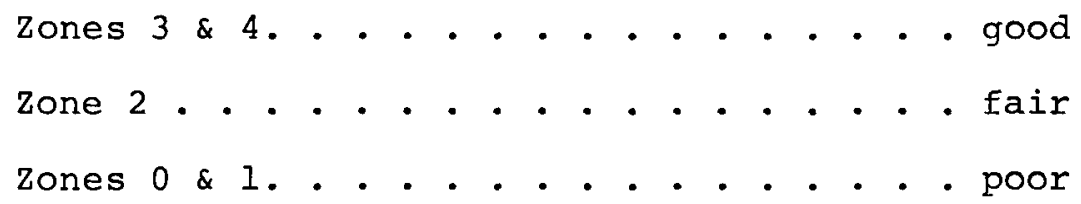

9. Peak Construction Work Force: Wtg. 1

Less than 1500 workers . . . . . . good

1500 to 3000 workers ......... fair

More than 3000 workers . . . . . . poor

10. Continuous Airborne Sound (at nearest Wtg. 2 residential property boundary):

Less than $45 \mathrm{dBA}$. . . . . . . . . good

45 to $65 \mathrm{dBA}$............ . . fair

Greater than $65 \mathrm{dBA}$. . . . . . . . poor

11. Impulsive Airborne Sound (at nearest Wtg. 2 residential property boundary):

Less than 75 decibels. . . . . . . good 75 to 80 decibels. . . . . . . . fair

Greater than 80 decibels . . . . . . poor 
10. Waste Handling and Disposal

Overall Wtg. 4

Waste handling and disposal considers the in-plant handling, on-site disposal (or transportation) and off-site disposal of waste materials formed as a byproduct of the energy production process. Such wastes may include solid residues, fission products, activated structures and components, contaminated liquids, solids and gases. Waste handling and disposal requirements affect both the capital and operating costs of a plant.

Waste handing within the plant also may lead to increased complexity of operations, additional hazards, decreased plant reliability and the need for special personnel training. Waste disposal may lead to increased land area requirement and transportation needs. These considerations are covered elsewhere.

In addition, waste handling and disposal have other independent aspects. For example, toxic and radioactive waste disposal is becoming increasingly difficult, and increasing restrictions threaten the continued operation of nuclear plants.

The range of waste to be handled and disposed of by utilities is varied in quantity and type. The independent aspects of waste handing and disposal are concerned with impairment and restriction of plant operation. The quantity and toxicity of the waste, and the monitoring agency which has jurisdiction over its disposal are important factors.

\section{Factors}

1. Quantity of high level radioactive Wtg. 3 waste produced by a 1000 MWe plant:

None. . . . . . . . . . . . $\operatorname{good}$

0.2 to 2 metric tons per year... . fair

Over 2 metric tons per year . . . . poor 
2. Quantity of low level radioactive

Wtg. 2

waste produced by a 1000 MWe plant:

None. . . . . . . . . . . . . . good

20 to 200 metric tons per year. . . fair

Over 200 metric tons per year. . . poor

3. Chemically toxic wastes: Wtg. 2

None. . . . . . . . . . . good

Recycled or reclaimed . . . . . . fair

Requires disposal or treatment. . . poor

4. Frequency with which wastes have Wtg. 2 to be moved offsite:

Less than annually. . . . . . . good

Annually to monthly . . . . . . fair

More than monthly . . . . . . . poor

\section{Decommissioning}

Overal1 Wtg. 3

Decommissioning refers to the steps taken to render a plant safe to the environment after its operating lifetime. The cost of decommissioning affects the cost of energy, but not the capital cost, since the funds to cover these costs can be accumulated over the operating life of the plant. Other aspects of decommissioning include the diversity of utility personnel required to carry out the operation, and the increased opportunity for public opposition.

The degree of difficulty associated with decommissioning is a function of the presence of fission products, extent of component and structure activation, and the configuration and overall size of the contaminated areas.

\section{Factors}

If plant decommissioning entails:

Abandonment . . . . . . . . . . . good

Dismantling and decontamination . . . fair

Entombment. . . . . . . . . . . . poor 


\section{Licensability}

Overall Wtg. 5

This requirement considers how readily a fusion option can be expected to receive regulatory approvals. While a plant must be ultimately licensable to be of any interest to a utility, there can be different degrees of difficulty with which regulatory approval can be obtained.

Factors which affect licensability are: perceived potential accident hazards, perceived normal operating hazards and nuisances, presence of accident mechanisms, demonstrated effectiveness of accident prevention or suppression systems, similarity to previously licensed plants, and public acceptance. For many of these factors it is possible to list associated plant features or characteristics and to determine the relative importance of the various features in terms of their impact on licensing. This has been done below, where appropriate. Note that in evaluating a plant, not only would the presence of a potentially hazardous feature or characteristic be considered, but also the quantitative and qualitative nature of hazards, the accident mechanisms which release the hazards, and the systems and features contained in the design for the prevention and mitigation of accidents.

\section{Factors}

1. Perceived Potential Accident Hazards: Wtg. 3 (subwtgs.)
a) Quantities of gaseous radioactive (3) materials onsite
b) Quantities of volatile radioactive ( 3 ) materials onsite
c) Quantities of toxic liquids, gases, ( 2 ) or potential gases onsite
d) Quantities of explosive materials ( 2 ) onsite
e) Shipment of volatile, liquid, or gaseous radioactive material to or from the plant 
f) Shipment of toxic chemicals to

or from the plant

g) Shipment of explosive materials to or from the plant

2. Perceived Normal Operating Hazards and Nuisances:

a) Radioactive releases

Wtg. 2 (subwtgs.)

b) Toxic releases - air

C) Electromagnetic radiation

d) Transportation accidents

e) Noise

f) Water pollution

(1)

g) Heat rejection

3. Presence of Features Associated with Accident Mechanisms:

Wtg. 2 (subwtgs.)
a) Cryogenic systems
(2)
b) Liquid metals
(2)
C) Plasma disruptions
(2)
d) Laser or particle beam disruptions
(2)
e) Quantities of volatile material
(2) under pressure
f) Quantities of stored energy
g) Superconducting materials
(1)
h) Quantities of explosive materials
( 2 )
i) Missile generating equipment
(2)
j) Afterheat requiring forced cooling
( 3 )

4. Demonstrated Effectiveness of Accident Wtg. 3 Prevention or Suppression Systems:

For each of the accident mechanisms listed in (3), which release a potential hazard listed in (1), is the normal prevention or suppression mechanism the same as or similar to well proven or demonstrated technology? Count up number of "no" answers to this question. 


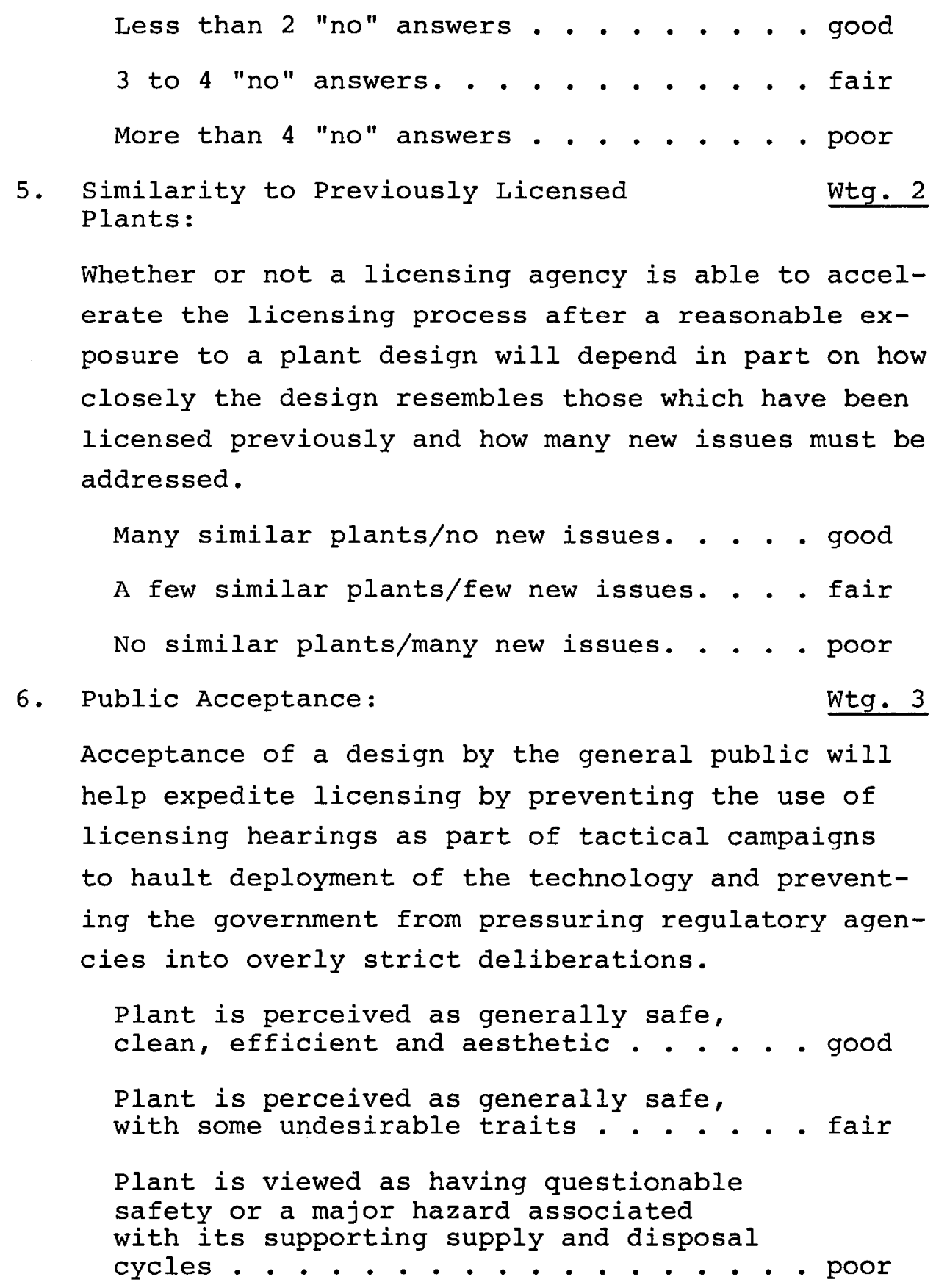

\section{Weapons Proliferation}

Overall Wtg. 3

Recently, the U.S. Government has declared that the prevention of fissile material from being diverted to weapons production by terrorist groups, criminals, or nations not presently in possession of nuclear weapons to be a major national priority. This action has led to the suspension of 
nuclear fuel reprocessing in this country and the search for plants utilizing proliferation resistant technologies and fuel cycles. The resistance of a plant to weapons proliferation impacts its attractiveness through its licensability, public acceptance, security related costs and operating requirements.

The weapons proliferation requirement is broken into two parts. The first is the proliferation resistance of the technology. The second is the proliferation resistance of the fuel cycle.

\section{Factors}

1. Technology:

$\underline{\text { Wtg. } 2}$

No connection between the technology

and nuclear weapons proliferation. . . good

A technology which may be modified to produce weapons grade material. . . fair

A technology, such as a flexible neutron source, which can be directly used to produce weapons grade material . . . . . . . . . poor

2. Fuel Cycle:

$\underline{\text { Wtg. } 3}$

A fuel cycle which at no point has
a connection to nuclear weapons
proliferation. . . . . . . . . . good

A fuel cycle in which some material, which can be refined to weapons grade by the application of moderately sophisticated chemical or physical techniques, is on-site or frequently shipped. . . . . . . . . . . . f fair

A fuel cycle in which weapons grade material is on-site or frequently shipped................ . poor

\section{Plant Operating Requirements \\ Overall Wtg. 4}

This requirement considers process stability and control interactions between process variables during startup and shutdown as well as plant operating work force. 


\section{Factors}

1. Process:

$\underline{\operatorname{wtg} \cdot 3}$

Stable process, long reaction times for complex procedures, relatively insensitive to manipulative skills. . . . . . good

Many possible plant trip initiators and system interactions requiring timely response, extensive procedure knowledge, similar to an LWR. . . . . . . . . . . fair

Need for complex judgement in a short time span, inherently unstable process requiring extensive automated protection system. . . . . . . . . . . . poor

2. Operating Work Force Per Unit $\quad$ Wtg. 1 W (including all shifts):

Less than 100 personnel. . . . . . . good

100 to 150 personnel ........ . fair

Greater than 150 personnel . . . . . poor

15. Plant Maintenance Requirements Overall Wtg. 4

Plant maintenance requirements are broken down into three parts. The first considers all the work tasks for day-today and periodic and/or preventive maintenance throughout

the life of the plant. The second considers the numbers and skills of the personnel required to carry out the maintenance. The third considers the radiation exposure from maintenance and surveillance activities.

\section{Factors}

1. Work Tasks :

$\underline{W t g} \cdot 3$

1 to 12 simple day-to-day repairs that have potential for impacting plant output, 1-2 major yearly repairs/overhauls which can be done in parallel. . . . . . good

13 to 20 simple day-to-day repairs, 1-2 major yearly repairs/overhauls which cannot be done in parallel. . . . . . . fair

More than 21 day-to-day repairs, more than 2 major yearly repairs/overhauls which cannot be done in parallel. . . . . poor 
2. Personnel:

Wtg. 1

Less than 15 specialized skilled

people............... . good

15 to 30 specialized skilled people. . . fair

More than 30 specialized skilled

people . . . . . . . . . . . poor

3. Radiation Exposure: $\underline{\text { Wtg. } 3}$

Less than 50 man-rem per year

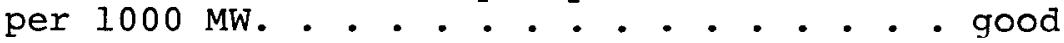

50 to 200 man-rem per year per

1000 MW. ............. . fair

Greater than 200 man-rem per year

per $1000 \mathrm{MW}$. . . . . . . . . . . poor

\section{Electrical Performance Overall Wtg. 4}

This requirement considers all of the electrical operating characteristics of a plant. In particular, a plant must operate stably from startup through steady state to shutdown, and it must react predictably without erratic transients under faulted conditions. Since all fusion concepts require electrical energy to operate, even applications which ostensibly use a fusion reactor to generate heat only, must either be able to stably satisfy their electrical needs internally or be able to satisfy them from an external network. In the latter case, the input impedance presented to an existing network must be properly matched for stable operation, and the input must be protected from transients on the network. For an application in which electrical power is the primary product, the output impedance of the fusion system must be easily matched to the existing network for stable operation.

\section{Factors}

A plant which is:

Inherently stable, easily matched to existing networks, and insensitive to network transients... . . . . . good 
Stable but sensitive to network

transients . . . . . . . . . . . . . fair

of questionable stability under

faulted conditions. . . . . . . . . . poor

\section{Capability for Load Change}

Overall Wtg. 2

This requirement considers the mechanical and thermal characteristics that limit the rate of response of a unit to changes in load or that restrict the time required for startup or shutdown. This factor affects the decision by the utility to dispatch the plant under system load changes, and therefore, affects the unit's average capacity factor. It is expected that the same characteristics that affect the rate of load following will also affect the rate of startup from a warm condition.

\section{Factors}

Time to change between full load to 50\% load - going up or coming down in load, whichever is longer:

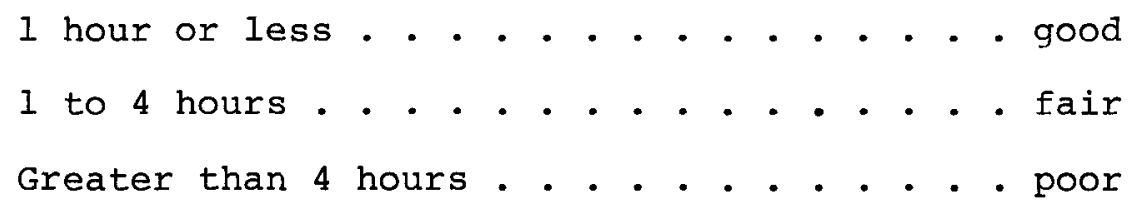

18. Part Load Efficiency

Overall Wtg. 2

Part load efficiency is evaluated at $50 \%$ load, or the minimum load obtainable if the unit cannot operate continuously at $50 \%$ load. The ratio of the change in efficiency to the change in load going from full load down to half load will be referred to as "R".

The factor of concern is the value of $R$. A low $R$ value indicates a small change of efficiency with reduced load. A high $R$ value indicates a significant efficiency reduction with load reduction.

\section{Factors}

A plant with a value of $R$ : 


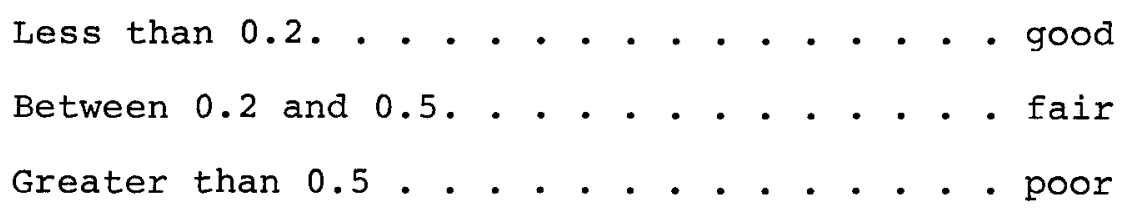

\section{Minimum Load}

Overall Wtg. 2

The minimum load is the energy output level below which the plant cannot operate continuously. A low minimum load capability facilitates load following, shakedown operation (license to operate at reduced load) and minimizes the potential for damaging generating equipment when picking up load.

\section{Factors}

The minimum percent of full load operation at which a plant can operate continuously:

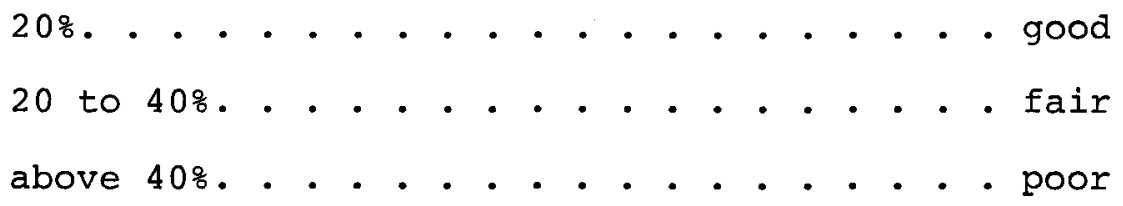

\section{Startup Power Requirements Overall Wtg. 3}

The startup power required by a fusion option impacts utility system planning, power reserves, and dispatching. Large startup power requirements could produce electrical grid upsets in bringing units on line or require the use of large, on site "bootstrap" auxiliary generating equipment.

\section{Factors}

A plant requiring startup power of:

$$
\begin{aligned}
& 5 \% \text { of rated net output . . . . . . . . good } \\
& 5 \text { to } 15 \% \text { of rated net output. . . . . . fair } \\
& \text { More than 15\% of rated net output... . . poor }
\end{aligned}
$$

21. Hardware Materials Availability Overall Wtg. 4

This requirement considers the use of strategically important materials apart from their effects reflected in plant capital 
and operating costs. All materials associated with plant construction and operation are considered except fuel and breeding material (e.g. helium, lithium).

The aspects of materials availability which are of concern are the number of critical materials needed to build the plant and their relative abundance. If substitute materials are used in the design of the plant, this constitutes a new design.

\section{Factors}

A critical material is categorized by the fraction of world reserve $500 \mathrm{GW}$ of installed power requires: (a) less than 28 of world reserves; (b) between $2 \%$ and $10 \%$; or (c) more than 10 \%

Add the number of critical materials in category "(a)" plus $3 \mathrm{X}$ the number of critical materials in category "(b) " plus $5 \mathrm{x}$ the number of critical materials in category "(c)". If the sum total for a plant is:

Less than 5. . . . . . . . . . . . good

Between 5 and 20 .......... fair

Greater than 20........... . poor

Note: Any plant for which a significant installed capacity requires more than 308 of the world's known reserves of a critical material should be dropped from consideration.

\section{Industrial Base Overall Wtg. 4}

This requirement considers the industrial capability to manufacture the components of a fusion plant and the preprocessing and reprocessing of fuels when the technology has reached the point of commercialization. In order to achieve general acceptance of fusion technology, the existence of a supporting industrial base will be necessary. 


\section{Factors}

Present equipment and methods generally applicable, and two vendors using existing manufacturing technology available

for key components . . . . . . . . . . . good

New equipment and methods needed requiring considerable development and one vendor available to supply key components. A manufacturing development program of less than $5 \mathrm{X}$ the product selling price is required by each vendor to supply a key component. . . . . . . . . . . . . . fair

Radically new equipment and methods needed and only the prototype vendor is available. A manufacturing development program greater than $5 \mathrm{X}$ the product selling price is required by each potential vendor of a key component. . . . . . . . . . . . poor

23. Fuel and Fertile Material Overall Wtg. 4

For a fusion option to be attractive, it must utilize a fuel which is either readily available in adequate quantities or which can be bred in a reasonable manner from a readily available material. Recent history has indicated that basing energy production on a fuel which is in short supply or subject to control by a small number of firms or nations can have disastrous results.

If a fuel must be bred, the availability of the equipment or plant required to perform this breeding must be considered.

\section{Factors}

An option which utilizes fuels or fertile materials that are:

Widely distributed and available (such as deuterium and lithium). . . . . . . good

Moderately well distributed, including deposits in this country or friendly nations. . . . . . . . . . . . . . fair

Narrowly distributed and subject to cartel control or embargo. . . . . . . . poor 